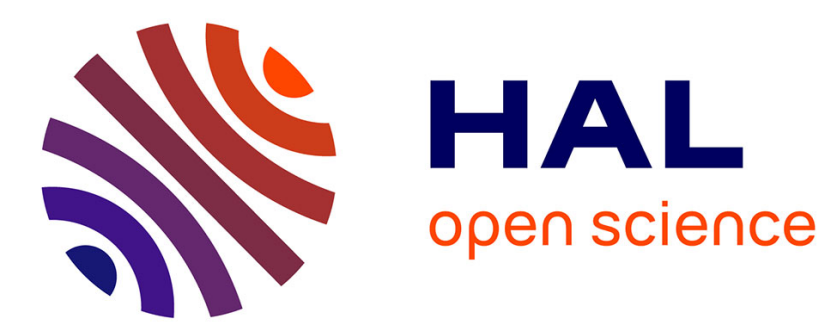

\title{
Tombes et architecture
}

Roger Guéry, Gilbert Hallier

\section{To cite this version:}

Roger Guéry, Gilbert Hallier. Tombes et architecture. Gallia - Fouilles et monuments archéologiques en France métropolitaine, 1990, Le mausolée de Cucuron (Vaucluse), 47, pp.148-185. 10.3406/galia.1990.3159 . hal-02477668

\section{HAL Id: hal-02477668 \\ https://hal.science/hal-02477668}

Submitted on 13 Feb 2020

HAL is a multi-disciplinary open access archive for the deposit and dissemination of scientific research documents, whether they are published or not. The documents may come from teaching and research institutions in France or abroad, or from public or private research centers.
L'archive ouverte pluridisciplinaire HAL, est destinée au dépôt et à la diffusion de documents scientifiques de niveau recherche, publiés ou non, émanant des établissements d'enseignement et de recherche français ou étrangers, des laboratoires publics ou privés.

\section{(이) $\$$}

Distributed under a Creative Commons Attribution - NonCommercial - NoDerivatives 44.0 


\section{TOMBES ET ARCHITECTURE}

Le terme de "mausolée» recouvre en réalité plusieurs structures de nature et de chronologie différentes : on discerne, à l'intérieur d'un mur de clôture cernant une area de plan carré, les vestiges d'un enclos en fer à cheval avec les fondations d'un petit columbarium (fig. 2 et 3 ) et cinq périodes d'utilisation peuvent être identifiées. A l'origine, une fosse rectangulaire fut ouverte en pleine terre et

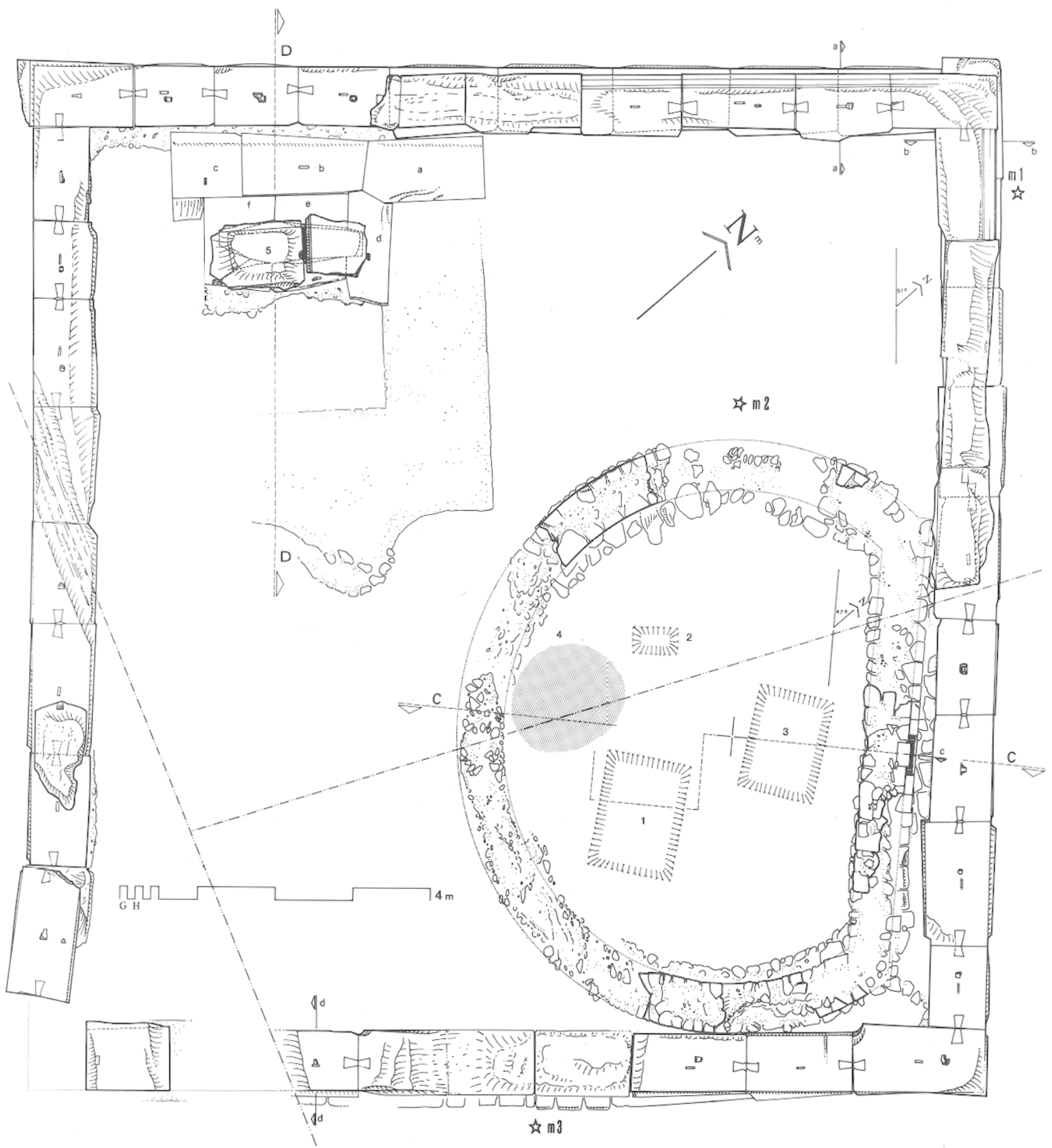

Fig. 2 - Plan d'ensemble de l'enclos funéraire avec le bustum et les fondations partielles du columbarium. $\mathrm{m} 1, \mathrm{~m} 2, \mathrm{~m} 3:$ lieux de découverte des masques; $1,2,3,4,5:$ tombes. 
reçut les restes d'une incinération. Un mur circulaire, recoupé par une section rectiligne, vint circonscrire la parcelle qui recevra par la suite trois autres dépôts cinéraires. D'une construction implantée postérieurement, juste au sud-ouest de la précédente, ne subsistent que les substructions plus ou moins profondément arasées et, pour finir, les deux installations seront englobées à l'intérieur d'une enceinte en grand appareil de facture soignée. Beaucoup plus tard, le massif de soubassement du second édicule fut retaillé pour obtenir en négatif un sarcophage à inhumation. Ces aménagements successifs seront décrits dans l'ordre, du plus ancien au plus récent.

\section{LE BUSTUM}

\section{La Clôture AVEugle}

Le dispositif en fer à cheval, première construc- tion élevée sur le site funéraire, se dressait à l'écart, semble-t-il, car aucun habitat n'a encore été signalé dans le voisinage immédiat. Il occupait au sol un encombrement maximal de quelque $7,10 \mathrm{~m}$; le mur, épais de 2 pieds romains, enfermait un espace de 20 pieds de diamètre en œuvre et la circonférence était recoupée par une corde de 20 pieds regardant le nord - nord-ouest (fig. 21).

La fondation de mauvais caementicium en saillie très irrégulière, parfois inappréciable, sur l'élévation, ne dépasse pas 1 pied de haut, entre les cotes $-0,80 \mathrm{~m}^{1}$ à l'assiette et $-0,55 \mathrm{~m}$ à l'arase, dans une tranchée ouverte à même l'argile naturelle. La partie visible était chemisée extérieurement d'un petit appareil soigneusement parementé où les pas-

1 Le zéro de référence est arbitrairement fixé au lit d'attente sur la première assise en grand appareil de l'enclos funéraire (fig. 10).

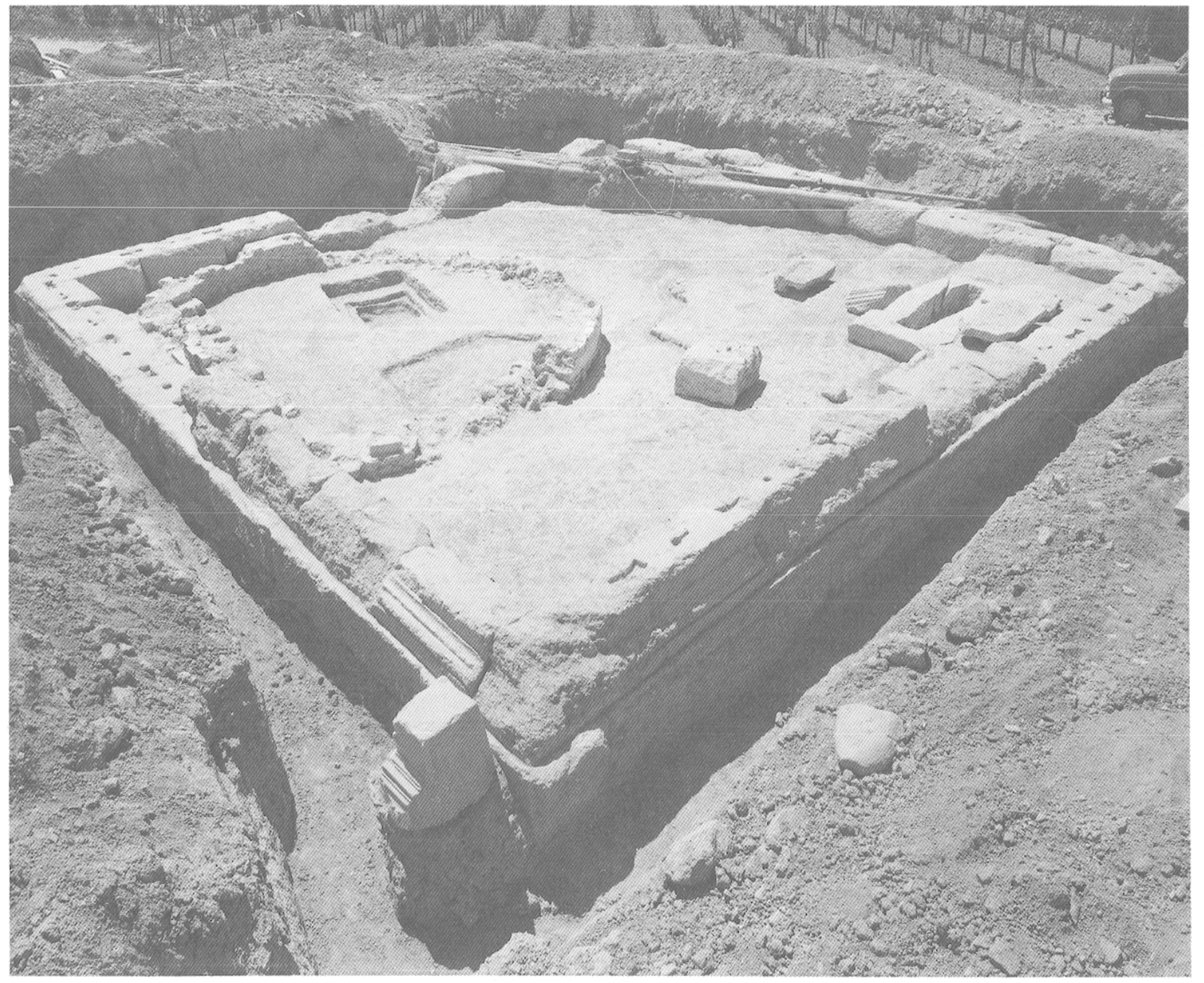

Fig. 3 - Vue générale de l'ensemble fouillé. 


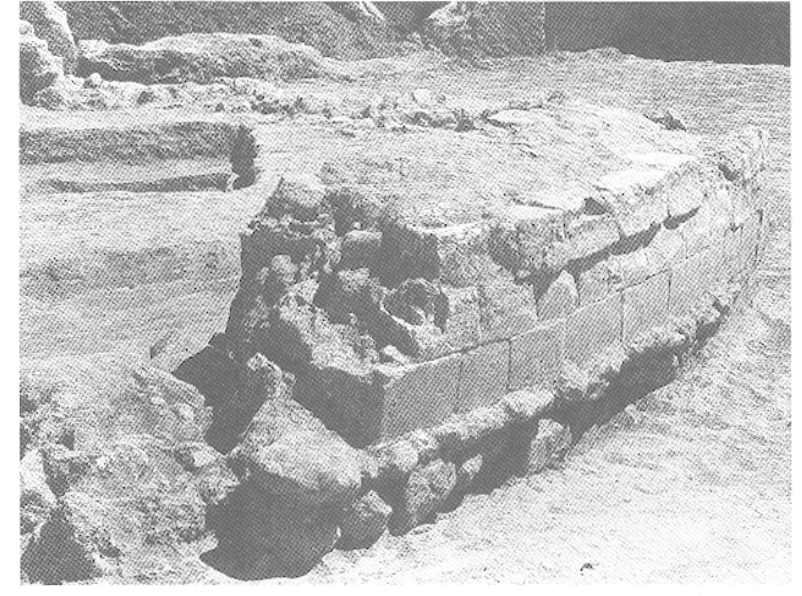

Fig. 4 - Vue de face de la convexité ouest du bustum avec le mur d'enclos apparent. au second plan.

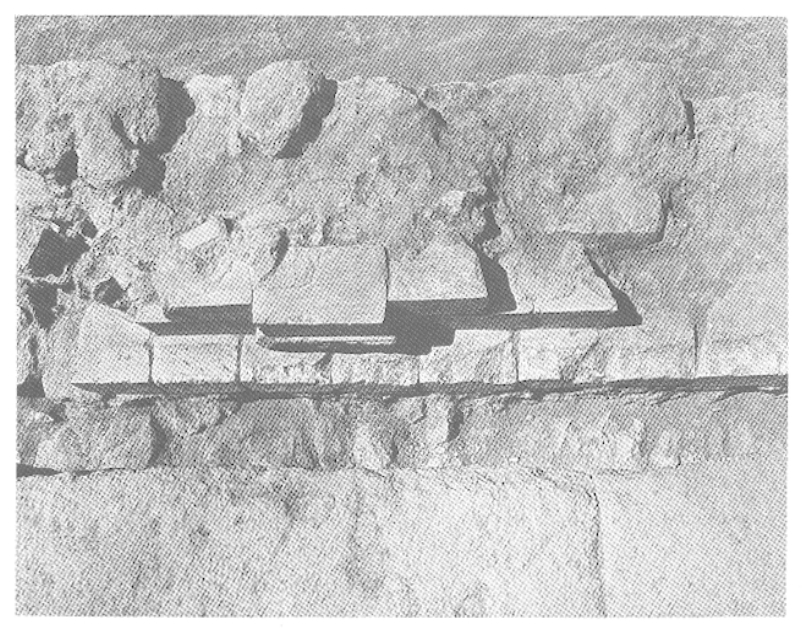

Fig. 5 - Pilastre et base de la façade nord du bustum, vus d'en haut et de face.

toureaux, taillés dans un calcaire blanchâtre de provenance locale (cf. note 39 ), tendre et se rayant à l'ongle, mesurent aux lits de 18 à $21 \mathrm{~cm}$ de face sur 9 en queue, pour des coupes de joints conservées de 14 , 11 et 12. Le liant, à faible teneur de chaux, était de fort médiocre qualité, même si les joints extérieurs étaient repris au fer. Quelques rares tronçons restaient observables : à l'ouest, un arc de cercle était en place sur trois assises et $1,50 \mathrm{~m}$ de développement de $0,58 \mathrm{~m} / 0,60 \mathrm{~m}$ d'épaisseur (fig. 4); au contact du dièdre nord, deux pierres du premier niveau occupaient une longueur résiduelle de $0,36 \mathrm{~m}$ à $0,62 \mathrm{~m} / 0,63 \mathrm{~m}$ et, à l'angle nord-est, un résidu de $0,66 \mathrm{~m}$ à $0,62 \mathrm{~m}$ se maintenait avec encore trois rangées sur sa plus grande hauteur.

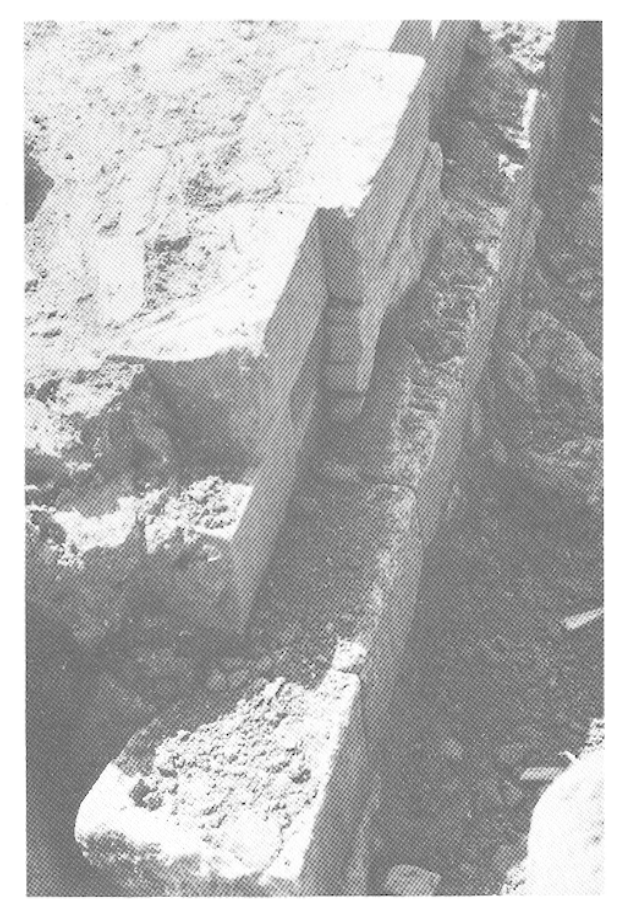

Fig. 6 - Détail du pilastre du bustum.

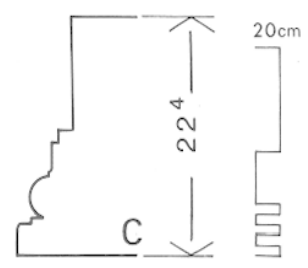

Fig. 7 - Profil de la base et du départ du pilastre du bustum.

Tout au long du pan coupé, la première assise hors sol respectait un débord uniforme de $11 \mathrm{~cm}$ formant stéréobate. Cette paroi rectilinéaire, maintenue sur un segment d'environ $1 \mathrm{~m}$ (fig. 5), arrêté à $-0,16 \mathrm{~m}$, était scandée en son milieu par un pilastre large de 1 pied $(0,29 \mathrm{~m})$ et saillant de $4 \mathrm{~cm}$ sur le parement. Le départ du fût était taillé dans un même bloc (fig. 6) que la base organisée avec une plinthe maigre encore affaiblie par un coup de scie horizontal, un tore avec un filet relié par un congé à un bandeau sommé d'une réglette en forte saillie sur le vif, l'assise doublée occupant trois palmes $(0,224)$ (fig. 7).

Le tracé et les arrachements de la maçonnerie suggèrent que le front architecturé devait être arrêté à ses extrémités par deux autres pilastres de calage et la restitution (fig. 8) se traduit par un alignement de 20 pieds, rythmé de trois parastades de 1 pied encadrant deux tapisseries de huit pieds el demi ; les 


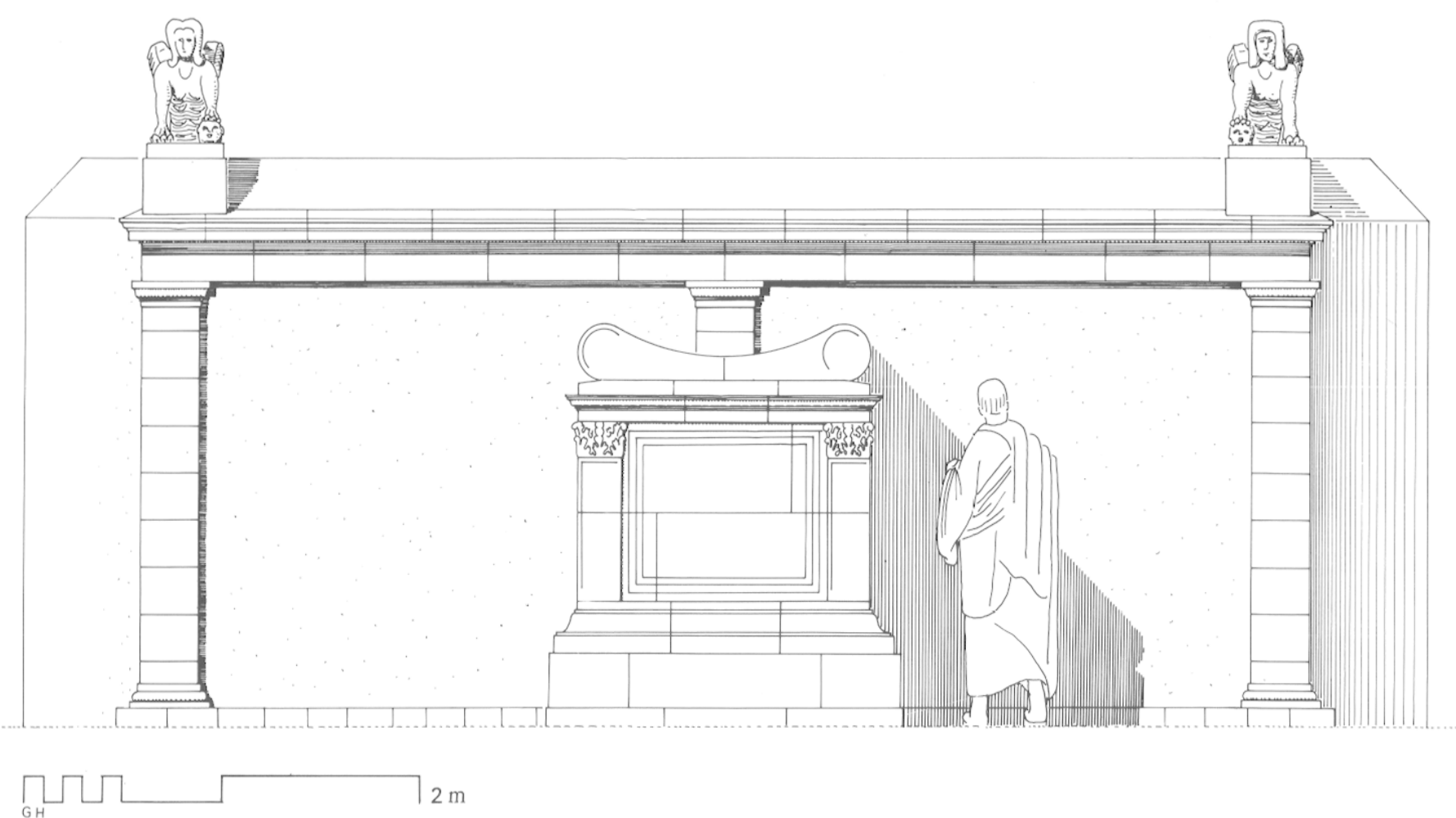

Fig. 8 - Reconstitution de la paroi rectiligne au pan coupé du bustum avec l'autel et les deux sphinges présumées.

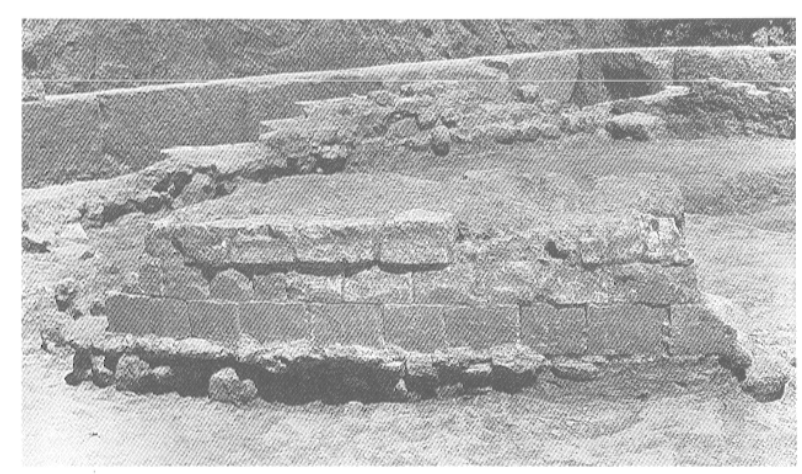

Fig. 9 - Vue interne des deux angles du bustum et de l'enclos, avec traces de tranchage au pic en carrière et de dégrossissage à la broche : au premier plan, arrondi ouest du buslum.

20 pieds du diamètre intérieur se reportaient, mais hors œuvre, sur l'axe perpendiculaire au pan coupé. Aucune trace de seuil ou de scellement de jambage n'était visible qui pût indiquer la présence d'une porte, l'élévation du dedans n'était pas parementée (fig. 9) et tout fait à penser que le mur était aveugle.

\section{LES TOMBES}

Quatre dépôts funéraires se répartissent librement dans l'enclos. Seules les fosses 1 et 2 ont été découvertes par R. Guéry et fouillées avec l'aide de collaborateurs bénévoles; aussi dispose-t-on d'éléments précis pour leur description. Un texte d'A. Dumoulin leur attribue un mobilier dont certaines pièces de provenance très douteuse, ce qui soulève des hésitations dans l'affectation aux autres tombes de ce qui leur revient. R. Coutel et L. Lambert avaient dressé sur place, au moment de sa détection, un plan de situation de la tombe 3 et d'un contenu dont la distribution était encore lisible. Là encore, le catalogue établi par A. Dumoulin retient davantage d'offrandes que n'en comptait la sépulture; quelques objets erratiques, susceptibles d'avoir été dispersés, pourraient sans doute lui être restitués, mais sans qu'on puisse les identifier avec précision et nous avons jugé prudent de les écarter. A s'en tenir aux certitudes, on dispose malgré tout d'indications suffisantes pour analyser le mobilier des trois premières tombes. On ne connaît en revanche de la quatrième que l'inventaire Dumoulin où figurent le récipient en plomb et l'urne de verre qu'il contenait, tous deux ramassés par $\mathrm{H}$. Reynier sur les déblais de la tranchée qui fut à l'origine de la fouille, à quoi s'ajoutent les objets recueillis quelques jours après sur son emplacement présumé. Aussi ne tiendrons-nous compte là encore que du mobilier qui, avec certitude, peut lui être restitué. Toutefois, la position de la tombe n'est attestée que par des 


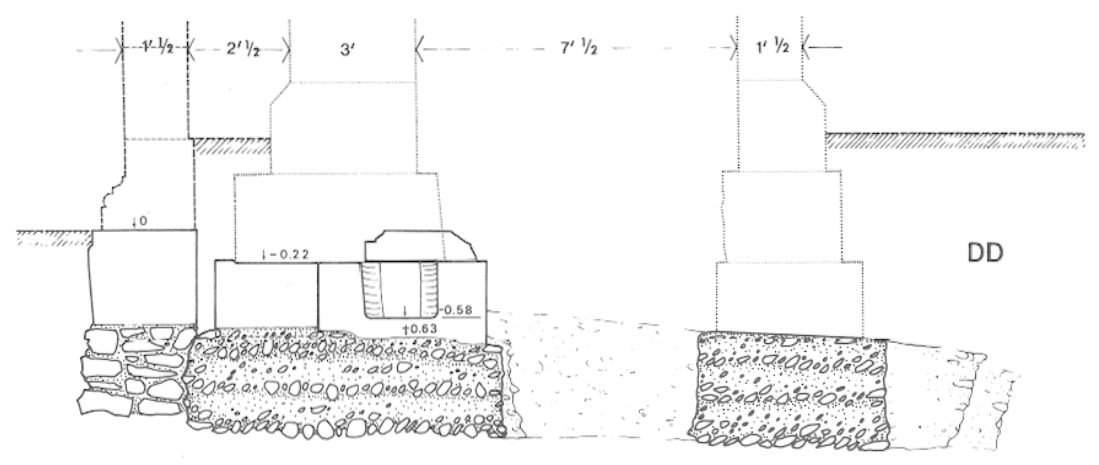

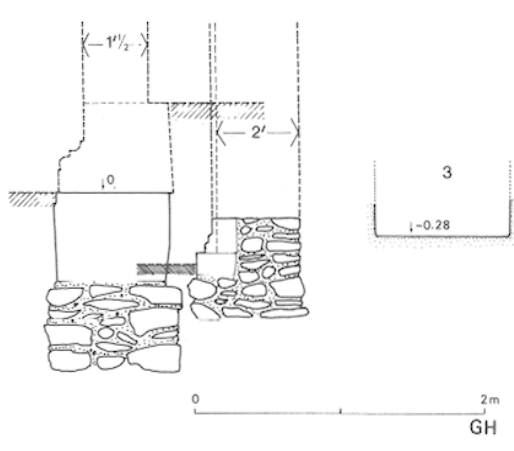

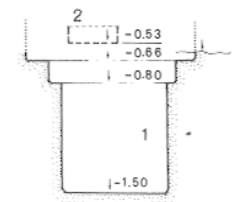

renseignements verbaux qui s'accordent néanmoins pour la situer en un lieu bien localisé, au sud de l'area, en deçà du mur encore invisible au moment de la trouvaille.

\section{TOMBE I}

C'est une fosse rectangulaire de $1,40 \mathrm{~m}$ sur $1,10 \mathrm{~m}$, ouverte dans l'argile de la couche 3 (cf. infra, p. 178). Ces dimensions sont réduites, au niveau - 0,66 $\mathrm{m}$, par un gradin périphérique de $0,18 \mathrm{~m}$ au giron puis, à $0,26 \mathrm{~m}$ en contrebas, par un second degré de $0,10 \mathrm{~m}$; quelques pierres sont groupées au nord. Les flancs descendent ensuite à la verticale jusqu'à $-1,50 \mathrm{~m}$ (fig. 2 et 10 ). Une chape d'argile rapportée oblitérait l'excavation jusqu'au replat supérieur. La cavité était entièrement remplie de cendres charbonneuses noirâtres relativement pures où était ennoyé le mobilier suivant.

\section{Céramique}

1 Coupelle de lampe à huile à pâte tendre grise; engobe disparu. Décor de Victoire ailée debout de face, tenant un bouclier de la main gauche. Types Deneauve V-A (Auguste/fin du ror s. de notre ère); Bailey Bii Q. 855 (Tibère/début de l'époque de Trajan).

\section{Verrerie}

2a, b Urne cinéraire et son couvercle (fig. 11).

a. Urne. Formes Kisa 170; Morin-Jean 1; Isings 67a; Calvi, "olla" $A^{\alpha}$; Goethert-Polaschek 147b. Verre de bonne qualité. La forme est assez caractéristique de la seconde moitié du jer $\mathrm{s}$. b. Couvercle. Formes Isings $66 \mathrm{~b}$; Calvi $B$. Verre vert de bonne qualité. Cette forme accompagne généralement l'urne Isings $67 \mathrm{a}$.

A. KISA, Das Glas in Alterlume, Leipzig, 1908; Morin-Jean, La verrerie en Gaule sous l'empire romain,

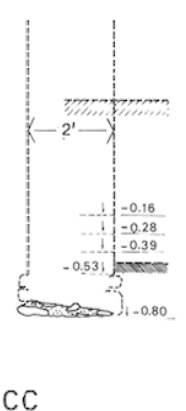

Fig. $10-$

Coupe nord-est/sud-ouest sur l'enclos,

le bustum et ses tombes (en CC) ;

coupe nord-ouest/sud-est sur l'enclos et le columbarium (en DD).

Paris, 1923; - C. Isings, Roman Glass from Dated Finds, Groningue, 1957; - L. Bragrer, Römische Gläser aus Vindonissa, Bâle, 1960 ; - D. Charı.rsworth, Glass from Pompei in Alnwick Castle Museum, Archeologia Aeliana, 43, 1965; - M. C. CALvI, I vetri romani del museo di Aquileia, Aquilée, 1968; - K. GoethertPolascheк, Kalalog der römischen Gläser des Rheinischen Landesmuseums Trier, Mayence, 1977; - C. Pistolet, Les verres de la nécropole de Lattes (Ilérault), Archéologie en Languedoc, 4, 1981; - L. TABorel..I, Su alcuni unguentari di vetro delle necropoli urbani : la forma $28 \mathrm{~b}$ della classificazione Isings, Nolizie degli scavi, 36, 1982

- C. Landes, Verres gallo-romains, Catalogues d'Art et d'Histoire du Musée Carnavalet, IV, Paris, 1983.

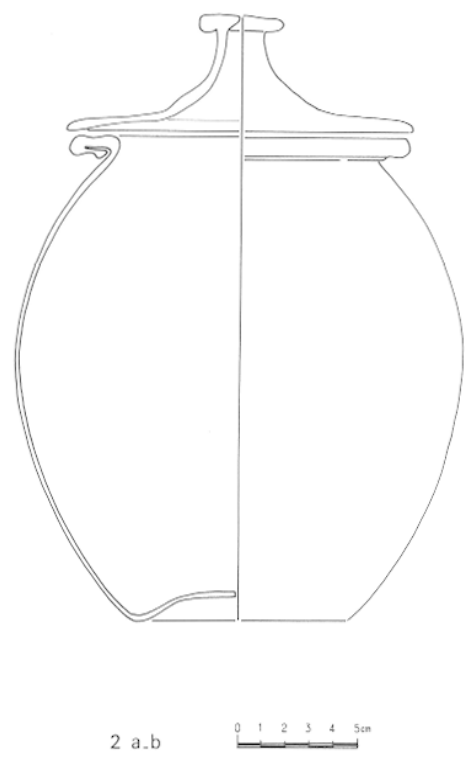

Fig. 11 - Tombe 1. Urne de verre avec son couvercle. 


\section{Tabletterie}

3 Plus de 4000 fragments d'os gravés et sculptés, dont 64 contenus dans l'urne; l'un des éclats adhérait à une esquille d'os humain. Le reste était dispersé dans les cendres. Ces éléments tournés ou sculptés, considérés d'abord comme le décor d'un coffret, en bois, sont attribuables en fait à un lit, funéraire à décor d'os.

L'examen détaillé de ce matériel fera l'objet d'une publication particulière ${ }^{2}$ en raison du volume même de la documentation à traiter. Nous nous en tiendrons donc ici à l'énumération rapide des caractéristiques qui ressortent de l'étude que nous en avons faite.

La forme du lit n'est que partiellement restituable; on peut penser que les pieds comportaient une série de trois volumes, séparés par des tubes, et surmontés sans doute d'un décor figuré d'identification assez délicate (fig. 12). La hauteur du pied lui-même était de $54 \mathrm{~cm}$. Cet ensemble supportait le châssis du lit, orné d'une bordure à motif végétal, et, près des angles, de chevaux au galop entre lesquels se répartissaient plusieurs tableautins d'inspiration bachique, aquatique ou militaire (fig. 13 et 14). Au-dessus du châssis s'élevaient peutètre des accoudoirs ornés de têtes ou de bustes ailés. L'ensemble de cette décoration place sans doute le lit de Cucuron parmi les exemplaires les plus richement ornés de ce type de meuble et en tout cas parmi ceux dont le décor est le mieux conservé. Elle renvoie à des thématiques bien attestées dans l'art funéraire.

Les rapprochements que l'on peut établir entre ce lit et certains des autres exemplaires connus dans l'Empire romain permettent de le rattacher à un petit groupe iconographiquement et chronologiquement assez homogène, qui comporte en premier lieu un exemplaire d'Aoste ${ }^{3}$. On peut considérer qu'il a été fabriqué, pour un usage purement funéraire, vers la fin du $\mathrm{I}^{\mathrm{er}} \mathbf{s}$. avant J.-C. ou au début du $\mathrm{I}^{\mathrm{er}} \mathrm{s}$. de notre ère; son décor figuré doit avoir été sculpté en un lieu d'Italie difficile à préciser, mais on ne peut exclure que les autres éléments proviennent d'un atelier de tourneur gallo-romain.

Cette découverte fournit un témoignage évident du recours à ce genre de meuble dans certaines incinérations de la Gaule méridionale et des vallées du Rhòne et de la Saône, vers la fin de l'époque augustéenne ${ }^{4}$.

\section{Métaux}

4 Environ 700 clous de fer à tête conique, longs de 120 à $140 \mathrm{~mm}$.

5 Plus de 300 clous à tête plate, longs de 80 à $100 \mathrm{~mm}$. Il n'en reste souvent que la gangue d'oxyde concrétionnée autour du

2 A paraitre dans Gallia, 1991 : cette étude constituera la seconde partie du présent article.

3 Voir R. Mollo Mezzena, Augusta Praetoria, aggiornamento sulle conoscenze archeologiche della città e del suo territorio, Revue d'Eludes Ligures, XLI-XLII, 1975-1976, p. 208-210.

4 Sur la diffusion de ce type de meuble en Gaule, voir J.-Cl. BÉAl., Éléments en os de lits gallo-romains, Documents d'Archéologie Méridionale, 9, 1986, p. 111-117; - I. BÉRAud, Ch. GÉbara, Les lits funéraires de la nécropole gallo-romaine de Saint-Lambert (Fréjus), Revue Archéologique de Narbonnaise, 19, 1986, p. 183-210. La plus récente synthèse sur les lits funéraires du monde antique est celle de C. Letra, Due letti funerari in osso dal centro italico-romano della valle d'Amplero (Abruzzo), Monumenti Antichi, serie miscellanea, III-3, 1984, p. 67-115, pl. I-IX.

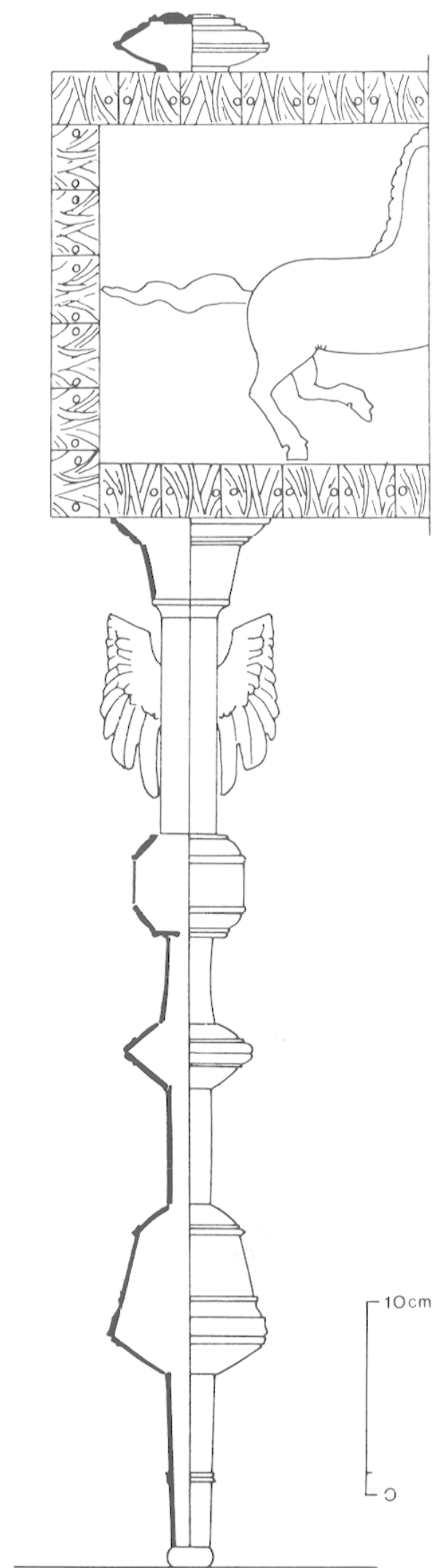

Fig. 12 - Tombe 1. Reconstitution d'un pied du lit en os. 

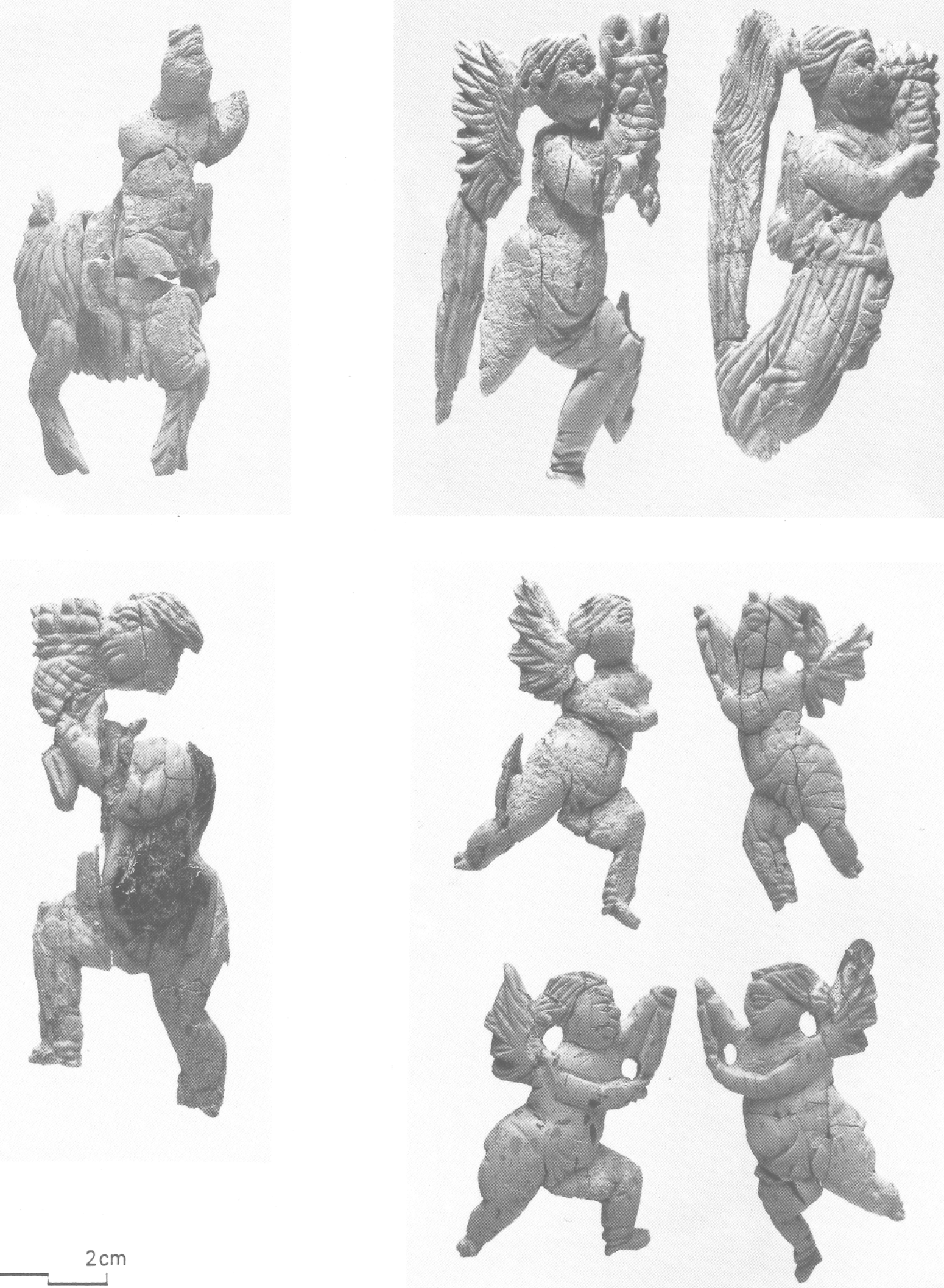

Fig. 13 - Tombe 1. Éléments de placage en os du lit funéraire (pufti et centaures). 

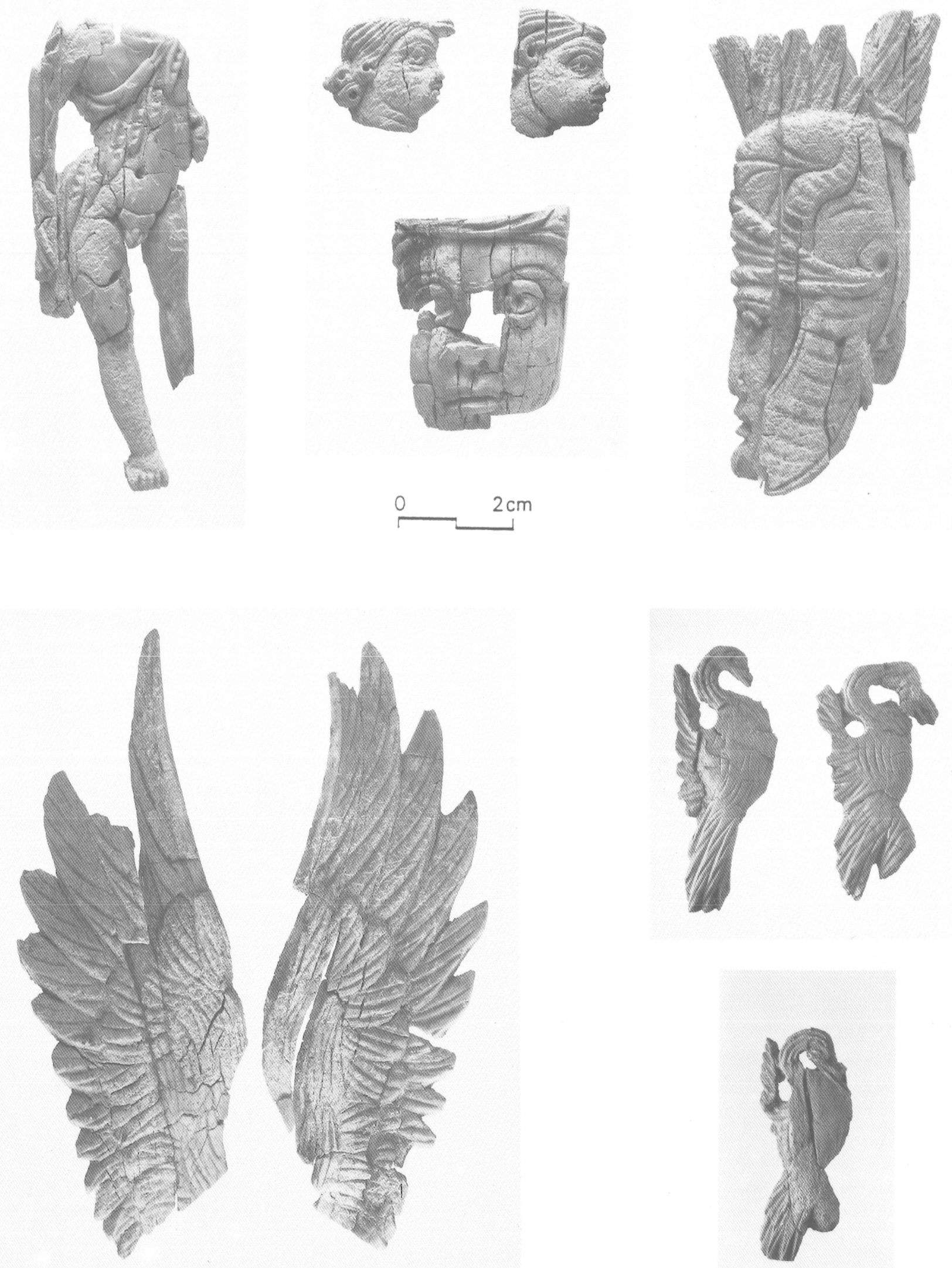

Fig. 14 - Tombe 1. Eléments de placage en os du lit funéraire (ailes, casque et cygnes). 
corps de section carrée entièrement érodé. Une vingtaine d'exemplaires présentent des traces de bois fossilisées par la rouille. Les pointes sont généralement rabattues.

6 Quelques petites pointes en bronze à tête plate et corps pyramidal. Longueur : $19 \mathrm{~mm}$; diamètre de la tête : $5 \mathrm{~mm}$; épaisseur maximale du corps : $1,5 \mathrm{~mm}$. Une d'entre elles était engagée dans la perforation d'un élément de placage d'os gravé qu'elle fixait sur son support; ce procédé de fortune, dont on ne retrouve nulle trace ailleurs, pourrait ètre une réparation.

Le poids total de l'ensemble métallique s'élève à $11,850 \mathrm{~kg}$.

Un faisceau d'indices concordants permet de rétablir avec une forte vraisemblance les phases de l'incinération. Le bûcher, assez imposant, fut dressé à l'écart de la tombe, sur un emplacement indéterminé; il devait être renforcé par un bâti de charpente clouté. Le défunt y fut hissé, allongé sur une civière à décor de marqueterie d'os travaillés. Après la crémation, quelques ossements, confondus parfois avec des éléments de placage du lit funéraire, furent recueillis et regroupés dans une urne en verre. Les cendres du bûcher, mêlées au reliquat des os gravés, furent ensuite déposées avec le vase dans la fosse ouverte à cette intention; il ne subsiste du mobilier qui accompagnait vraisemblablement le mort qu'un fragment de lampe.

Les vestiges osseux humains appartiennent à un individu plutôt jeune de sexe masculin.

En chronologie relative, la tombe est antérieure aux sépultures voisines (tombes 2 à 4) et si l'on ignore à partir de quel sol d'utilisation elle fut ouverte $^{5}$, le fond est largement en contrebas des fondations de l'enclos et, plus encore, du radier des autres fosses (fig. 10, coupe CC). Il est fort probable qu'elle fut aménagée avant même la construction pseudo-circulaire; aussi ne peut-on écarter la possibilité qu'elle ait pu recevoir les restes d'un dynaste familial et motiver par la suite l'érection du premier enclos.

Le critère de chronologie absolue le plus précis serait le lit funèbre que J.-C. Béal rattache à une série attestée de la fin du $\mathrm{I}^{\text {er }} \mathrm{s}$. avant notre ère au début du $\mathrm{I}^{\text {er }}$ après $\mathrm{J}$.-C., ce que n'infirme pas la lampe que les auteurs placent dans une fourchette comprise entre Auguste ou Tibère et le règne de Trajan. L'urne de verre serait "assez caractéristique de la seconde moitié du $\mathrm{I}^{\mathrm{er}} \mathrm{s}$." (Morin-Jean) mais cette datation paraît basse et, compte tenu de la chronolo-

5 La situation en avait èté repérée au détecteur de métaux quand la fouille de la couche 3 venait d'être achevée; rien ne permettait autrement de distinguer la fosse des terres avoisinantes. Une amphore gréco-italique avait été découverte antérieurement au-dessus de cet emplacement (cf. infra, p. 185).

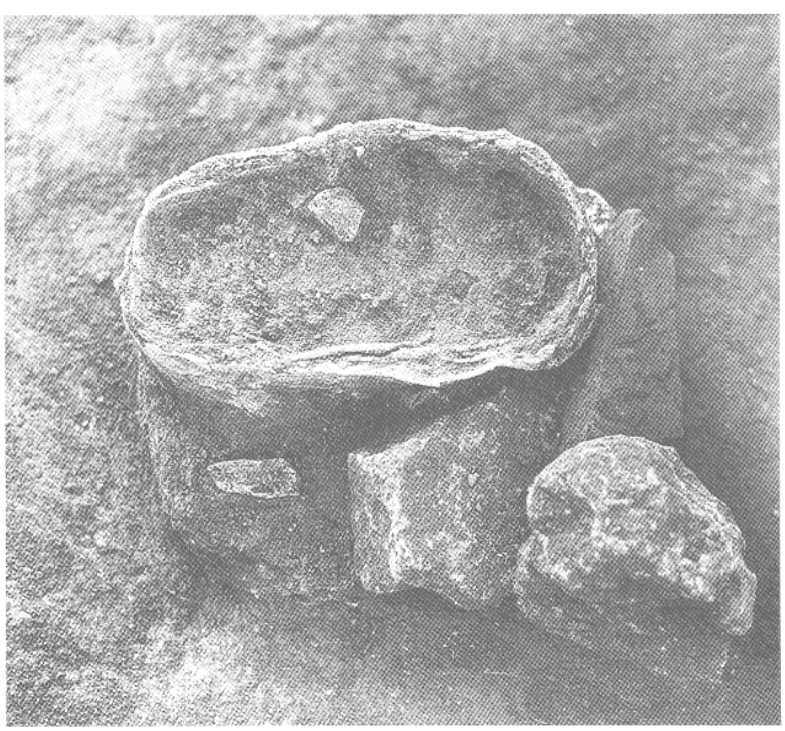

Fig. 15 - Tombe 2. Urne en plomb avec son blocage.

gie des tombes suivantes, nous serions enclins à retenir le premier quart du $\mathrm{I}^{\text {er }} \mathrm{s}$.

\section{TOMBE 2}

Située dans le quadrant est de l'area, symétriquement à la tombe 1 , elle se réduit à une urne en plomb posée au niveau $-0,53 \mathrm{~m}$ et calée par de grosses pierres affleurant à $-0,23 \mathrm{~m}$ (fig. 15).

\section{Verrerie}

1-2 Unguentaria translucides broyés sur place, sans espoir de reconstitution graphique; toutefois la présence de deux exemplaires est assurée grâce aux restes de rebords annulaires. Ces vases avaient été déposés au sud de l'urne, sous une pierre dont le poids a provoqué leur écrasement.

\section{Métaux}

3 Coffret en plomb, oblong et arrondi en demi-cercle aux extrémités (fig. 15); fermé par un couvercle plat à rebord de $25 \mathrm{~mm}$. Longueur : $34 \mathrm{~cm}$; largeur : $18 \mathrm{~cm}$; hauteur : $12 \mathrm{~cm}$; épaisseur des parois : $3 \mathrm{~mm}$. Le récipient, qui contenait des ossements humains carbonisés, s'est complètement désagrégé.

Les os sont ceux d'un jeune adulte de sexe indéterminé.

Aucun élément de datation n'a été recueilli.

\section{Tомве 3}

Aménagée dans l'axe de l'enclos, immédiatement en arrière de la paroi droite, elle se présente sous la forme d'une fosse rectangulaire de $1,20 \mathrm{~m} \mathrm{sur}$ $0,90 \mathrm{~m}$, nivelée à $-0,28 \mathrm{~m}$, garnie de quelques pierres à la périphérie, uniformément recouverte d'argile et partiellement comblée de cendres noirâtres. 


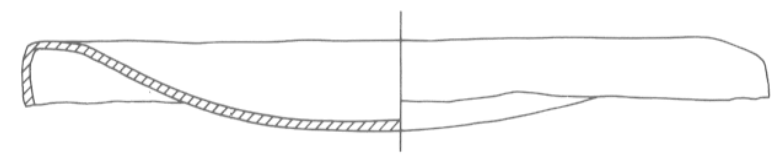

Fig. $16-$ Tombe 3. Mobilier.

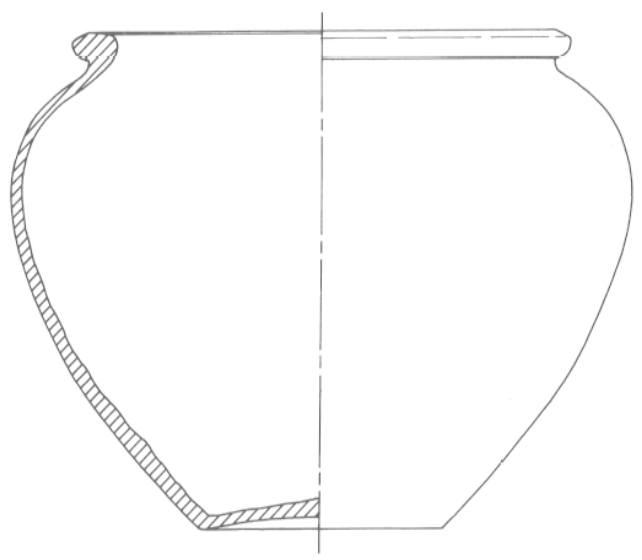

3
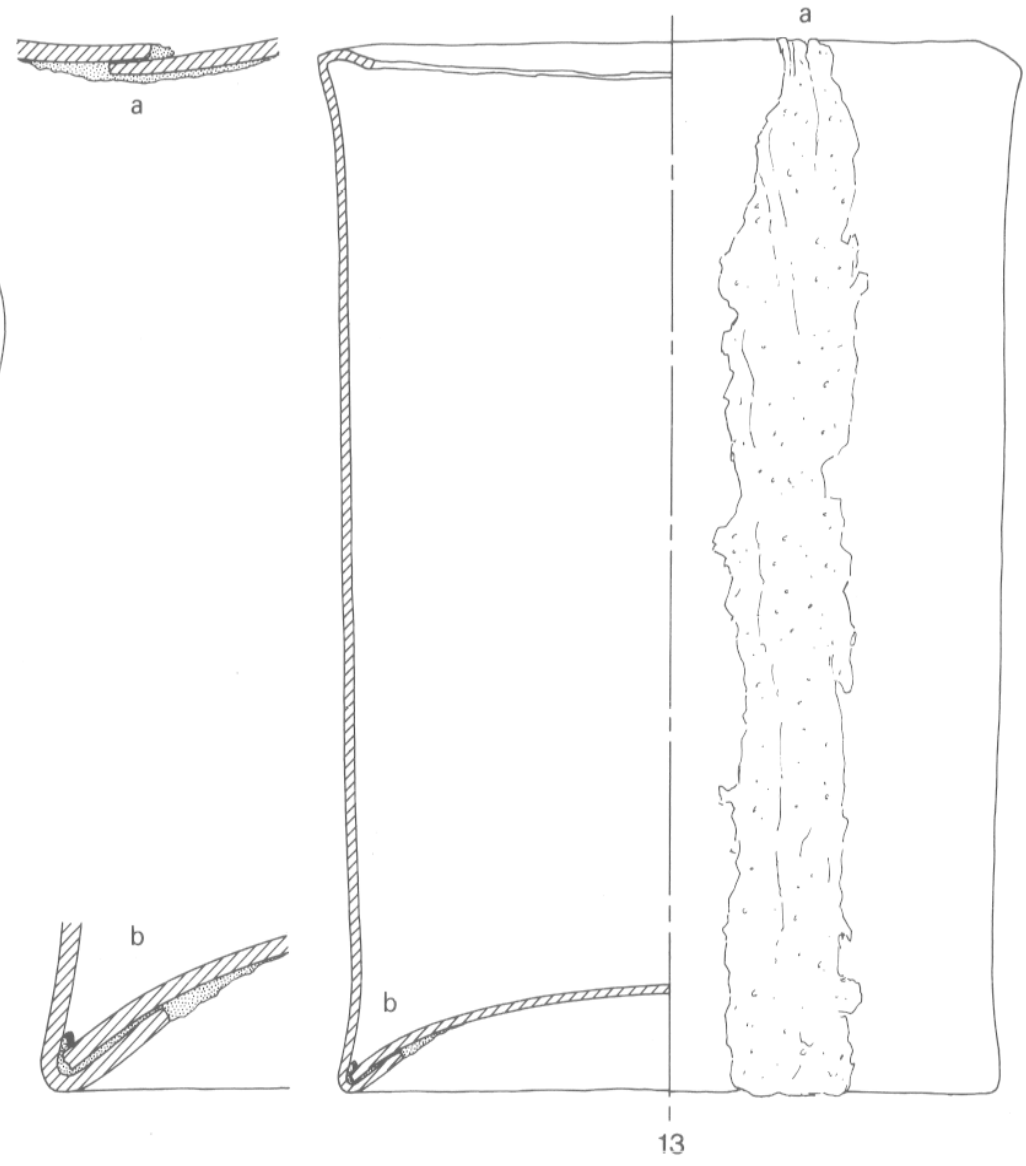

4
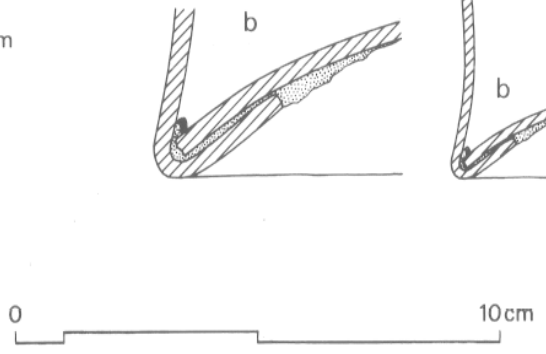

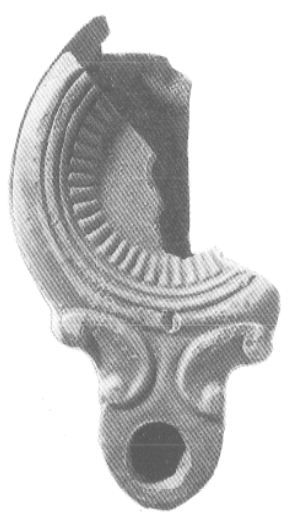

5
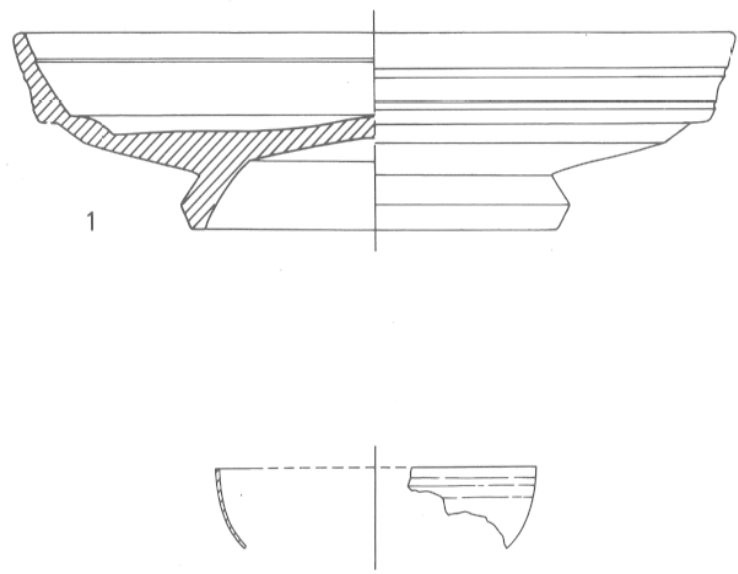

15

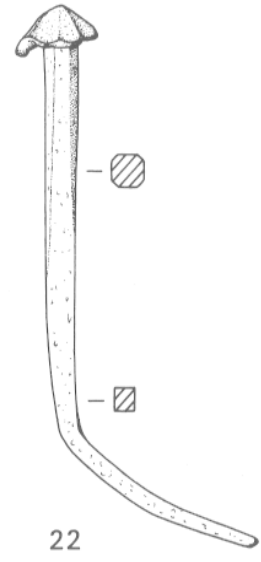

22

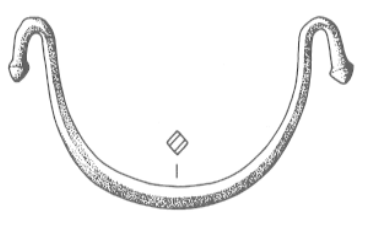

14 


\section{Céramique (fig. 16)}

Les numéros portés sur les figures 16 à 18 renvoient à ceux du catalogue.

1 Assiette en terre sigillée, brisée et partiellement reconstituée. Forme Drag. 15/17 (Pryce, p. 180, pl. XLV, 7 : Tibère/Claude). Au centre du fond interne, estampille incomplète IVN[---] (peut-être Iunius qui paraît le seul développement possible); La Graufesenque ou Banassac (Oswald, p. 153 : Claude/Vespasien).

2 Assiette de terre sigillée fragmentée, recollée mais incomplète. Forme Drag. 18/31 (Pryce, p. 172, pl. XLII, 23 : Claude). Marque disparue.

3 Pot fragmenté, en partie recollé, graphiquement reconstituable. Panse ovoïde, lèvre en amande retournée vers l'extérieur, fond concave. Côtes de tournage internes. A l'extérieur, large sillon peu marqué sous la lèvre; rangées de stries obliques espacées et discrètes en bas de la panse. Pâte granuleuse, cassante, variant du brun-rouge (E. 44) au brun-gris (F. 61), à petites paillettes de quartz et nombreux grains de dégraissant de calcaire blanc apparents en surface.

4 Fragment de col d'un pot. Rebord en bourrelet arrondi à l'extérieur. Pâte lourde, pesante, à paillettes de quartz, cassures très irrégulières, gris foncé en surface (F. 10), plus clair au cœur. Surface brun-gris (F. 62); sans couverte.

5 Fragment de lampe à huile limité au bec rond encadré de volutes saillantes et à la moitié du réservoir; sans marque. Orifice de remplissage central et amorce du trou d'évent. Cuvette ornée de bâtonnets rayonnants. Bandeau circonscrit par deux cercles concentriques rapprochés. Pâte fine, assez dure, brun très pâle (A. 62). Couverte intacte mate, peu épaisse, jaune-rouge (D. 46). Type Deneauve V-A (Auguste/1er s.); Bailey Biii proche du décor Q.926 (fin de l'époque de Tibère, début du règne de Trajan).

Verrerie (fig. 17)

6 Urne. Même type que le no 2 a (cf. supra, p. 152). Verre de couleur verte, bullé.

7 Tasse. Forme rare pour laquelle n'existe pas de parallèle précis. Verre transparent légèrement vert-jaune, très fragile. L'embouchure, coupée aux ciseaux, a été adoucie. L'anse en ruban est annulaire. Son ourlet d'attache sur la panse se poursuit par un fil de verre. Près de la lèvre, elle se développe en un court poucier. La panse est ornée de stries parallèles. 8 Tasse. Forme et matière proches du no 7 .

9 Gobelet. Forme rare apparentée aux coupes Calvi, groupe $\mathrm{B}$ mais dont l'embouchure est différente. Verre transparent légèrement vert-jaune de bonne qualité. L'embouchure, coupée aux ciseaux, a été adoucie. Elle est soulignée par une fine cannelure sur sa face externe. La panse est ornée de quatre fines cannelures parallèles.

10 Gobelet. Forme et matière proches du no 9 .

11 Flacon muni de deux anses. Forme rare pour laquelle nous n'avons pas trouvé de parallèle exact. Verre transparent, légèrement vert-jaune, très fragile. Sur le col, on remarque l'attache des anses : les ourlets s'y prolongent par un petit fil de verre qui court sur presque toute la surface externe de celles-ci.

12 Flacon muni de deux anses. Présente à peu près la même forme que le $n^{\circ} 11$. Verre transparent, légèrement vert-jaune, très fragile. L'embouchure, coupée aux ciseaux, est adoucie et soulignée par une fine cannelure. La panse est striée de deux fines cannelures parallèles.

Métaux (fig. 16)

13 Récipient en plomb formé d'une feuille de 2,5 à $3 \mathrm{~mm}$

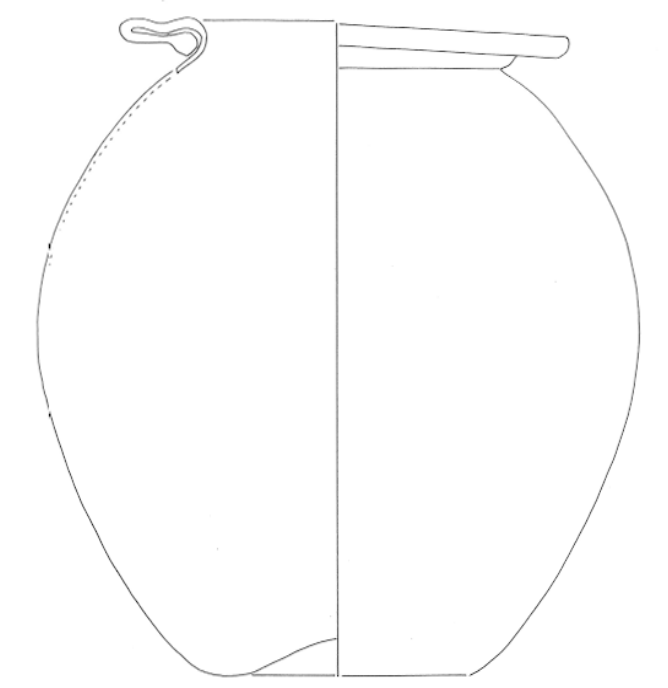

6
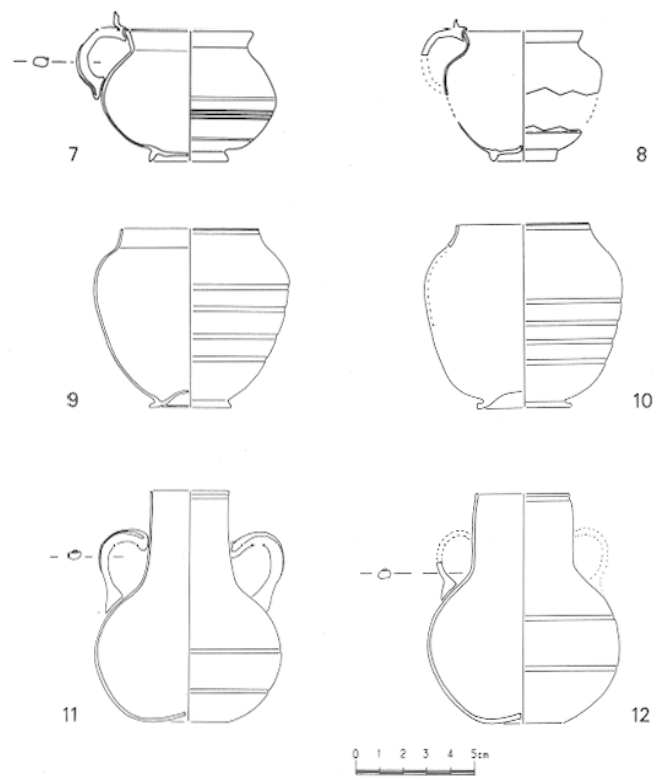

Fig. 17 - Tombe 3. Verreries.

d'épaisseur, arrondie en manchon cylindrique légèrement évasé en haut et en bas. Les bords latéraux, superposés sont fermés par une soudure extérieure; l'ourlet supérieur est replié à angle droit vers l'intérieur; sur le bord inférieur, qui forme un coude arrondi rentrant, est soudé un fond circulaire concave. La circonférence du couvercle est rabattue à $90^{\circ}$. Déformé et rempli de terres cendreuses enrobant l'urne en verre $n^{\circ} 6$ (fig. 17).

14 Anse de bronze semi-circulaire pouvant appartenir à une petite situle. Section rhomboïdale. Amincie aux extrémités qui se recourbent vers l'extérieur et se terminent par des bossettes tronconiques.

15 Coupelle hémisphérique en tôle de bronze, partiellement reconstituée.

16 Bague en bronze constituée d'un jonc plat; épaisseur : $1 \mathrm{~mm}$; largeur : $2 \mathrm{~mm}$; diamètre : $19,2 \mathrm{~mm}$.

17 Bouton de bronze tronconique perforé au centre; diamètre : $16 \mathrm{~mm}$; hauteur : $6 \mathrm{~mm}$.

1810 semences de bronze à tête hémisphérique; diamètre de la tête : $8 \mathrm{~mm}$. 

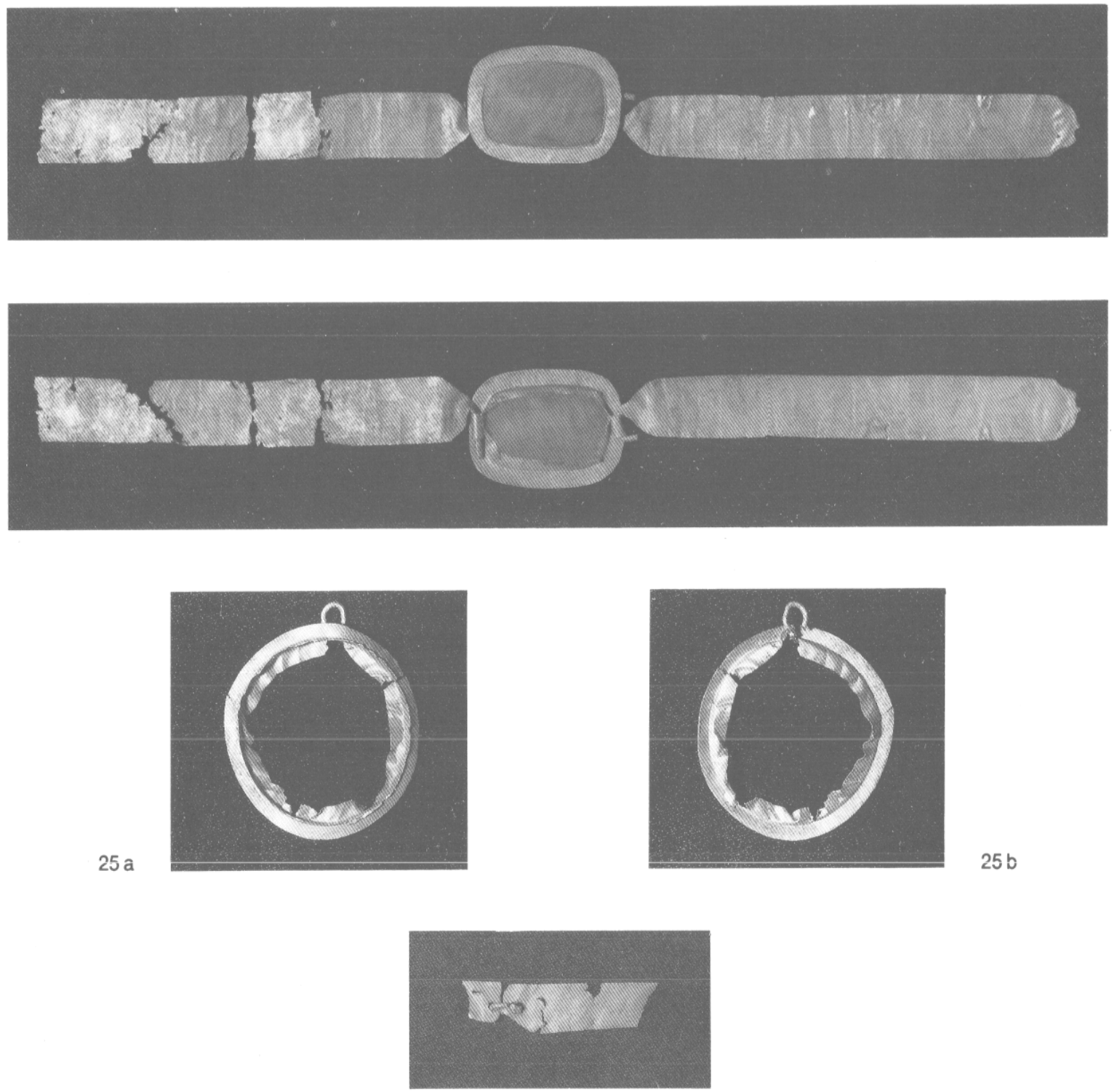

26
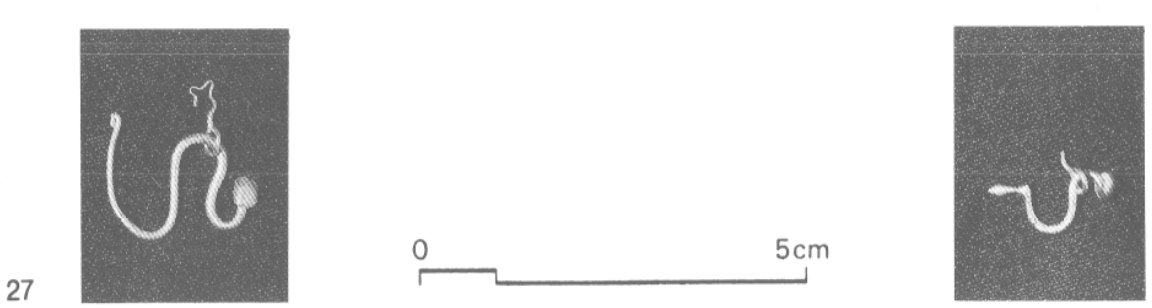

28

Fig. 18 - Tombe 3. Bijoux en or.

19 Une trentaine de menus fragments de bronze érodés provenant d'objets indéfinissables.

20271 clous de fer incomplets, à tête plate; longueur probable : entre 10 et $12 \mathrm{~cm}$.

211003 débris de fers ronds informes, peut-être des clous. 2248 gros clous de charpente en fer, tête pyramidale et tige carrée; longueur : $90 \mathrm{~mm}$ environ.

23 Six chutes de fer plat.

\section{Parures (fig. 18)}

24 Médaillon d'or constitué d'un cadre rectangulaire aux angles arrondis ménageant un évidement central dans lequel est sertie une opale translucide. Au revers de la monture et à chaque extrémité, est soudé un petit fourreau qui reçoit les pendants, façonnés en crochets, de deux minces rubans de feuille d'or, l'un à peu près complet, l'autre déchiré en quatre 
fragments; les rubans devaient se rattacher par un fermail disparu. La longueur développée de l'ensemble est évaluée à un peu plus de $190 \mathrm{~mm}$, ce qui correspond à la circonférence d'un bracelet. Le cabochon a été retrouvé à quelque $3 \mathrm{~m}$ à l'ouest de la tombe : cette dispersion suggère, plutôt qu'un pillage de la sépulture, un bouleversement, vraisemblable des terres à une date indéterminée qu'on mettra en relatiun avec la récupération des pierres de grand appareil.

25 Anneau circulaire déformé constitué d'une mince feuille d'or dont la circonférence interne est repliée sur elle-mème en ourlet pour constituer le sertissage d'un médaillon central perdu. Au revers et en bordure de la monture, est soudée une bélière de suspension en forme d'anneau ouvert.

26 Minces rubans de feuille d'or incomplets perforés à une extrémité et raccordés par un anneau allongé ouvert.

27 Boucle d'oreille en or en forme de serpent. La pointe de la queue est repliée sur elle-mème, le corps coudé en trois méandres inégaux. Un petit anneau fermé, sur lequel est soudé un fil d'or ondulé de suspension, encercle le corps; le point d'équilibre du bijou se situe au milieu du méandre supérieur. 28 Autre boucle d'oreille serpentiforme plus petite que la précédente. Le corps est replié en $\mathrm{U}$; la queue horizontale se termine par un renflement; la tête ovale est soudée à l'autre extrémité. L'anneau sur lequel est attaché le départ du fil de suspension est soudé en arrière de la tête.

29 Fibule à charnière en bronze, dite d'Aucissa (Hülsenscharnierfibeln) du type Ettlinger 29. L'arc est orné d'une nervure médiane décorée de fines perlettes. Pied à bouton terminal; tête plate nervurée; ardillon disparu. Le type apparaît dans les camps rhénans de l'époque d'Auguste jusqu'au début de la dynastie flavienne.

E. Etturngre, Die römischen Filben in der Schweiz, Berne, 1973.

30 Bracelet de bronze ouvert, en fragments; le jonc cylindrique strié se termine par un renflement globulaire. Déformé par le feu.

31 Chaînette de section carrée en 32 morceaux, composée de fils de cuivre tressés, avec goupille de fixation aux extrémités. Longueur : $550 \mathrm{~mm}$; section : $3 \mathrm{~mm}$.

32 Cadre de miroir en bronze, 12 fragments. Tôle étroite repliée emprisonnant une bordure moins large de même facture; douille cylindrique. Diamètre du miroir : $190 \mathrm{~mm}$; diamètre du manche : $10 \mathrm{~mm}$; largeur totale de l'encadrement : $12 \mathrm{~mm}$; épaisseur : $4 \mathrm{~mm}$. Aucune trace du réflecteur. 33 Perle tronconique en quartz hyalin, biseautée aux angles et percée en son axe. Diamètre : $18 \mathrm{~mm}$; hauteur : $6 \mathrm{~mm}$.

\section{Monnaies}

34 As posthume d'Auguste.

D/ Tète radiée à gauche. IJVVS AVGVSTVS PATER.

R/ Autel. De part et d'autre, S.C. A l'exergue, PROVIDENT $\left(R I C, \mathrm{I}, \mathrm{n}^{\circ} 149\right)$. Frappé sous Tibère.

35 Autre as identique.

36 Denier d'Agrippine et de Néron.

D/ Tète de Véron nu et buste drapé d'Agrippine se faisant face. AGRIPP.AVG. DIVI CLAVD. NERONIS CAES.MATER.

R/ Couronne de chêne. NERONI CLAVD. DIVI F.CAES. AVG.GERM.IMP.TR.P. Exergue S.C. (RIC, I, no 3). 54 après J.-C.

Les restes humains appartiennent vraisemblablement à un adulte de sexe inconnu.
$\mathrm{Ni}$ la verrerie, dont les formes sont peu communes, ni les bijoux ne permettent de datation fine; en revanche, la lampe et la fibule suggèrent le $\mathrm{I}^{\mathrm{er}} \mathrm{s}$. de notre ère. La chronologie est précisée par le denier qui fixe un terminus a quo en 54 , ce que confirment les deux assiettes sigillées de Gaule méridionale, datées au plus tôt du règne de Claude. Une datation de la seconde moitié du $\mathrm{I}^{\mathrm{er}} \mathrm{s}$., voire du troisième quart, conviendrait à cette tombe.

\section{TOMBE 4}

On ignore à peu près tout de sa position, sinon que les informations recueillies auprès des premiers fouilleurs s'accordent pour la placer en un point assez bien localisé situé sur le passage d'une tranchée de canalisation indiquée sur le plan par un pointillétireté (fig. 2): elle se trouverait en face de la tombe 3 , les dépôts cinéraires se répartissant aux angles d'un quadrilatère. De même éprouve-t-on quelques doutes sur le contenu de la sépulture. Le récipient de plomb et son urne en verre ont été fortuitement mis au jour dans les déblais de la tranchée où a été ouvert un sondage d'où provient le reste du mobilier attribué à la tombe par A. Dumoulin. Les verreries et les céramiques à parois fines, intactes ou entièrement reconstituables qu'il mentionne, devraient provenir du mème contexte, compte tenu de leur fragilité et de l'espace réduit où elles furent trouvées. Toutefois, nous ne ferons état que des seuls objets dont l'attribution est confirmée par des rapports oraux concordants.

\section{Céramique (fig. 19)}

Les numéros portés sur les figures 19 et 20 renvoient à ceux du catalogue.

1 Bol à parois fines type Ricci $2 / 410$. Fond concave étroit, bas de panse d'allure convexe largement évasé, surmonté d'un registre vertical occupé par deux bourrelets au repoussé ourlant une bande guillochée. Lèvre très fine légèrement renflée à l'extérieur. Guillochures obliques de part et d'autre de l'arrondi de la panse. Traces de surfaçage doré à la feuille (cf. PÉtrone, Satyricon, 73,15 : calices ... fitiles inauratos). Pâte dure, très fine, grise (F. 90). Tibère/Claude.

2 Tasse à parois fines en menus fragments. Deux anses arrondies de section rectangulaire, creusées d'une gorge médiane. Pied absent, panse arrondie en bas, verticale en haut. Lèvre étroite soulignée d'un sillon. Sous le rebord, zone réticulée de petits losanges disposés en quinconce, haute de $27 \mathrm{~mm}$. Pâte fine, cassante, assez tendre, grise (D. 90); sans couverte apparente. Forme Ricci 2/348, Marabini XXXVI, Mayet XXXV. Milieu du $\mathrm{I}^{\mathrm{er}} \mathrm{s}$./premières décennies du $\mathrm{II}^{\mathrm{c}} \mathrm{s}$. 3 Unguentarium à fond plat, panse piriforme et long col en tronc de cône renversé terminé par une lèvre plate, ouverte en quart de cercle sur l'extérieur. Pâte fine, peu dure, grise (D. 90); sans couverte. Traces de tournage plus apparentes en bas de la panse. 


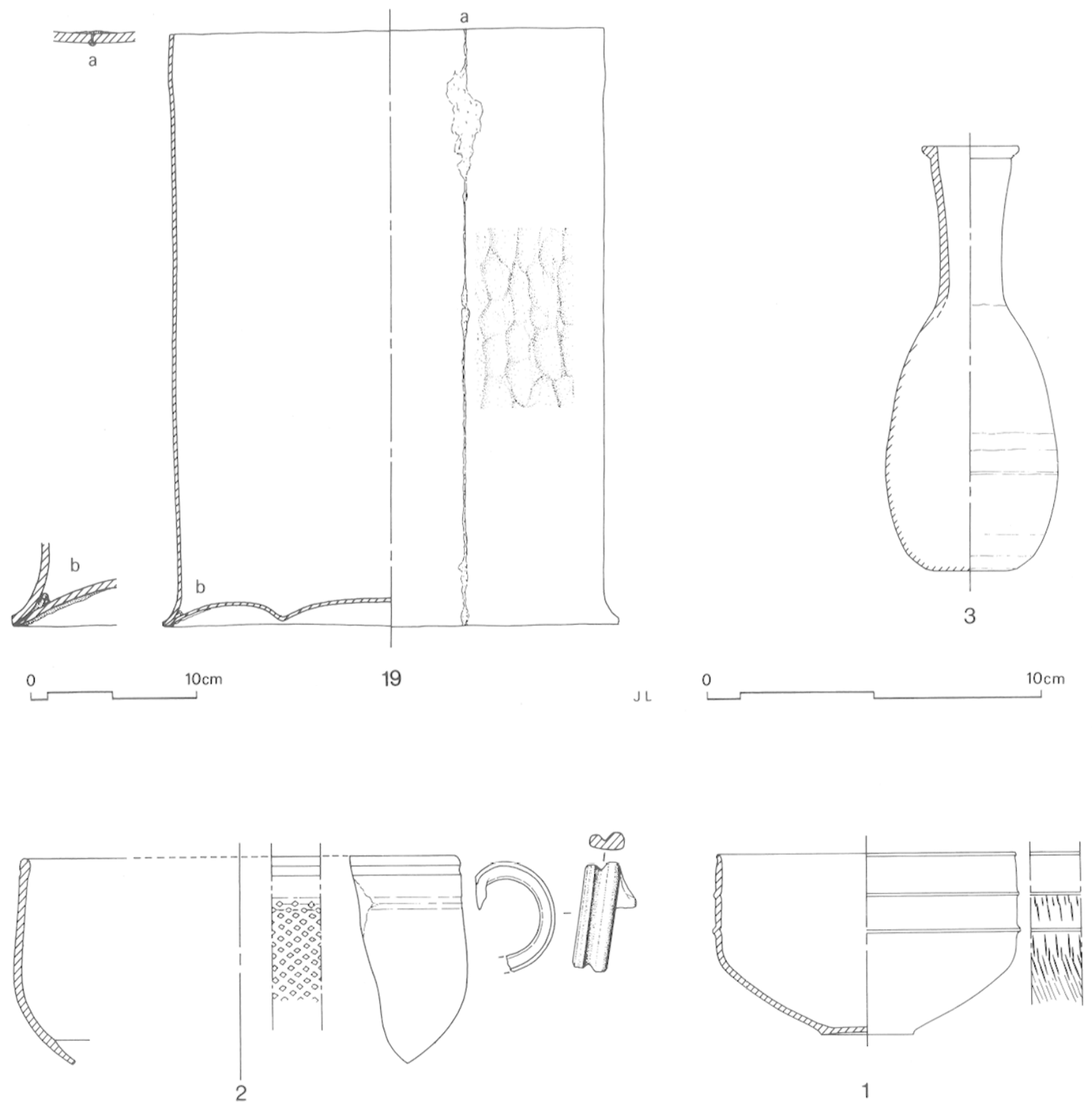

Fig. 19 - Tombe 4. Mobilier.

\section{Verrerie (fig. 20)}

4 Urne à deux anses. Formes Kisa 167; Morin-Jean 2; Isings 63; Calvi, "olla" $\mathrm{A}^{\beta}$ (anse du type 2); GoethertPolaschek 150 . Verre de couleur verte de bonne qualité. La lèvre horizontale est ourlée. Fréquente durant le $\mathrm{i}^{\mathrm{er}} \mathrm{s}$. et la première moitiè du ${ }_{I I}{ }^{e} s$.

Charlesworth, 1965, p. 230.

5 Coupelle. Formes Isings 44; Goethert-Polaschek 22. Verre bleu-vert, légèrement bullé mais de bonne qualité. La lèvre est ourlée vers l'intérieur. Fermait l'ouverture de l'urne no 4.

6 Rhyton. Formes Morin-Jean 118 (124); Isings 73b; Goethert-Polaschek 165 . Verre opaque, légèrement vert-jaune, de bonne qualité mais très fragile. L'embouchure, coupée aux ciseaux, est soulignée par une rainure; une autre apparaît au tiers supérieur de la hauteur. La petite ouverture a été adoucie par polissage. Les rhytons de verre sont datés en règle générale de la seconde moitie du ier $\mathbf{s}$., mais ils connurent aussi un grand succès durant l'Antiquité tardive (III-IVe s.).

7 Aiguière. Forme Isings 88a. Verre de couleur verte, de bonne qualité mais très fragile. Il est difficile de trouver des parallèles exacts à cette forme dont la qualité du verre suggère une date haute : jer-r $^{\text {e }} \mathrm{s}$.

8 Balsamaire. Formes Morin-Jean 22; Isings 28a/b; Calvi, balsamaire 2e, groupe $\mathrm{H}$; Goethert-Polaschek 69a. Verre de bonne qualité de couleur verte. Cette fiole, qui marque une évolution de la forme Isings $8 / 28$, est caractéristique de la seconde moitié du ${ }^{\text {er }} \mathrm{s}$.

TABORELLI, 1982, p. 409 et 415. 


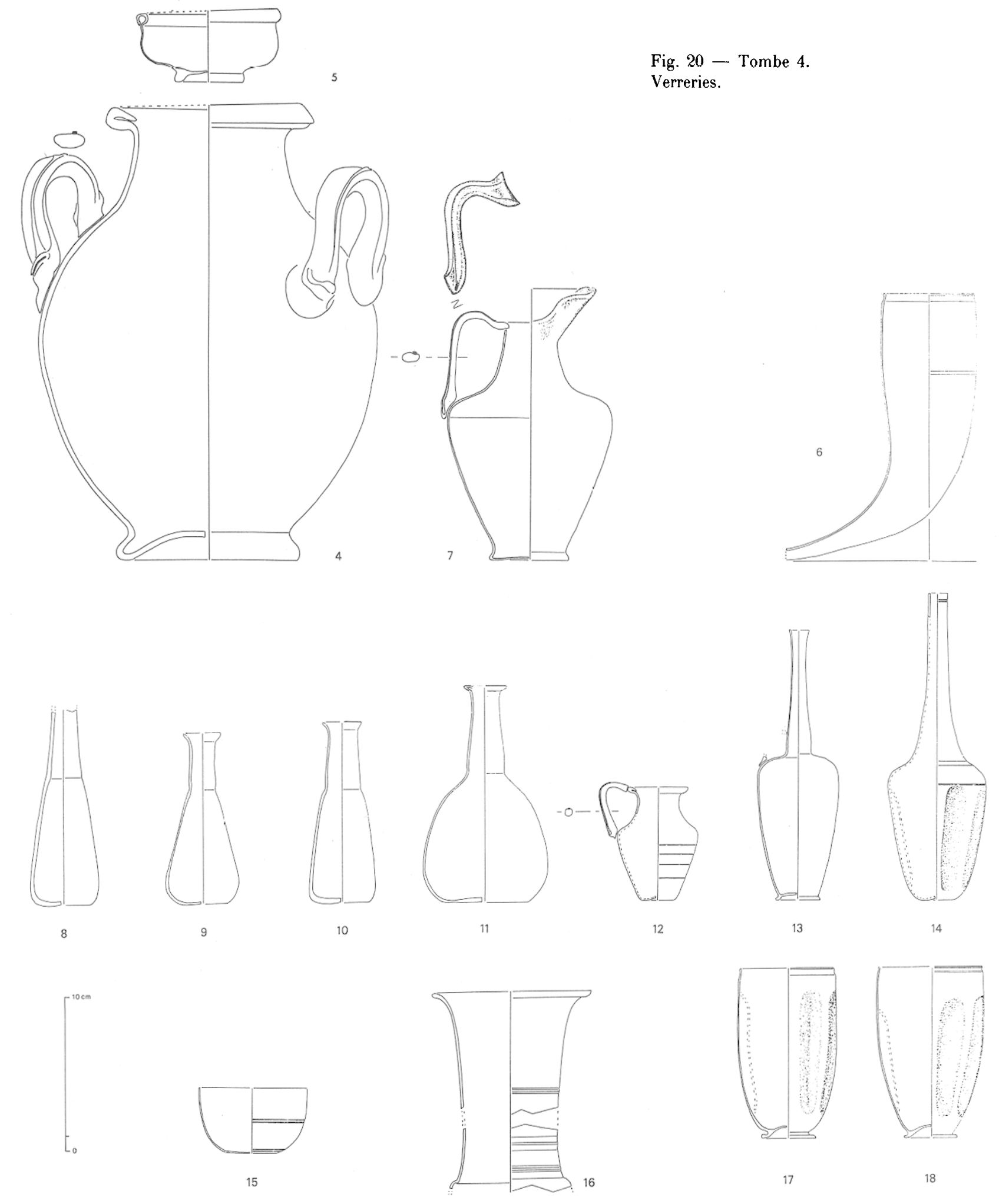


9 Balsamaire. Même forme que le no 8 . Verre de couleur verte de bonne qualité. L'embouchure est coupée aux ciseaux et adoucie.

10 Balsamaire. Mème forme que les nos 8 et 9 . Verre de bonne qualité mais légèrement piqué. L'embouchure, coupée aux ciseaux, a été adoucie.

11 Flacon. Formes Morin-Jean 26; Isings 28a; Calvi, bouteille, groupe B; Goethert-Polaschek 71. Verre de couleur verte de bonne qualité. Cette forme est très répandue aux I er $^{\text {et }}$ II $\mathrm{s}$.

LANDEs, 1983, nos 58 à 60 , p. 65 .

12 Petit flacon ansé. Forme Morin-Jean 44? Verre transparent, légèrement filandreux. Anse en cordon ornée sur sa surface externe d'un filet de verre qui prolonge l'ourlet de fixation sur l'épaule. La panse est décorée de quatre stries parallèles. Cette forme est rare.

13 Bouteille ansée. Forme atypique. Verre transparent de bonne qualité. Embouchure coupée aux ciseaux et adoucie. 14 Bouteille à dépression. Verre transparent de bonne qualité. L'embouchure, coupée aux ciseaux, est soulignée par deux fines rainures parallèles. L'épaule est ornée de minces rainures parallèles et la panse marquee par dix dépressions verticales. Il est difficile de comparer cet objet qui n'existe que sous des formes voisines dans des contextes archéologiques allant de la fin du ier s. au in $\mathrm{e}$ s.

15 Gobelet. Formes Morin-Jean, proche de 71 ; Isings, voisin de 12; Goethert-Polaschek, analogue à 49a. Verre transparent très fragile. Embouchure coupée aux ciseaux. Vasque ornée de stries concentriques. Cette forme est présente à Vindonissa dans des couches d'occupation contemporaines de ClaudeNéron (Berger, 1960, p. $\left.44, \mathrm{n}^{\circ} 100\right)$ et dans la nécropole de Lattes au milieu du I $^{\text {er }} \mathrm{s}$. (Pistolet, 1981, no 183 , p. 49).

16 Col d'une urne? Forme Goethert-Polaschek 101 ou 111 ? Verre opaque légèrement vert-jaune. Col orné de stries parallèles.

17 Gobelet à dépressions. Formes Isings 35; Calvi, gobelet, groupe C. Verre opaque. Embouchure soulignée par une moulure. Panse marquée par douze dépressions allongées verticalement. Ce type apparaît au I $^{\text {er }} \mathrm{s}$. et se développe jusqu'au Irre.

18 Gobelet à dépressions. Mème forme que le $n^{\circ} 17$. Verre transparent légèrement teinté vert-jaune. Onze dépressions sur la panse.

\section{Métaux (fig. 19)}

19 Récipient de plomb cylindrique, légèrement évasé à la base, formé d'une tôle martelée arrondie en manchon dont les deux grands côtés sont discrètement soudés bord à bord. Fond concave avec arrondi convexe. A. Dumoulin signale un "couvercle emboittant" qui ne figure ni sur l'inventaire, ni dans les réserves du musée de Cucuron. Contenait l'urne no 4 .

2020 clous de fer à tête plate et tige ronde; se trouvaient sans doute sous le récipient 19 dont le fond conserve des traces de concrétions oxydées.

\section{Monnaies}

21 As de Claude.

D/ Tête nue à gauche. TI. CLAVDIVS CAESAR AVG M. TR.

P. IMP. ou IMP. P. P.

R/ La Liberté debout à droite, tenant un bonnet et tendant la main gauche. LIBERTAS AVGVSTA. Dans le champ, S. C. $\left(R I C, \mathrm{I}, \mathrm{n}^{\circ} 69\right)$. Entre 41 et 54.

La verrerie date la tombe de la seconde moitié du $\mathrm{r}^{\text {er }} \mathrm{s}$. ce que confirment la tasse à parois fines $\mathrm{n}^{0} 2$ et la monnaie de Claude.
Les vestiges osseux humains sont ceux d'un homme âgé.

Quelles conclusions peut-on tirer de l'étude de ce matériel très divers contenu dans les tombes dégagées? On remarquera d'abord l'importance du mobilier de verre ${ }^{6}$ : dans la tombe 1 , une seule urne et son couvercle, mais sept objets dans la tombe 3 et quinze dans la tombe $4^{7}$, soit au total vingt-quatre pièces de verre. C'est l'originalité des formes qui caractérise l'ensemble. Trois profils se distinguent parmi le mobilier de la tombe 3, en double exemplaire chacun, ce qui retient davantage l'attention. Cette remarque vaut aussi pour les gobelets à dépressions presque identiques de la tombe 4 . Certes, les urnes

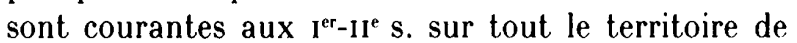
l'Empire et surtout en Gaule, comme d'ailleurs les balsamaires. Ces derniers, liés à l'utilisation des parfums et des onguents dans le rituel funéraire, se trouvent en abondance dans les nécropoles du HautEmpire. Des études détaillées de ces petites fioles à l'aspect apparemment répétitif révèlent cependant de grandes nuances de détail. Après les travaux fondamentaux de $\mathrm{C}$. Isings ${ }^{8}$ qui les classait en trois

6 Cette richesse a été déjà soulignée: Fr. Salviat, Informations archéologiques, Gallia, 30, 1972, p. 537. Nous remercions L. Lambert pour son accueil à Cucuron; il nous a largement facilité l'étude des verres déposés au musée municipal et nous a aidé à les classer par ensembles funéraires. La numérotation de la verrerie reprend celle qui lui a été attribuée dans la description des tombes respectives.

7 Certes, l'archéologie du verre en Gaule a bénéficié de quelques découvertes plus remarquables encore : signalons par exemple P.-H. Mitard, Une riche sépulture gallo-romaine découverte près de Niort (Deux-Sèvres), Gallia, 35, 1977, p. 217-222, trente-cinq objets en verre parmi le mobilier d'une tombe d'époque flavienne; une cinquantaine de verreries dans la sépulture de l'Ilot-les-Vases à Nalliers (seconde moitié du er s.) : C. Gendron, Les verres gallo-romains en Vendée, Archéologie, 68, 1974, p. 38. En Narbonnaise, citons la découverte déjà ancienne (1887) de Pigan (Hérault), treize vases et une cinquantaine de balsamaires dans une seule tombe à incinération : E. BONNET, Sur une sépulture gallo-romaine découverte à Pigan (Hérault), Mémoires de la Sociëlé Archéologique de Monipellier, 4/2, 1910, p. 290-295. La publication de quelques nécropoles du Haut-Empire donne une idée de l'importance prise par le verre parmi le mobilier funéraire : A. Dumoulin, Découverte d'une nécropole gallo-romaine à Apt (Vaucluse), Gallia, 22, 1964, p. 87-110; - C. Pistol.et, Les verres de la nécropole de Lattes (Hérault), Archéologie en Languedoc, 4, 1981, p. 5-58; - ID., Les nécropoles galloromaines de Fréjus, Fréjus, 1985.

8 Outre l'ouvrage devenu classique de C. Isings, Roman Glass from Dated Finds, Groningue, 1957, nous avons utilisé comme volumes de références aux notices du catalogue les ouvrages suivants: A. KISA, Das Glas in Alteriume, Leipzig, 1908; - Morin-Jean, La verrerie en Gaule sous l'empire romain, Paris, 1923 ; - M. C. CALVI, I vetri romani del museo di Aquileia, Aquilée, 1968; - K. GoethertPоцаsснек, Kalalog der römischen Gläser des Rheinischen Landesmuseums Trier, Mayence, 1977. 
groupes (Isings 28a et b, 8,6), L. Taborelli a tenté d'organiser cette diversité grâce à quelques observations effectuées sur le matériel funéraire des nécropoles d'Urbino' ${ }^{9}$. Avec les trois vases en double exemplaires de la tombe 3 , déjà cités, le rhyton $\mathrm{n}^{\circ} 6$, la tasse $n^{\circ} 15$, les bouteilles $n^{n s} 13$ et 14 et enfin l'aiguière $\mathrm{n}^{\circ} 7$ de la tombe 4 , nous nous éloignons des verreries courantes, non pas pour entrer dans le domaine de l'exceptionnelle verrerie de luxe ${ }^{10}$ mais pour aborder des formes du quotidien peu habituelles. Les décors, quant à eux, sont bien plus pauvres : des stries parallèles réalisées à froid, à la roulette ou au tour, fréquentes sur les verreries translucides, ou des dépressions effectuées à chaud qui ne sont en rien caractéristiques d'une époque ${ }^{11}$. En revanche, la qualité et la couleur de la matière permettent de préciser les conclusions de l'étude des formes pour proposer une fourchette chronologique. A Cucuron, le verre est généralement de bonne qualité, teinté naturellement par des oxydes métalliques en bleuvert, mais très souvent translucide. Or, on remarque l'importance des verres colorés, surtout en bleu, dans les nécropoles du $\mathrm{I}^{\mathrm{er}} \mathrm{s}$., à Fréjus ou à Lattes par exemple, et d'après J. Alarcão "on peut affirmer avec certitude que l'usage du verre incolore se généralise aux alentours de 70 après $\mathrm{J} .-\mathrm{C} .{ }^{12}{ }^{12}$. Les profils des vases ne permettent pas de proposer une date postérieure au $\mathrm{II}^{\prime \prime} \mathrm{s}$.

Un dernier problème, celui de l'origine, reste posé. S'agit-il d'une production locale ou régionale? S'agit-il d'importations? Une enquête rapide menée parmi les principales collections provençales ${ }^{13}$ ne nous a pas apporté de réponse: pas de formes comparables à celles de Cucuron, à l'exception, bien entendu, de celles des urnes et des balsamaires. Mais cet argument est bien faible pour parler d'importations. Les preuves a contrario sont, hélas, toutes

9 L. Taborelli, Su alcuni ungentari di vetro delle necropoli urbani : la forma $28 \mathrm{~b}$ della classificazione Isings, Notizie degli Scavi, 36, 1982, p. 408-415.

10 Sa grande ductibilité, qualité essentielle du verre parfaitement maîtrisée par les artistes verriers rhénans des

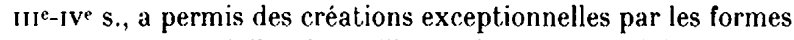
et les décors : strigiles, bouteilles en forme de sandales, seaux, casseroles : F. Fremersdorf, Römische Gläser mit Fadenauflage in Köln, 1959, Die Denkmäler des Römischen Köln, V, pl. 50-53; - F. Fremersiorf, C. Polonyi-Fremersdorf, Die Farblosen Gläsen der Frühzeit in Köln 2 und 3 Jahrundert, Cologne, 1984, IX, nos 247-252, p. 111-112; 262, p. 116; pl. 11, p. 142. Voir aussi Journal of Glass Studies, 3, 1961, p. 136, $n^{\circ} 7$ et $8 ; 14,1972$, p. 154, no 10.

11 Monin-Jean, op. cit., p. 193-194.

12 J. Al.arcĩo, Céramiques diverses et verres. Fouilles de Conimbriga, 6, Paris, 1976, p. 171 et note 42.

13 Nous avons visité les collections exposées des musées d'Apt., Cavaillon, Marseille. aussi légères quoique plausibles : il y a d'abord ces doubles dans les tombes 3 et 4 , puis des "tours de main" identiques (un mince fil de verre qui court sur toute la surface externe de l'anse après les replis de fixation sur l'épaule - $\mathrm{n}^{\text {os }} 4,7,12$ de la tombe 4) remarqués sur des formes différentes. Enfin, l'abondance même des verreries, comme l'homogénéité de la matière, plaident en faveur de l'existence d'un centre de production régional ${ }^{14}$.

D'autre part, en ce qui concerne le lit funéraire de la tombe 1, J.-Cl. Béal le date entre 10 avant J.-C. et Tibère; Deneauve date le fragment de lampe associé à cette sépulture du $\mathrm{I}^{\mathrm{rr}} \mathrm{s}$., ce que précise Bailey avec une datation comprise entre le règne de Tibère et le début de celui de Trajan. Dans l'hypothèse plus que vraisemblable où la lampe serait à prendre en compte, le dépôt se placerait à l'intérieur d'une fourchelle chronologique très étroite, au plus tôt la deuxième, au plus tard la quatrième décennie du siècle.

Les deux assiettes de terra sigillata de la tombe 3 ont été fabriquées, le $n^{0} 1$ de Tibère à Claude, le $\mathrm{n}^{\circ} 2$ sous Claude, mais le denier frappé en 54 fournit un terminus a quo précis; la datation de la lampe permet une chronologie plus ouverte (Tibère/ début de l'époque de Trajan). Les deux as posthumes d'Auguste, frappés sous Tibère, sont légèrement anachroniques, ce qui est normal pour des monnaies.

Un peu plus ancienne, peut-être contemporaine, serait la tombe 4 avec sa monnaie de 41/54 et le vase à parois fines $\mathrm{n}^{\circ} 2$ de $40 / 60$ dont l'extrême fragilité implique une utilisation brève. En tenant compte aussi de la majorité des verreries, on serait enclin à retenir la seconde moitié du ${ }^{\text {er }}$ s., voire le troisième quart.

La tombe 2 n'offre aucun élément de datation mais la cohérence de son implantation avec celle des trois autres justifierait une chronologie voisine de celle des tombes 3 et 4 . L'incinération 1 est à l'évidence antérieure d'au moins 15 ans; certains indices, on l'a vu, autorisent même à imaginer qu'elle pourrail être un peu plus ancienne que l'enclos. Elle n'en occupe pas le centre, ce qui semble illogique si le mur a été construit à l'intention de

14 Le fort pourcentage de céramiques sigillées galloromaines par rapport au reste du mobilier funéraire dans la nécropole de l'Hospitalet du Larzac (Aveyron) s'explique par la proximité des officines de potiers de La Graufesenque et la facilité des relations commerciales que ces deux sites entretenaient entre eux grâce à la voie Millau-Lodève. Voir A. Vernet, in: De l'Age du Fer aux temps barbares. Dix ans de recherches archéologiques en Midi-Pyrénées, catalogue d'exposition, Toulouse, musée Saint-Raymond, octobre 1987-janvier $1988, n^{\circ s} 365$ et 368 , p. 131. 
cette seule tombe et le fond de fosse descend nettement en dessous du niveau bas des fondations. Il est probable que le bustum fut aménagé ultérieurement en prévision d'autres sépultures, tout en tenant compte de l'existence de la plus ancienne pour conserver une répartition aérée, les tombes étant signalées en surface pour éviter tout chevauchement intempestif. L'écart important entre le niveau de la première fosse et ceux des dernières tombes s'explique si l'on admet que la sépulture primitive fut ouverte à partir du sol naturel et les suivantes dans une sorte de tumulus en remblai culminant à une cote difficile à préciser, sans doute au-dessus de $+1,50 \mathrm{~m}$ (fig. 10 , coupe CC).

\section{Place du premier enclos dans la typologie}

Le mur pseudo-annulaire appartient à un dispositif connu de sépultures à incinération réunies dans un cimetière familial. Les cendres de chaque défunt étaient enterrées à proximité de l'emplacement où le corps avait subi la crémation sur un bûcher construit, le rogus structus. L'association du tertre qui recouvre la récolte des os calcinés, des cendres et les clous du bûcher, avec l'enceinte aveugle ${ }^{15}$ qui protège le dépôt funéraire est un bustum ${ }^{16}$ et ce serait la plus ancienne forme de tombe en Italie centrale comme en Gaule transpadane. C'est ainsi que l'area cémetériale Saint-Roch d'Aoste a livré deux busta contigus de 8 pieds de côté en œuvre ${ }^{17}$ où furent retrouvés des débris de lit mortuaire provenant, semble-t-il bien, du même atelier que celui de Cucuron. Au monument des Concordii de Brescello, quatre busta, dont un contenait un lot de clous du

15 E. Cuq, s.v. funus, Dictionnaire des antiquités grecques el romaines, I I-2, 1896, p. 1394-1395.

16 Servius, Comm. in Verg. Aen., II, 22 (éd. G. Thill et H. Hagen, Leipzig, 1878, t. 1, p. 340) : exstructio lignorum "rogus "... crematio cadaveris "bustum ", locus " ustrina ", mais en XI, 185 (ibidem, t. 2, 1883, p. 497) : "pyra" esl lignorum congeries, "rogus " cum iam ardere coeperit dicilur, "bustum * vero iam exustum vocatur; - FEstus, De verborum significatione, 1, II (éd. C. O. Müller, Leipzig, 1839, p. 32) : bustum proprie dicitur locus in quo mortuus est combustus el sepullus; - OvIDE, Pontiques, III, 2, v. 31 : corpora debentur maestis exsanguia bustis/effugiunt structos nomen honorque rogos. Dans Lucain (La Pharsale, VIII, v. 791), le bustus désigne la pierre qui recouvre les ossements à demi consumés de Pompée et, au v. 771, la même pierre signale l'emplacement du bustus. Voir aussi Properce, Elégies, I, 19, v. 21 et II, 13, v, 33; - Ovide, Pontiques, III, v. 31. Pour le terme, cf. MAU, s.v. bustum, RE, III-1, 1897, col. 1078 et G. GoETz, Corpus glossariorum latinorum, t. 6, Leipzig, 1899, p. 157-158.

17 R. Mollo Mezzena, Augusta Praetoria, op. cit., p. 205-210. bûcher, se répartissaient à l'intérieur d'une enceinte basse de 30 pieds sur 36 hors œuvre dont la façade monumentale s'organisait de part et d'autre d'une stèle à décor figuré ${ }^{18}$; ces deux installations transalpines sont datées de l'époque julio-claudienne. Entre le milieu du $\mathrm{I}^{\mathrm{er}} \mathrm{s}$. et le début du Ir $\mathrm{s}$., on citera quatre enclos, tous de plan rectangulaire avec une face orientée plein nord, identifiès dans la nécropole $\mathrm{d}^{\prime}$ Albenga ${ }^{19}$, le plus petit de 10 pieds romains sur 12 hors œuvre, le plus grand de 10 sur 25 intérieurement. Les murs aveugles, de 1,25 $\mathrm{m}$ à $2 \mathrm{~m}$ hors sol, couverts d'un simple chaperon arrondi, présentaient quatre cornes aux angles. L'accès devait se faire à l'échelle bien qu'à l'intérieur des pierres saillantes fussent disposées pour faciliter l'escalade. Comme à Cucuron, les murs n'ètaient parementés qu'à l'extérieur. On retrouve un arrangement identique, à la charnière des $\mathrm{I}^{\text {er }}$ et $\mathrm{II}^{\mathrm{e}} \mathrm{s}$., dans les deux cimetières urbains d'Ostie ${ }^{20}$. La tombe 16 de la nécropole de la via Ostiense se limitait dans son premier état à une clôture de 20 pieds sur 25 , haute de quelque $2,20 \mathrm{~m}$, postérieure aux dépôts funéraires retrouvés dans l'area rectangulaire à ciel ouvert ${ }^{21}$. Le long de la via Laurentina, la tombe 43 , de 15 pieds sur 17 hors tout, avait son mur de $2,40 \mathrm{~m}$ arrêté par un chaperon muni de cornes aux angles et au milieu des longs pans; le terrain y est partagé par un refend partiel qui traduit une séparation entre ustrinum et bustum. Dans ces deux enclos, les dépôts cinéraires étaient disposés aux angles ou le long des parois ${ }^{22}$.

Il semble qu'il faille remonter vers la Germanie pour voir ce schéma rectangulaire céder la place à un plan circulaire. Tel est le cas du cénotaphe présumé de Nickenich au Luxembourg, érigé dans la première moitié $\mathrm{du} \mathrm{I}^{\mathrm{er}} \mathrm{s}$. sous la forme d'un mur en grand appareil de $7 \mathrm{~m}$ de diamètre enveloppant le pied d'un tertre ${ }^{23}$. Peut-être pourrait-on y ajouter trois cercles de $5,70 \mathrm{~m}$ de diamètre et un quatrième de

18 S. Aurigrmma, Cispadana. Boretto. Scoperte occasionato dello scavo del canale derivatore "Bonificazione Parmigiana-Moglia" e altre varie. Brixillum, Notizie degli Scavi, s. 7, 8 (329), 1932, p. 171-182.

19 P. Barocfild, Albintimilium, Monumenti Antichi, 29, 1923, col. 46-61, fig. 9-16.

20 M. Floriani Squarciapino, Le necropoli lungo la via Laurentina, Scavi di Ostia 3. Le necropoli I, Rome, 1958, p. 101-102; pour la datation, p. 109 et fig. 18 .

21 Ibid, p. 34-35 et fig. 1.

22 Ibid, p. 110.

23 E. Neuffre, Ein römisches Familiengrabmal von Nickenich bei Andernach, Germania, 16, 1932, p. 22-28; - ID., Zum Nickenicher Grabmal, ibid. (Der Rundbau), p. 287-288; - L. Weisgerber, Zum Inschrift von Nickenich, ibid., 17, 1933 , fig. 2 , p. 96 . On écartera de cette série la tombe de Bill au Luxembourg: ce n'est pas un bustum mais un tumulus 
$3,90 \mathrm{~m}$, regroupés à l'intérieur d'un enclos commun au voisinage de la villa rustica de Newel et datés, semble-t-il, du $\mathrm{II}^{\mathrm{e}} \mathrm{s.}^{24}$.

La brisure de la circonférence par un segment de droite sécant est assurement inhabituel et, curieusement, c'est à I élos qu'il faut aller rechercher deux éléments de comparaison (fig. 21). A mi-chemin entre le sanctuaire d'Apollon et le Gymnase, une sorte de péristyle ${ }^{25}$ a été reconnu comme le sanctuaire de l'archégète, le fondateur mythique de la cité délienne. Dans la cour, une enceinte grossière en ove aplatie regardant le nord contenait un amas de cendres et de tessons calcinés, résidus de sacrifices : c'est l'eschâron, autrement dit l'«autel creux" d'un hérôon ${ }^{26}$ (fig. 21). Selon l'interprétation communément admise, le cône formé par les cendres des sacrifices successifs tendant à couvrir naturellement au sol une surface arrondie, on se serait astreint, à pétrifier la limite atteinte ce qui expliquerait l'irrégularité de la courbure. La surface libre enfermée correspond à un peu plus de $35 \mathrm{~m}^{2}$ (fig. 22), chiffre voisin de la conversion des dix orgyes carrées ${ }^{27}$ mentionnées dans les comptes des hiéropes. Ph. Bruneau attribue le mur curvilinéaire à une

conique cerné d'un mur bas, de 80 pieds romains (24 m environ), daté de la fin du $\mathrm{I}^{\mathrm{e}} \mathrm{s}$./début du $\mathrm{w}^{\mathrm{e}} \mathrm{s}$., cf. G. Thils, Römischer Grabhügel mit. Ringmauer und eingebauten Altar bei Bill, Ilémechl, 1971, p. 317-330.

24 C. M. Ternes., I)ie Römerzeitliche Givitas Treverorum I, Aufstieg und Niedergang, II-4, 1975, fig. 26, p. 390.

25 P. Lemerle, Chronique des fouilles 1934, Bulletin de Correspondance Hellénique (BCHI), 1934-I, p. 299; Ch. Picari), Rapport sur les travaux de l'École d'Athènes en 1934-1935, Comples Rendus de l'Académie des Inscriptions et Belles-Lettres (CRAI), 1936, p. 112-113; - F. Roвknt, Thymélé, BEFAR, 147, Paris, 1939, escharôn, p. 189-190 et plan fig. 6 , les autels de centre à plan curviligne p. 191-193; R. Var.oos, L'archilecture hellénique et hellénistique à Délos jusqu'à l'éviction des Déliens (166 av. J.-C.). 1. Les monuments, BEFAR, 157, Paris, 1944 : le téménos de l'archègète, p. 72-74; - Io., Deliaca in prothysis. II, $B C H, 70,1946$, p. 582-584, fig. 2, p. 581, pl. XXIX; - F. Ronfrt, Le sanctuaire de l'archégète Anios à Iélos, Revue Archéologique (RA), s. 6, 41, 1953-I, p. 16-18 et plan fig. 1, p. 11; - H. Gai.t.et de Santerre, Délos primitive el archaïque, BEFAR, 192, Paris, 1958 : Anios et l'archégésion, p. 268-271;-G. DAux, Chronique des fouilles $1961, B C I I, 86,1962$-II : archégésion, p. 862865 ; - Ph. Brunenu, J. Ducat, Guide de Délos 2, Paris, 1966 : no 74 : l'archégésion, p. 126 ; - Ph. Brunfau, Recherches sur les culles de Délos à l'époque hellénistique el à l'époque impériale, BEFAR, 217, Paris, 1970 : l'archégésion, p. 420430, pl. ht 74; - G. KunN, Untersuchungen zur Funktion der Säulenhalle IV. Säulenhalle und Altar, Jahrbuch des deutschen archäologischen Instituts (.JDAI), 100, 1985, p. 227-229, plan fig. 14.

26 Escharôn est un augmentatif d'eschara; pour le terme, cf. RFisch, sv, RE, VI-1, 1907, col. 614-617.

27 Pour autant qu'on puisse analyser le tracé, la clôture grossièrement construite en moellons, épaisse d'une coudée du reconstruction tardive, "probablement en pleine époque impériale».

Situés à peu près dans l'axe du portique d'Antigone, la thékè d'Opis et Argè est une petite tombe à chambre et dromos censée remonter au milieu du $\mathrm{II}^{\mathrm{e}}$ millénaire. Elle s'est trouvée par la suite associée au culte des Vierges hyperboréennes et isolée par un abaton, une enceinte continue sans ouverture, refaite à l'époque hellénistique, vers la fin du iII ${ }^{e}$ s. avant J.-C. ${ }^{28}$. Le mur d'enclos en fer à cheval, épais d'une coudée, occupe 31 pieds attiques de $0,297 \mathrm{~m}^{29}$ sur son grand diamètre extérieur. La paroi rectiligne, face au nord, reprend exactement les 25 pieds mesurés sur le petit axe hors œuvre; une plate-forme était aménagée contre la façade nord aveugle, peut-être en fonction d'un autel disparu (fig. 21).

Un élément de mur courbe de dimensions comparables mais difficile à dater, peut être décelé en bordure nord de la route d'Italie, à la sortie orientale de l'enceinte hellénistique de Massalia, face à la pointe de la corne du port. Cette installation est en limite d'un secteur d'enclos funéraires archaïques (fig. 21). Le mur courbe a été arraché en grande partie jusque dans ses fondements quand furent construits une adduction d'eau romaine ${ }^{30}$ et un portique adossé à la muraille de l'aqueduc aligné est-

pied dorico-phidonien de $0,327 \mathrm{~m}$, suivait un demi-cercle de 26 pieds de diamètre hors ouvre, raccurdé par deux arrondis à une paroi rectiligne parementée de six dalles de marbre, forte de deux coudées et longue de 16 pieds, la profondeur hors tout était arrêtée à 22 pieds. La surface libre de l'area se décompose en un demi-cercle de onze pieds sur six et deux quarts de cercle de six pieds de rayon, soit:

$$
\begin{aligned}
& A=\frac{11}{7} \times 3,761^{2}=22,23 \\
& B=3,597 \times 1,962=7,06 \\
& C=\frac{11}{7} \times 1,962^{2}=6,05 \\
& A+B+C=35,34 \mathrm{~m}^{2} .
\end{aligned}
$$

Les dix orgyes carrées des comptes des hiéropes valent $60 \times 60=3600$ pieds carrés et $3600 \times 0,327^{2}=38,49 \mathrm{~m}^{2}$.

Cf. F. Dünnach, $I G \times \mathrm{X}-2$, Berlin, 1912, no 156-A, p. 39, 1. 22-24 (le texte est daté d'un peu avant 282 avant J.-C.).

28 F. Courby, Le portique d'Antigone ou du nord-est et les constructions voisines, Exploration archéologique de Délos 5, Paris, 1912 : le tombeau mycénien, p. 63-67, pl. I et II ; - H. Gallet de Santerre, Délos primitive et archaique, BEFAR, 192, Paris, 1968, p. 32-34, 93-94, 271 ; - Cl. VArin, Délos prémycénienne, $B C H, 89,1965-\mathrm{I}$, p. 225-230; Ph. Bruneau, J. Ducat, Guide de Délos 2, Paris, 1966, n“ 32 , p. 94 et plan $I$.

29 F. Courry, Exploration archéologique de Délos 5, op. cit., p. 19; - ID., Les temples d'Apollon, Paris, 1931, p. 93, n. 3 .

30 R. Guéry, G. Iallier, Réflexions sur les ouvrages hydrauliques de Marseille antique, in : L'eau et les hommes en Méditerranée, Paris, 1987, p. 272-274 et fig. 8. 


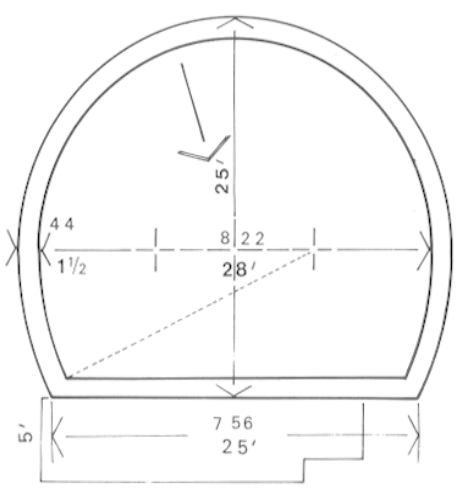

DELOS abaton de la Thékè d Opis et Argè

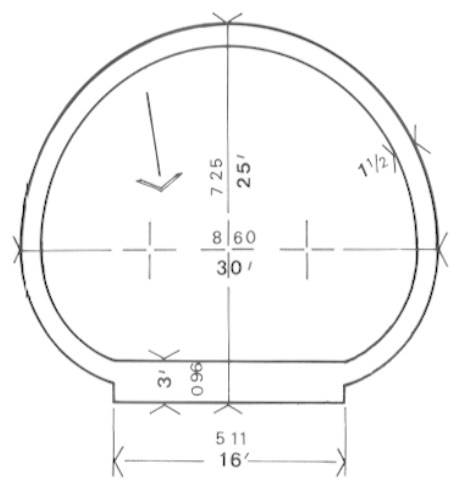

DELOS escharón de / Archégésion

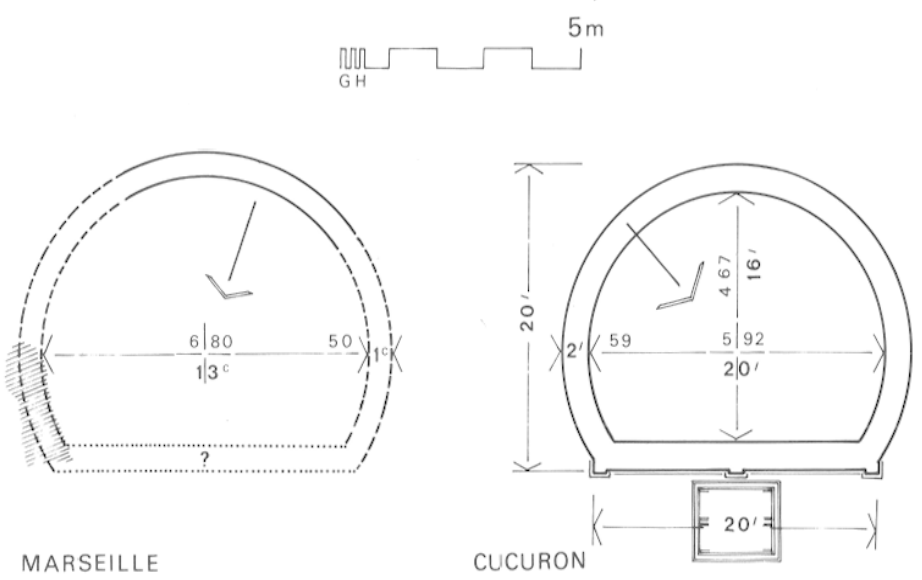

Fig. 21 - Comparaison à la même échelle des enclos de Délos, Marseille et Cucuron.

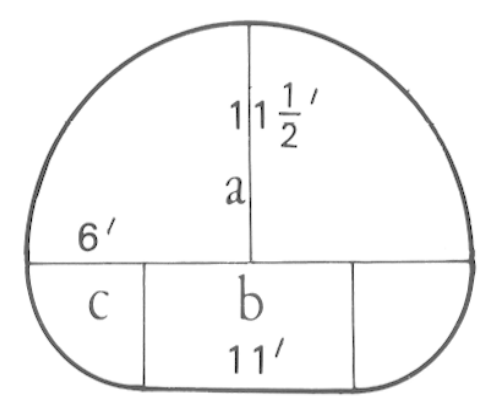

Fig. 22 - Tracé du parement intérieur de l'escharôn de l'Archégésion à Délos, en pieds dorico-phidoniens. ouest, parallèlement à la chaussée ${ }^{31}$. Restaient en place cinq blocs de la première assise en élévation de la courbe sud et un tronçon de soubassement du quadrant nord-est. Le mur circulaire est épais d'une coudée massaliote de $0,525 \mathrm{~m}$ et le diamètre atteignait 15 coudées hors tout $(7,80 \mathrm{~m}$ environ); on ne peut affirmer que le tracé de cet enclos était en fer à cheval mais rien ne s'y oppose car la section détruite correspond justement à ce qui pourrait être le pan coupé qui, là encore, regarderait le nord.

Ainsi disposons-nous d'une série limitée mais curieusement homogène d'enceintes aveugles pseudo-circulaires d'échelle fort comparable : les dimensions majeures frisent $9,30 \mathrm{~m}$ pour la thékè d'Opis et Argè, $8,60 \mathrm{~m}$ à l'archégésion, 7,80 $\mathrm{m}$ à Marseille et $7,10 \mathrm{~m}$ à Cucuron (fig. 21). Pour les trois cas assurés, le cercle est recoupé par une façade droite tracée face au nord. Le pan coupé de l'abaton des Vierges hyperboréennes est associé à une terrasse vraisem-

31 R. Guéry, A. Pralong, La voie suburbaine estouest et la zone au nord du port (zone III), in : M. EuzenNat et alii, Les fouilles de la Bourse à Marseille (campagnes 19751976), Revue Archéologique de Narbonnaise, 10, 1977, p. 242 et plan fig. 1 p. 236. blablement accessible par un perron latéral el celui de l'escharôn offrait un parement de marbre.

Il n'est pas interdit de tenter une reconstitution de la face ordonnancée du premier enclos funéraire de Cucuron (fig. 8). La largeur du pilastre suggère un module de trois quarts de pied $(0,222 \mathrm{~m})$ et deux fragments moulurés erratiques peuvent appartenir à la corniche $\left(b_{1}\right.$ et $b_{2}$, fig. 23 , tabl. I); corona et filet d'appui sont sommés d'un réglet associè à une cimaise en doucine abattue au lit d'attente mais le larmier normalement attendu a été oublié; les dimensions élémentaires des deux débris sont cohérentes.

Tableau I. Comparaison des dimensions des fragments moulurés $b_{1}$ et $b_{2}$ (en $\mathrm{mm}$ ).

\begin{tabular}{|l|cc|cc|}
\hline & \multicolumn{2}{|c|}{ Hauteurs $^{2}$} & \multicolumn{2}{|c|}{ Saillies } \\
& $\mathrm{b}_{1}$ & $\mathrm{~b}_{2}$ & $\mathrm{~b}_{1}$ & $\mathrm{~b}_{2}$ \\
\hline Filet au lit de pose & $?$ & 13 & $?$ & $?$ \\
Corona $\ldots \ldots \ldots \ldots \ldots$ & 49 & 46 & $?$ & 42 \\
Réglet $\ldots \ldots \ldots \ldots \ldots$ & 12 & 12 & 15 & 18 \\
Cimaise $\ldots \ldots \ldots \ldots$. & 23 & 22 & 30 & 30 \\
\hline Total .............. & & 93 & & \\
\hline
\end{tabular}



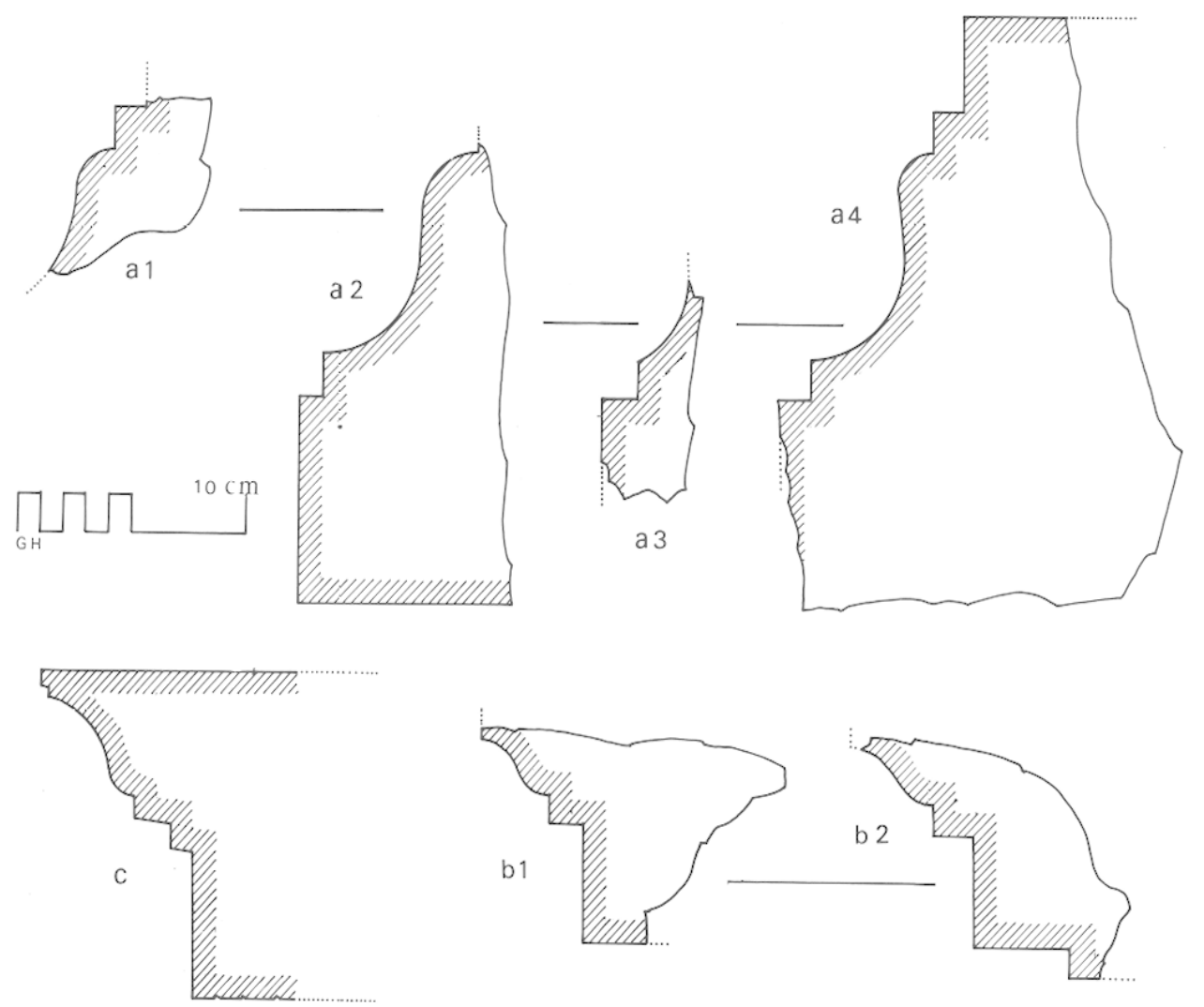

Fig. 23 - Profils des éclats appartenant au socle (a) et au couronnement (c) de l'autel, ainsi qu'à la corniche du pan coupé du bustum (b).
En admettant, au-dessus du présumé stéréobate qui resterait visible sur la hauteur de 1 palme, neuf assises identiques de 3 palmes dans la hauteur totale des pilastres en y comprenant un chapiteau toscan, puis une corniche architravée et un chaperon d'un pied chacun, l'ordre de grandeur de la dimension verticale de l'enclos serait voisin de neuf pieds ( $2,66 \mathrm{~m}$ environ).

\section{LA «TARASQUE»}

Un fragment sculpté résiduel (fig. 24) ne laisse deviner que deux antérieurs de fauve, l'appui d'une patte droite à quatre puissantes griffes et une patte gauche posée sur une tête humaine décharnée, le tout assis sur un socle parallélépipédique épais de $6 \mathrm{~cm}$, large de $38 \mathrm{~cm}$ et d'une profondeur indéterminée mais supérieure à $32 \mathrm{~cm}$. Trouvé au nord et à l'extérieur de l'area funéraire ${ }^{32}$, l'animal ne peut guère appartenir qu'à la première période d'occupation du site (cf. note 39 ). On serait tenté, en première analyse, de renvoyer à l'ours de Porcuna dans la

32 Signalé par F. Salviat, Informations archéologiques, Circonscription de Provence, Gallia, 30, 197\%, p. 537. région de Cordoue ${ }^{33}$, à ceci près que la bête $y$ maintient sous sa patte gauche, non pas une tête mais un hermès sommé d'une tête. Les interprétations les plus raisonnées tendent à rattacher l'œuvre andalouse à un type de sculpture symbolique où le monstre personnifie la Mort tutélaire. Ces représentations sont apparues dans les contrées hellénisées de l'Espagne méridionale et de la basse vallée du Rhône avec la "tarasque» de Noves de La Tène II, le lion de Biencervida à Albacète et le Cerbère trajanien de Gênes, l'ancêtre de la série pouvant être, au IV $\mathbf{s}$. avant notre ère, le lion de Vulci ${ }^{34}$; le groupe de

33 P. Paris, Deux sculptures ibériques, Mélanges Gustave Glotz, t. 2, Paris, 1932, p. 702-705, fig. 1 ; F. IIeıcheiheim, Tierdämonen, $R E$, VI-A-1, 1936, col. 924 ; - A. Garcia y Bellido, Esculturas romanas de España y Portugal, Madrid, 1949, n³15, p. 311-312, pl. 250; F. Benort, L'aire méditerranéenne de la "tête coupée", Rivista di Studi Liguri, 15, 1949-2, p. 246-251.

34 F. Benolt, Le Cerbère de Gênes et les têtes coupées de la Narbonnaise, Rivista di Studi Liguri, 12, 1946, p. 82-84; - M. Renard, Les "têtes coupées" d'Entremont, L'Antiquité Classique, 16, 1947-2, p. 307-309, fig. 3-5; - F. Benort, La statuaire d'Entremont. Recherches sur les sources de la mythologie celto-ligure, Revue d'Études Ligures, 16, 1948, 


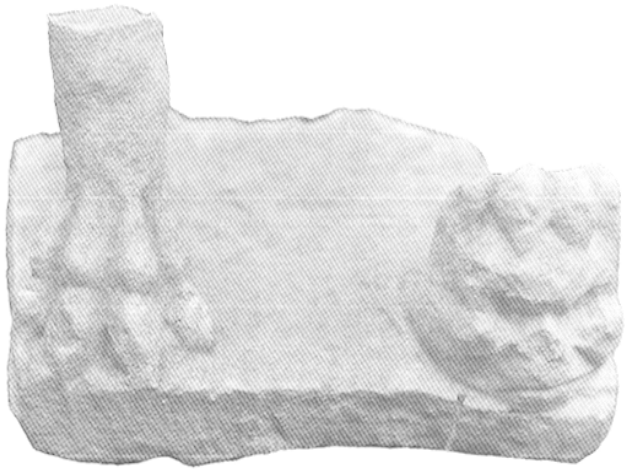

Fig. 24 - Tablette d'appui et griffes antérieures de la "tarasque".

Caranusca en pays mosellan, avec une tête humaine gisant entre les pattes d'un lion, serait daté du $\mathrm{I}^{\mathrm{er}} \mathrm{s} .{ }^{35}$. Mais surtout, on ne peut ignorer la quantité de sphinges mortuaires trouvées en Italie, en Dacie et en Bretagne ${ }^{36}$ et nos deux griffes énigmatiques

p. 81 ; - M. Renard, Des sculptures celtiques aux sculptures médiévales: fauves androphages, Ilommages à J. Bidez et à F. Cumont (coll. Latomus 2), Bruxelles, 1949, p. 279-281 ; F. BENoIt, La estatuaria provenzal en sus relaciones con la estatuaria iberica en la epoca preromana, Archivo Español de Arqueologia, 22, 1949, p. 141-142, fig. 18-20; - In., L'aire méditerranéenne de la "tête coupéen, loc. cit., p. 252; S. Srucchi, Le "têtes coupées" e la raffigurazione della Morte nell'ambiente Mediterraneo, Rendiconti Instituto Lombardo di Scienze e Lettere (classe di lettere e scienze morali e storiche), 83 , 1950 , p. $225 ;-$ F. Benolt, L'art primitif mediterranéen de la vallée du Rhône 2, Publication des Annales de la Faculté des Lettres d'Aix, nouvelle série, 9, 1955, p. 34-37, pl. XIV-1, XVI-I.4, XVIII-3, XIX.

35 R. LantiEr, Le lion androphage de Suzange (Moselle), RA, 1936-I, p. 126 ; E. Espranandeu, Recueil des bas-reliefs de la Gaule romaine, t. 11 supplément, Paris, 1938, no 7815 p. 123 ; - M. RFnarD, Des sculptures celtiques aux sculptures médiévales, loc. cil., p. 284-285.

36 En Italie, la sphinge funéraire du cippe cylindrique de Cologna Veneta, avec la tête coupée barbue entre les pattes de devant, est datée de l'époque claudienne (V. Gall.sazzo, Scullure greche e romane del museo civico di Vicenza, Trévise, 1976, no 34, p. 130-132); les deux sphinges en acrotère du musée de Torcello sont placées dans la première moitié du rer $\mathbf{s}$. (F. Ghedini, G. Rosada, Sculture greche e romane del museo provinciale di Torcello, Rome, 1982, no 34-35, p. 104-107). Le musée d'Alba Iulia conserve, en provenance des nécropoles d'Apulum, huit exemplaires de sphinges accroupies tenant des masques humains, datés du ur $\mathrm{s}$. semble-t-il ; quatre sculptures plus frustes ont été localisées à Ulpia Traiana. Le Norique en a fourni deux échantillons à Saint-Pölten et à Wels. Trois sphinx à tête virile ont été trouvés à Augusla Raurica, Benningen et Obernburg en Germanie, de même qu'un monstre accroupi tenant un crâne décharné sous sa griffe gauche à Naix-auxForges (Meuse) et en Bretagne à Camulodunum (Colchester), un bel exemple en ronde-bosse qui se situerait à la charnière des $\mathrm{I}^{\mathrm{er}}$ et $I^{\mathrm{e}} \mathrm{S}$. La corniche du tumulus de Nickenich supportait deux lions dévorant et une sphinge (E. NFuffer, Bericht über die Tätigkeit der Provinzialmuseums in Bonn, Bonner Jahrbücher, pouvaient appartenir à un couple de bêtes infernales placées en acrotères aux deux retours du front pilastré (fig. 8), un peu comme à la fin de l'époque républicaine au mausolée d'Asfionus Rufus de Sarsina ${ }^{37}$. La créature, dont la patte posée sur la tête du défunt marque une relation mystérieuse, apparaît généralement comme protectrice de la tombe et du mort, pour exprimer l'éternel sommeil du disparu sous l'égidè du monstre apaisé ${ }^{38}$.

\section{L'AUTEL}

Un lot de fragments erratiques récoltés sur place, sculptés ou moulurés, faisaient partie d'un autel qu'on serait tenté de replacer en avant de la paroi nord du bustum : les éléments en sont taillés dans une même pierre calcaire ${ }^{39}$ et le traitement relativement médiocre de la taille est homogènc. Un segment de pulvinar ${ }^{40}$ conserve une face et un départ de balustre latéral décoré d'écailles imbriquées,

136-137, 1932, p. 314 ; - ID., Bericht über die Tätigkeit der Provinzialmuseums in Bonn, Bonner Jahrbucher, 1338, 1933, p. 154-155 et pl. 21, 1). On mentionnera les chimères, harpies et furies des mausolées de Trion (A. Alcmar et P. Dissard, Trion. Antiquités découvertes en 1885-1886 au quartier de Trion, Lyon, 1888, p. 303-304). M. Renard (Sphinx à masque funéraire. Apulum, 7,1968 , p. 273-303) remarque que les représentations de Cisalpine sont de la première moitié du $\mathrm{I}^{\text {er }} \mathrm{s}$.; elles seraient ainsi contemporaines de la bête de Cucuron.

37 S. Aurigrmma, I monumenti della necropoli romana di Sarsina, Bollettino del Centro di Studi per la Storia dell' Architettura, 19, 1963, fig. 15 p. 27, fig. 46-49 p. 50-51, fig. 52-54 p. 53-55.

38 M. Renard, Sphinx ravisseurs et "têtes coupées", Latomus, 9, 1950, p. 303-310, pl. 6-9 : l'auteur retient, les exemples d'Alba Iulia et de Colchester.

39 Un examen pétrographique d'échantillons prélevés sur le pulvinus et la frise de l'autel en même temps que sur la tarasque par E. Colomb et J. Gervais, du Laboratoire de Stratigraphie et de Paléoécologie de l'Université de Provence (Aix-Marseille I), conclut à une origine commune des fragments de l'autel : il s'agit d'un calcaire bioclastique finement poreux à ciment micritique peu abondant, contenant plus de $50 \%$ de bryozoaires associés à des fragments de mélobésiées, des débris de lamellibranches indéterminables, de rares tests d'èchinidés et de très rares grains de quartz peu usés. Le calcaire biodétritique de la tarasque est légèrement jaunàtre et contient $20 \%$ de grains de quartz émoussés, des Foraminifères (rotalidae) bien conservés, de rares grains de glauconies mais pas de Mélobésiées. Tous ces fragments sont attribuables à un même âge burdigalien; d'après la stratigraphie locale du Miocène, les prélèvements peuvent provenir de niveaux rattachès à la partie supérieure du Burdigalien inférieur. Des roches comparables affleurent sur la bordure méridionale du Lubéron, à Lourmarin à l'ouest et Saint-Martin-de-la-Brasque à l'est, c'est-à-dire à quelque $3 \mathrm{~km}$ de part et d'autre du site.

40 Mentionné par F. Salviat, Informations archéologiques, Circonscription de Provence, Gallia, 30, 1972, p. 537, fig. 41. 


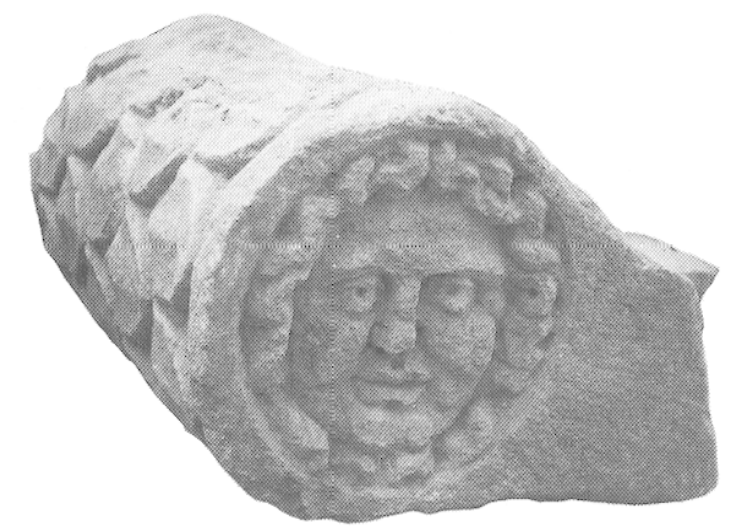

Fig. 25 - Fragment du pulvinus gauche de l'autel avec le gorgonéion et le départ de balustre.

modelées en relief avec les nervures, indiquées en forte convexité, disposées dans le sens longitudinal (fig. 25); le rouleau se raccorde sans solution de continuité à l'ensellement de liaison formant focus. Le disque frontal est rempli par une tête de Méduse joufflue et lippue, encadrée d'une couronne continue de cheveux bouclés ${ }^{41}$. Le diamètre extérieur de l'enroulement circonscrit au gorgonéion mesure 15 digili $(27 \mathrm{~cm})$, diminués par un méplat périmétral de $2 \mathrm{~cm}$. La demi-longueur du coussin, brisé à $65 \mathrm{~cm}$, est bûchée juste à l'emplacement de l'embrasse médiane d'où jaillissent cinq rangs d'écailles arrêtés sur l'anneau de $3 \mathrm{~cm}$ retourné perpendiculairement au médaillon. Le pulvinus s'inscrit dans un cylindre, sans qu'il faille toutefois alléguer quelque maladresse du tâcheron car un monument de Neumagen montre qu'un travail habile est compatible avec des balustres non galbés ${ }^{42}$.

11 Ce décor est peu fréquent; le médaillon qui garnit l'about du balustre est généralement occupé par une simple rosace. Le gorgonéion apparait sur une tombe de la via Appia (F.S. Kifiner, Early Roman Putto-and-Garland Reliefs, Bulletin Antieke Beschaving (BABesch), 55-1, 1980, fig. 2-5 p. 45-46) et à Sarsina, avec l'autel funéraire de Caesellia Gazza (S. Aurigrmma, loc. cit., p. 103-104 et fig. 106); - on le rencontre au pulvinus du musée des Thermes (B. Petrinau, Museo nazionale romano. Le sculture, I, 7-II, Rome, 1974, no XV $^{\circ} 44$, p. 489), sur le coussin de l'autel cubique "des guirlandes" (M. EISNER, Zur Typologie der Grabbauten in Suburbium Roms, $26^{\circ}$ suppl. aux Mitteilungen des Deutschen Archäologischen Instituts (Röm. Abt.), (MDAI-R), Mayence, 1986, pl. 14,5) et sur l'autel-ossuaire de P. Ciartus Prepons de la via Ostiense, daté de l'èpoque flavienne par B. Candida (Altari e cippi nel Museo nazionale romano, Rome, 1970, no 27 p. 23-25 et pl. VII). Le motif est présent dans la région de Barcelone sur trois autels funéraires du $\mathrm{II}^{\mathrm{e}} \mathrm{S}$. (A. Garcia Y Bri.t.ıDo, Esculturas romanas de España y Portugal, Madrid, 1949) : le no 306 (p. 306-307 et pl. 246) avec une tête d'Hypnos ou de Méduse dans un disque de $0,46 \mathrm{~m}$ de diamètre extérieur; le n" 307 (p. 307 et pl. 246) avec un gorgonéion de 0,32 et le $n^{\circ} 308$, haut de 0,44 avec acrotère surélevé.

42 Voir l'autel funéraire de Neumagen (M. EISNER, op.

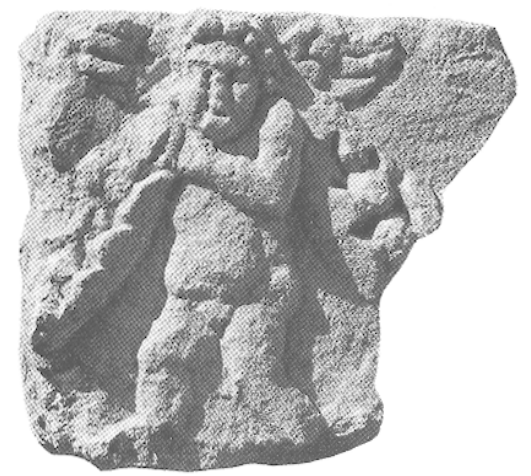

Fig. 26 - Putto guirlandophore de la frise basse de l'autel.

Deux dèbris renvoient à une frise d'amours guirlandophores nus et ailés.

Un putto (fig. 26), ployant sous le faix et marchant vers la gauche, provient de la face principale du bandeau : c'était le second en partant de la gauche d'un cortège de quatre erotes orientés vraisemblablement, deux par deux, vers les angles de la façade. Les ailes, attachées derrière la tête plutôt qu'aux épaules, comportent trois rémiges visibles pour la dextre et quatre pour la senestre; vers la gauche, s'amorce une guirlande en forme d'écharpe à moitié fermée et le tissu s'ouvre à droite sur deux fruits.

Une seconde retaille, à replacer au retour latéral droit, figure une guirlande entière, complétée à gauche d'une aile à cinq rémiges tandis qu'à droite se devinent les pointes de trois rémiges. La poche est, maintenue par deux bandelettes censées empêcher le contenu de s'échapper; dans la partie médiane rigidement horizontale, un gros fruit apparaît par la déchirure béante et, dans les deux pendants, les encarpae débordent du crevé à la rencontre des rubans cependant qu'au relevé de gauche, le sculpteur n'a figuré que le remplissage du sac. La cassure de droite interdit d'y restituer un personnage debout, elle suggère en revanche un amour en position d'envol semi-horizontal comme on les rencontre couramment sur les sarcophages, en tenants de cartouches à queue d'aronde ${ }^{43}$. La frise doit être

cit., fig. 331), le traversin du musée des Thermes cité à la note 41 et le rouleau de l'autel du Génie de Vespasien à Pompéi (W. Aı.rmann, Die römischen Grabaltäre der Kaiserzeit, Berlin, 1905, no 242, fig. 145a, p. 181); on peut écarter, entre les deux pulvini jumeaux, toute restitution de pseudo-fronton droit, courbe ou à enroulements affrontés.

43 Le socle du tombeau pompéien delle Ghirlande est scandé sur ses faces latérales de trois pilastres où les chapiteaux sont reliés par des guirlandes simples 
insérée ici, non pas en haut du dé, entre les pilastres ou en entablement, mais très certainement en socle d'assiette comme dans l'autel augustéen de Caesellia Cazza, retrouvé en place à Sarsina : les putti porteurs de guirlandes y sont répartis sur les trois faces vues, au centre et aux angles, en décor d'un bloc posé sur une quadrata de fondation et sous-jacent à l'autel proprement dit ${ }^{44}$.

Des pilastres d'angles peuvent être rétablis grâce à trois fragments d'importance inégale, le plus significatif appartenant à la moitié haute du pilastre commun à la face principale et au retour de droite (fig. 27 et 28), taillé dans une des deux assises du dé,

(W. Altmann, op. cit., fig. 52 p. 60 et V. Kockfl, Die Grabbauten vor dem Herkulaner Tor in Pompeji, Mayence, 1983, p. 146-147 et pl. 40b); le même dispositif figurait à l'ètage inférieur du mausolée de l'île du Comte à Beaucaire (A. Roth-Congés, Le mausolée de l'île du Comte, Ugernum, Beaucaire et le Beaucairois à l'époque romaine, 2, Association pour la Recherche Archéologique en Languedoc Oriental, cahier no 16, Caveirac, 1987, p. 53 et pl. I). L'association pultiguirlandes est présente sur des exemples répertoriés par F. S. Kleiner, (Early Roman Putto-and-Garland Reliefs, $B A$ Besch, 55-1, 1980, p. 37-48) et surtout par G. Calza (Le necropoli del Porto di Roma nell'Isola sacra, Rome, p. 190-195). Sur une frise de hauteur double du chapiteau et déroulée sur le registre supérieur du dé dans l'autel funéraire de T. Flauius Aug. L. Philetus (W. Altmann, op. cit., fig. 135a p. 166), trois putti traînent des guirlandes où chaque ensellement supporte un gorgonéion. Même thème sur les autels de T. Flauius Alcon (ibid., fig. 136, p. 167) et de Licinia Chrysis (ibid., fig. 137, p. 168). Voir aussi le sarcophage décoré d'une procession d'amours porteurs : L. Musso, Museo nazionale romano. Le sculture, I-2, Rome, 1981, no 17, p. 110-111, ou encore les multiples exemples que propose M. Honroth (Städtrömische Girlanden. Ein Versuch zur Entwicklungsgeschichte römischen Ornamentik, Sonderschriften der OAl, 17, Vienne, 1971): fragment de frise trajanienne du Staatliche Museen de Berlin (no 75, pl. VI-2 et p. 83), de la basilique d'Ostie (no 77, p. 8384 , pl. VII-1, époque de Trajan/début du règne d'Hadrien), du musée d'Ostie (no 81 , pl. VII-2, vers 120); sarcophage de Pise (no 79 , p. 84 , pl. VII-3, vers 120 ); élément no 93 (p. 87, pl. VIII-1, fin de l'époque d'Hadrien); de l'Isola sacra d'Ostie (no 96 , p. 87 , pl. VIII-1, fin du règne d'Hadrien); du Musée national de Naples (no 82, p. 84, pl. VIII-2, vers 120); sarcophage de Volusia Prosodos à Ostie (n॰ 108, p. 89, pl. X-2, début du règne d'Antonin); de Santa Maria Antiqua à Rome (n० 111 , p. 90 , pl. XI-I, vers 160); du musée des Thermes (no 114 , p. 90 , pl. XI-2, fin $I^{\mathrm{e}} ; \mathrm{n}^{\circ} 119$, p. 91, pl. XII-2, début du II $^{\mathrm{e}} \mathrm{s}$ ); sarcophage d'enfant du Louvre (no 120 p. 91, pl. XII-3, début du Ive s.). J. Bodel (La collezione epigrafica dei musei capitolini, Rome, 1987) date l'autel-ossuaire de C. Vistilius Primigenius (no 150 , p. 234-235 et pl. IX-3) du dernier quart du Ier $^{\text {s. }}$; selon cet auteur, (n. 1078) les eroles guirlandophores ne seraient pas attestés avant 69 , début du principat de Vespasien, notre autel pourrait donc refleter l'influence en province de l'évolution du décor funéraire dans l'Urbs.

44 S. Aurigemma, op. cit., (cf. note 37 ), fig. 5 , p. 12, p. 103-104 et fig. $106 \mathrm{~b}$.

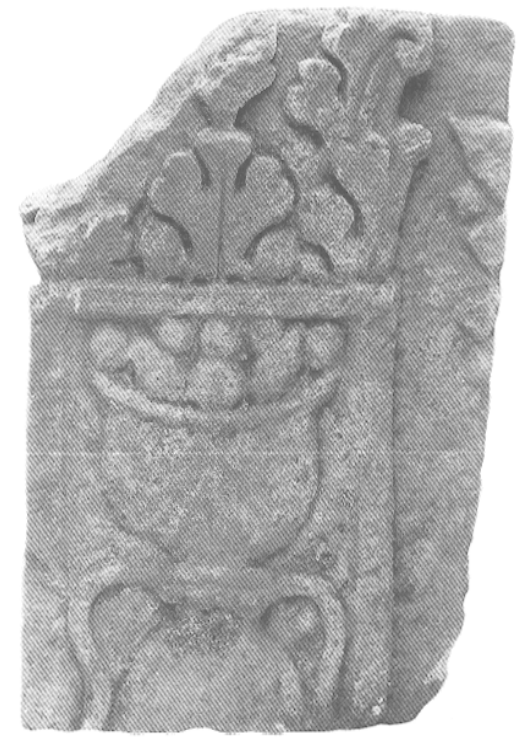

Fig. 27 - Détail du pilastre de l'autel et de son chapiteau avec l'amorce de la feuillée de laurier.

haute de $0,426 \mathrm{~m}$ (1 pied 7 digiti). Le tronçon de fût, large de $0,232 / 0,233 \mathrm{~m}(12$ digiti) pour une dimension verticale de $0,262 \mathrm{~m}$ (14 digiti) est cerné d'un filet de $20 \mathrm{~mm}$ retourné horizontalement en $12,5 \mathrm{~mm}$. Le champ est occupé par la panse incomplète d'une jarre à deux anses sinueuses pendant librement et attachées à un col en bourrelet qui reçoit le pied d'un pot campaniforme débordant de sept fruits ronds composés avec une paire de poivrons (?). Le chapiteau, haut de $0,164 \mathrm{~m}$ (9 digiti) et conservé aux deux tiers sur le retour, se limite à deux rangées de feuilles de chêne recourbées en crosse à l'emplacement habituel des volutes. Le bloc est brisé en face frontale aux dépens du filet d'encadrement et en face latérale à $5 / 7 \mathrm{~cm}$ au-delà du pilastre, assez pour qu'on y devine trois pointes de feuilles de laurier.

Un autre fragment à cassure latérale droite provient de la tête d'un second pilastre où se répète en partie la même nature morte avec, sur la "pomme» centrale, l'indication de la cicatrice florale.

Un troisième élément à joint latéral gauche, précise le traitement de la base du pilastre : audessus d'un méplat de $47 \mathrm{~mm}$, le retour inférieur du filet se rétrécit à $10 \mathrm{~mm}$; le départ d'un pied galbé appartient soit à un tabouret, soit plutôt à un trépied en bois plus apte à caler la jarre ${ }^{45}$.

45 Les pilastres sont le plus souvent historiés de rinceaux ou de tiges feuillues. C'est un empilage de vases sur une armoire qui décore les côtés du cadre épigraphique dans le monument des Haterii (Altmann, op. cit., fig. 18 p. 24) et, sur l'autel d'un prêtre d'Isis (ibid., fig. 191 p. 237), des étagères chargées de récipients sont entassées de part et d'autre du dédicant; sur le ciste de Cacia Daphné à Ostie, les garnitures 

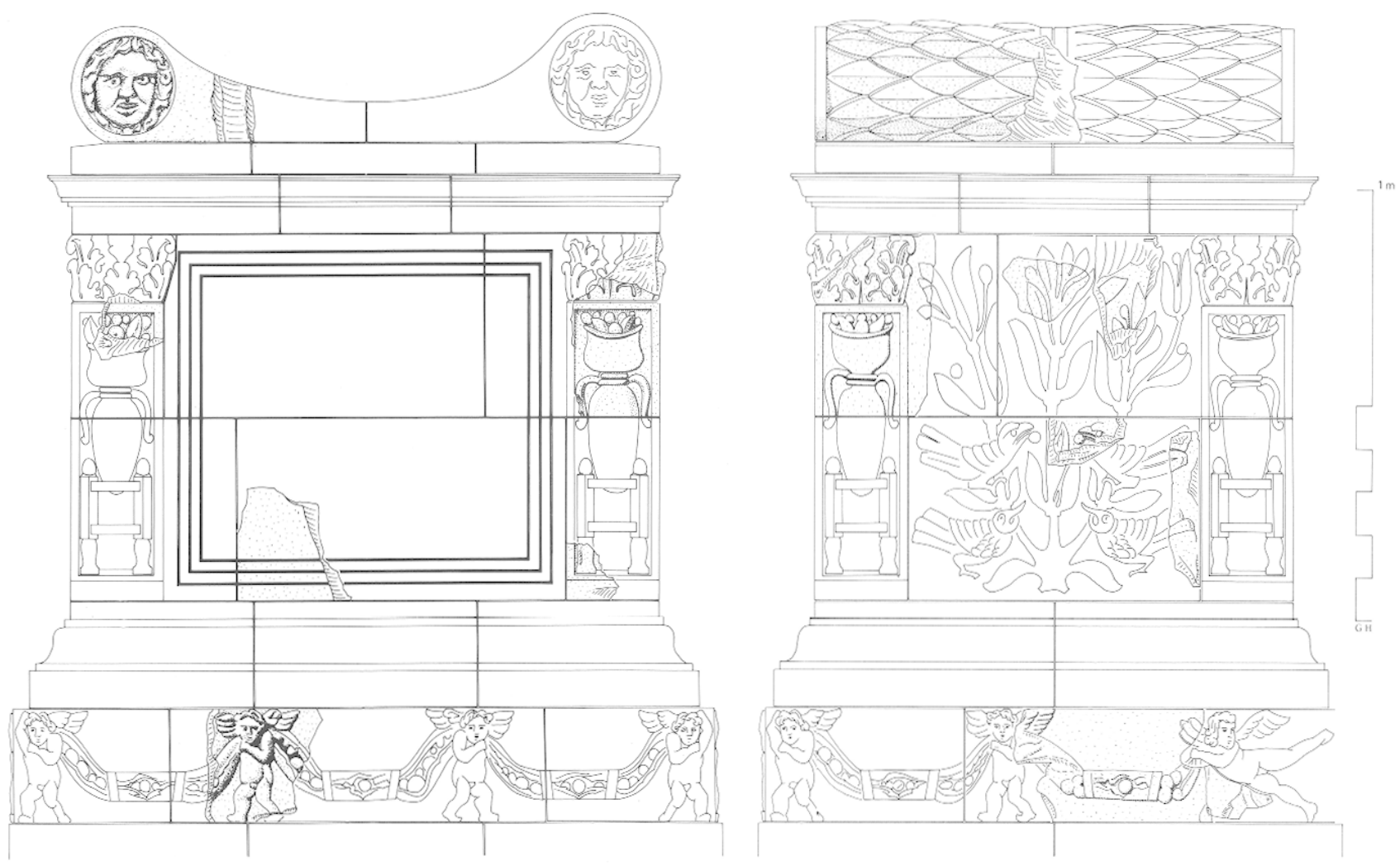

Fig. 28 - Reconstitution du front et d'un flanc de l'autel; les fragments retrouvés sont indiqués en pointillé.

Trois menus éclats sculptés confirment la présence de branchées de laurier en garniture des deux flancs du dé. Un élément laisse deviner, avec ce qui reste d'un lit d'attente largement épaufré, la trace d'une mortaise d'agrafage, la pointe d'une large feuille et le haut d'un bouquet d'au moins deux feuilles nervurées avec une baie portée sur son pédoncule. Un éclat informe conserve une section de branche avec à gauche deux feuilles nervurées encadrant un fruit et à droite l'attache de deux autres feuilles. Un troisième fragment, à joint vertical sur la droite, reçoit l'arrivée de trois rémiges appartenant à la queue d'un oiseau et, au-dessus, est esquissé le bout de la queue d'un autre volatile gobeur dont la tête, prête à becqueter une baie, est décelable sur une cassure où le lit d'attente est conservé ${ }^{46}$.

latérales sont occupées par un vase calé sur un trépied (ibid., fig. 97 p. 120). Les angles de l'autel-ossuaire claudien de C. Iulius Proculus sont garnis d'un décor, traité en rondebosse, de trépieds de bronze supportant des vases godronnés (B. Candida, op. cit., no 11, p. 34-37 et pl. XII-XIII).

46 Le laurier ébranché devait appartenir à la même famille que la feuillée figurée sur un autel dédié aux Lares et daté du milieu du I $^{\text {r }} \mathrm{s}$. (A. L. Lombard, Museo nazionale romano. Le sculture, I-2, Rome, 1981, n IV-35, p. 330-331); -
Quelques morceaux moulurés viennent compléter la silhouette du monument. La base du dé se retrouve à partir de quatre tronçons qui s'additionnent ( $a_{1}$ à $a_{4}$, fig. 23, tabl. II) : elle comportait, audessus d'une plinthe, une doucine renversée entre

autres exemples sur l'autel flavien de Rubria Philetis (F. TAgLIETtI, ibid., nº II-7 p. 93-95), sur un autel funéraire daté des Antonins (ibid., no IV-58 p. 361-364) ou sur un cippe de provenance inconnue, daté entre les Flaviens et le début du II $^{\mathrm{e}}$ s. (P. Rencini, ibid., I-3, 1982, no Il-22 p. 53-55). Des oiseaux picoreurs apparaissent sur le cinerarium de Julia Anthis et Tiberius Claudius daté du troisième quart du per $^{e}$. (L. Budda, R. Nicholls, A Catalogue of the Greek and Roman Sculpture in the FitzWilliam Museum Cambridge, Cambridge, 1964, pl. 47 fig. 146 et p. 91) : les auteurs notent que le laurier peuplé se rencontre vers l'époque claudienne, ce que confirme l'autel apollinien retrouvé au pied de la scenae frons du théâtre d'Arles, qui est une cuvre augustéenne de l'avant-dernière décennie avant notre ère ( $P$. Gros, Remarques sur les fondations urbaines de Narbonnaise et de Cisalpine au début de l'Empire, in: Sludi Lunensi e Prospettive sull'Occidente romano, Lerici, 1985, Quaderni, 10-12, 1987, p. 84 et fig. 9 p. 91) tout comme l'autel funéraire de Claudia lanuaria, daté de l'époque claudienne tardive (B. Candida, op. cit., no 14 , p. 41-44 et pl. XVI), où deux cigognes affrontées au pied du laurier se disputent un serpent. Un relief décoré d'un laurier peuplé proviendrait du forum d'Emerita (Museo nacional de arle romano, Merida, Madrid, 1988, p. 24). 
Tableau II. Comparaison des dimensions des fragments moulurés $a_{1}, a_{2}, a_{3}$ et $a_{4}(e n m m)$.

\begin{tabular}{|l|cccc|cccc|}
\hline & \multicolumn{5}{|c|}{ Hauteurs } & \multicolumn{5}{c|}{ Saillies } \\
& $\mathrm{a}_{1}$ & $\mathrm{a}_{2}$ & $\mathrm{a}_{3}$ & $\mathrm{a}_{4}$ & $\mathrm{a}_{1}$ & $\mathrm{a}_{2}$ & $\mathrm{a}_{3}$ & $\mathrm{a}_{4}$ \\
\hline Départ du dé...... & $?$ & $?$ & $?$ & 40 & - & - & - & - \\
Filet $\ldots \ldots \ldots \ldots \ldots$ & 18 & $?$ & $?$ & 17 & 15 & $?$ & $?$ & 14 \\
Doucine renversée & $?$ & 85 & $?$ & 85 & $?$ & 68 & $?$ & 55 \\
Filet $\ldots \ldots \ldots \ldots \ldots$ & $?$ & 18 & 15 & 17 & $?$ & 11 & 15 & 15 \\
Plinthe $\ldots \ldots \ldots \ldots$ & $?$ & 85 & $?$ & $?$ & - & - & - & - \\
\hline
\end{tabular}

deux filets, puis le départ du dé, pour une hauteur d'assise de quelque $0,242 \mathrm{~mm} / 0,246 \mathrm{~mm}$ (13 digiti) et une saillie évaluée à $0,084 / 0,094$ ( 5 digiti).

Le couronnement n'a livré qu'un seul segment (c, fig. 23, tabl. III), suffisant à restituer la modénature qui se superpose au bandeau prolongeant le nu du dé, deux filets aux soffites légèrement redressés, une cimaise en doucine et, de nouveau, une redondance de deux listels; le lit de pose était dressé au taillant et le lit d'attente égrisé. Le bloc, haut de $134 \mathrm{~mm}$ (7 digiti), présente une saillie de $67 \mathrm{~mm}$ (4 digiti) sur le corps central de l'autel.

Une chute de pierre d'appareil, qui conserve l'angle d'un lit horizontal et d'un joint montant, atteste l'encadrement du panneau frontal du dé et garde la trace de trois filets parallèles gravés en anglet.

Nous sommes en présence d'une combinaison de deux types : l'autel "coussin» et l'autel "bloc»" ; les détails du décor, sans être absolument inédits, sont traités avec originalité. La silhouette générale n'est pas sans rappeler, à l'échelle près, celle du tombeau pompéien des Allei ${ }^{48}$ daté des années 30/40. Les résidus de débitage retrouvés justifient une reconstruction vraisemblable de l'autel (fig. 28) qui s'inscrit frontalement dans un carré de 5 pieds romains de côté et se retourne de 4 pieds (fig. 29). On s'est contenté d'ajouter un stéréobate semi-enterré, nécessaire pour surélever la frise basse et l'écarter du sol, ainsi qu'une tablette intermédiaire entre couronnement du dé et pulvinar, deux registres de pierre taillée facilement remployables et pour cette raison disparus en totalité.

47 Cf. la terminologie "Blockaltar» et "Polsteraltar" de ReIsch, s.v. allar, RE, I-2, 1894, col. 1672-1675.

48 KосKFL, op. cil., p. 166-168 et pl. 60a; la comparaison ne vaut que pour le jeu des volumes car le dé pompéien n'offre aucun décor.
Tableau III. Dimensions du bloc c (en $\mathrm{mm})$.

\begin{tabular}{|l|c|c|}
\hline & Hauteurs & Saillies \\
\hline Bandeau ... & 60 & - \\
Filet 1 ... & 11 & 10 \\
Filet 2 ... & 11 & 16 \\
Cimaise ... & 40 & 38 \\
Listel 1 ... & 6 & 3 \\
Listel 2 ... & 6 & - \\
\hline Total ...... & 134 & 67 \\
\hline
\end{tabular}

\section{LA STĖLE AUX VESTIGIA}

Une stèle fruste anépigraphe, avec la représentation de deux plantae pedum (orteils dressés), sculptées en relief et jumelées dans un même cartouche (cf. infra, p. 199) gisait en dehors de l'enclos carré, à proximité immédiate de son angle nord-ouest ${ }^{49}$. Ce type de bétyle trahit une fonction funéraire et à ce titre, on est fondé à le rapprocher de trois autres monuments trouvés dans cette partie du Lubéron, dont une autre pierre identique à la taille près, encore inédite et découverte dans les années 1970 sur l'oppidum du Castellar à Cadenet. Une "tombale" en marbre, aujourd'hui perdue et jadis encastrée dans l'enceinte du Castellar, portait sous une inscription gallo-grecque deux empreintes de semelles gravées, pointes en haut ${ }^{50}$; un cippe pyramidal de Saint-Saturnin-d'Apt porte les mêmes foulées parallèles mais dirigées vers le bas ${ }^{51}$.

49 Cf. F. Salviat, Informations archéologiques. Circonscription de Provence, Gallia, 30, 1972, fig. 42, p. 538.

50 E. RABIET, Inscriptions antiques trouvées à Cadenet (Vaucluse), Mémoires de la Société Nationale des Antiquaires de France, série 5, 8, 1887, p. 337-338; - M. LfJfunf, Recueil des inscriptions gauloises. I - Textes gallo-grecs, $45^{\circ}$ suppl. à Gallia, Paris, Ed. du CNRS, 1985, no G. 112, p. 138-140.

51 Ibid., no G. 152, p. 201-204. Tout autour de la Méditerranée, ces couples de pieds, parfois redoublés en itu et reditu, correspondent généralement, soit à des ex-voto de pèlerins (M. Guarducci, Le impronte del "Quo vadis", Rendiconti della Pontificia Accademia di Archeologia, XIX, 3-4, 19421943, p. 305-344; - L. Castigl.one, Vestigia I, Footprints Cut in Rocks, Acta archaeologica Academiae scientiarum Hungaricae, 22, 1970, p. 95-132 et pl. VI-XXI, avec renvois à Delattre, Inscription du Khangat el Hadjaj, Bullelin de la Société Nationale des Antiquaires de France, 1889, p. 231-232 et S. Gsell, Chronique archéologique africaine, Mélanges de l'École Française de Rome, 21, 1901, p. 219-220, 228-229) soit, dans des amphithéâtres, à des dédicaces de magistrats à Némésis-Caelestis (Delattre, Bullelin du Comilè des Travaux Historiques, 1899, p. CCXV-CCXvI; - Museo arqueologico de Sevilla, Guias de los museos de España, 71, Madrid, 1957, 


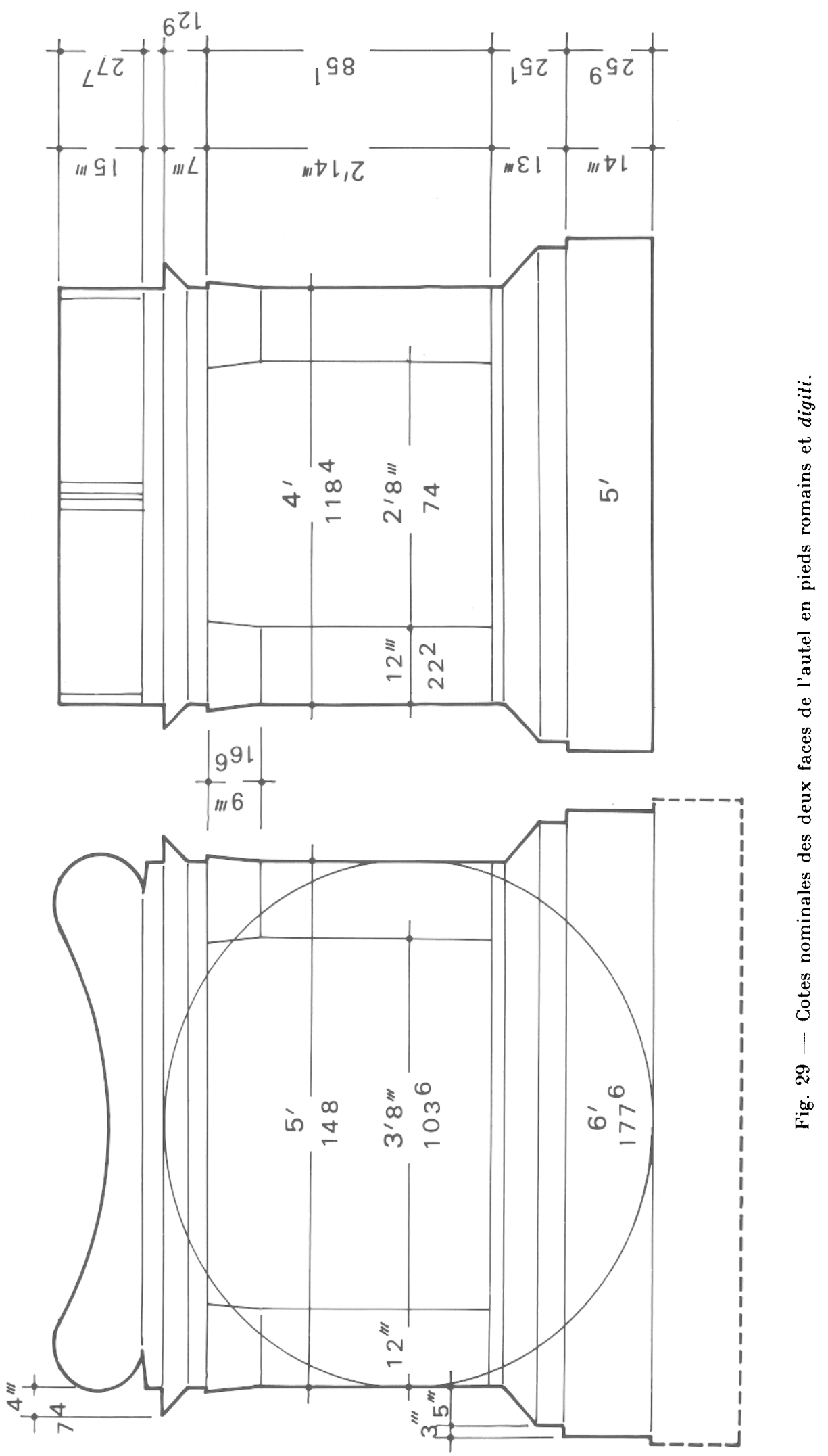


Si l'on tient compte des différents éléments qui s'y rattachent et qui ont été successivement décrits, la tombe initiale se serait limitée, dans la première moitié, voire le premier quart du ire s., à un tertre simplement signalé par la stèle aux vestigia; le buslum en fer à cheval fut ajouté, dans le troisième quart du siècle, en vue de protéger les sépultures groupées autour de celle de l'ancêtre. Cet aménagement, d'esprit gallo-grec, n'a sans doute eu qu'une existence très brève. Le mortier du mur était très médiocre et les fondations réduites au minimum. Le niveau supérieur des tombes 2 à 4 montre que d'importantes masses de remblais avaient été rapportées à l'intérieur de l'enclos. L'absence de barbacanes d'écoulement à la base des maçonneries ne permettait pas aux eaux de pluie de s'écouler librement en dehors et les poussées consécutives ont pu entraîner une désagrégation rapide de l'ouvrage; les utilisateurs du bustum furent ainsi amenès à envisager une rénovation a fundamentis des installations.

\section{LE COLUMBARIUM}

A l'intérieur de l'enclos carré et dans sa partie ouest affleuraient quelques traces de fondation dont l'angle oriental pointait à moins de $60 \mathrm{~cm}$ du bustum, substruction accolée mais non confondue avec le pied des murs sud-ouest et nord-ouest du péribole. Les grandes dimensions-enveloppes relevées à partir du parement interne de la clôture ne dépassent pas $4,50 \mathrm{~m}$ dans le sens nord-ouest/sud-est et $5,20 \mathrm{~m}$ perpendiculairement (fig. 2). La maçonnerie de réglage dans l'édifice quadrangulaire disparu est un caementicium coulé en tranchée, d'environ $1,30 \mathrm{~m}$ d'épaisseur sur quelque 2 pieds en profondeur. Au milieu de ce qu'on soupçonne être la façade, un épaississement irrégulier de $0,90 \mathrm{~m}$ en direction du sud-est suggère l'existence d'un emmarchement.

La première assise de grand appareil est très partiellement conservée en bordure du mur nordouest de l'enclos (fig. 30). Les six quadratae jointives en place sont restées brutes de carrière au lit de pose et les irrégularités y sont absorbées par le béton de propreté sous-jacent. Leur module théorique approchait les deux pieds en excès (tabl. IV). Les blocs ont été ajustés latéralement à l'économie en se bornant à

p. 83-88, pl. 62-69; - A. Fraschetti, Reditus. Enciclopedia dell'Arte Antica, suppl. 1973, p. 657; - A.-M. Canto, Les plaques votives avec plantae pedum d'Italica, Zeitschrift für Papyrologie und Epigraphik, 54, 1984, p. 183-194).

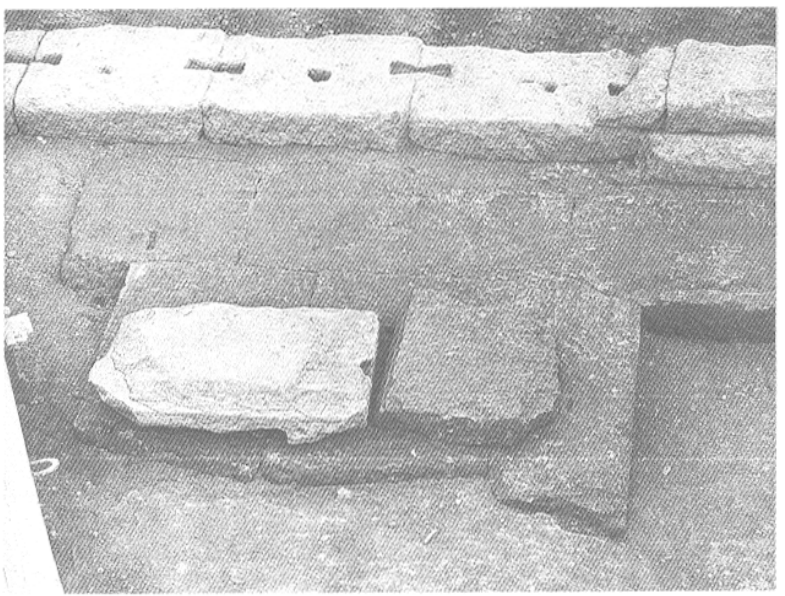

Fig. 30 - Fondation résiduelle du columbarium accolée à l'alignement nord-ouest de l'enclos carré; le couvercle de la tombe tardive $n^{\circ} 5$ à inhumation est en place.

Tableau IV. Dimensions maximales des blocs de la première assise de fondation* (en $\mathrm{m}$ ); les lettres désignant les blocs renvoient à la figure 2 .

\begin{tabular}{|l|c|l|}
\hline & Longueurs & Largeurs \\
\hline a. & 1,56 & 0,755 \\
b. & 1,625 & 0,74 \\
c. & 0,93 & 0,925 \\
d. & 1,345 & 0,58 \\
e. & 1,195 & 0,955 \\
f. & 1,15 & 0,915 \\
\hline
\end{tabular}

aligner à la scie les joints contigus quand c'était possible ${ }^{52}$ et à remplacer par des pans abattus les crossettes trop fragiles; l'adhérence n'est vraiment parfaite que là où le passage d'une égoïne était possible, de préférence normalement à l'orientation générale du mur. Le lit d'attente est uniformément arasé; un léger bourrelet conservé parallèlement au péribole nord-ouest reflète une moindre largeur des parpaings de la seconde assise de pierre de taille, probablement posés en boutisses. Compte tenu du niveau de sol dans l'enclos, il semble qu'il y ait eu

* Là encore, en dépit des irrégularités, on devine après conversions, des mesures en carrière voisines de $2,2 \frac{1}{2}, 3,4,5$ et 6 pieds romains. L'édicule ne devait pas être très différent du columbarium de la villa Borghèse : $H$. von Hesberg, M. Pfanner, Ein augusteiches columbarium im Park der Villa Borghese, JDAI, 103, 1988, fig. 4 et 13 p. 468, 473.

52 Cf. les remarques sur la taille des joints à la scie dans la contribution de R. Amy, in: L'arc d'Orange, $15^{e}$ suppl. à Gallia, Paris, Éd. du CNRS, 1962, appendice B, p. 63-72 et fig. 28. Pour le sciage de la pierre tendre, cf. P. NoËL, Technologie de la pierre de taille, Paris, 1968, p. 316-317. 
deux assises de grand appareil enterrées en fondation et, comme ce sera le cas pour la clôture de l'area, une troisième assise moulurée amorçait le départ de l'élévation (fig. 10, coupe DD). A ce niveau, la construction mesurait hors œuvre 12 pieds de côté avec des murs de 1 pied et demi d'épaisseur, hormis le pignon postérieur porté à 3 pieds justifiés par un très probable aménagement de niches destinées à recevoir des urnes funéraires (plan restitué fig. 31); la porte du local s'ouvrait au sud-est.

Trois fragments erratiques sont susceptibles de provenir de l'édifice.

Une dalle de $0,44 \mathrm{~m}$ ( 1 pied et demi), large de $0,90 \mathrm{~m}$ ( 3 pieds) pourrait appartenir à la dernière assise sous corniche du mur arrière occupé par les loculi; le lit d'attente porte un trou de louve et une cuvette de ripage, la pierre est brisée sur sa longueur (fig. 32, a).

Un débris de corniche (fig. 33) d'une hauteur maximale de $0,63 \mathrm{~m}$ était rompu sur sa longueur; la largeur au lit de pose, $0,435 \mathrm{~m}$, et la taille en contrefruit de la face arrière imposent la présence d'un antithema doublant, l'épaisseur et la pierre appartiendrait alors au mur de fond. Le joint conservé comporte un cadre d'anathyrose en pi, large de $9 \mathrm{~cm}$ verticalement et de $18 \mathrm{~cm}$ au lit d'attente, la cuvette est creusée de 1 à $3 \mathrm{~cm}$. Sommant le nu du parement terminal qui a une hauteur de $0,29 \mathrm{~m}$ (1 pied), la mouluration superpose: de bas en haut, un talon coiffé d'un filet, un larmier timidement esquissé avec un soffite en contre-pente légère et sa plate-bande, enfin la cimaise de couronnement avec son listel d'appui et un épais bandeau épaufré, l'ensemble occupant 1 pied 2 digiti en hauteur pour une saillie de 10 digiti.

Le processus de taille peut être ainsi reconstitué (fig. 34) :

a - par une première entaille de 1 pied de haut sur 10 digiti de profondeur, on obtient le parement du mur; une seconde entaille à l'arête saillante ainsi dégagée, de 5 digiti sur les deux dimensions du profil, définit les deux épannelages de la corona et de la cimaise.

$b$ - après partage en deux de la hauteur et de la profondeur, le bas du registre médian est découpé et l'arête basse abattue à $45^{\circ}$. Le registre supérieur est divisé verticalement en trois et le tiers inférieur chanfreiné, toujours à $45^{\circ}$.

c - il ne reste plus qu'à dégager, en ôtant à chaque fois un strict minimum de matière au ciseau et au grattoir, la doucine haute, le soffite du larmier et le talon bas.

Un troisième bloc, large de $0,67 \mathrm{~m}$, long de

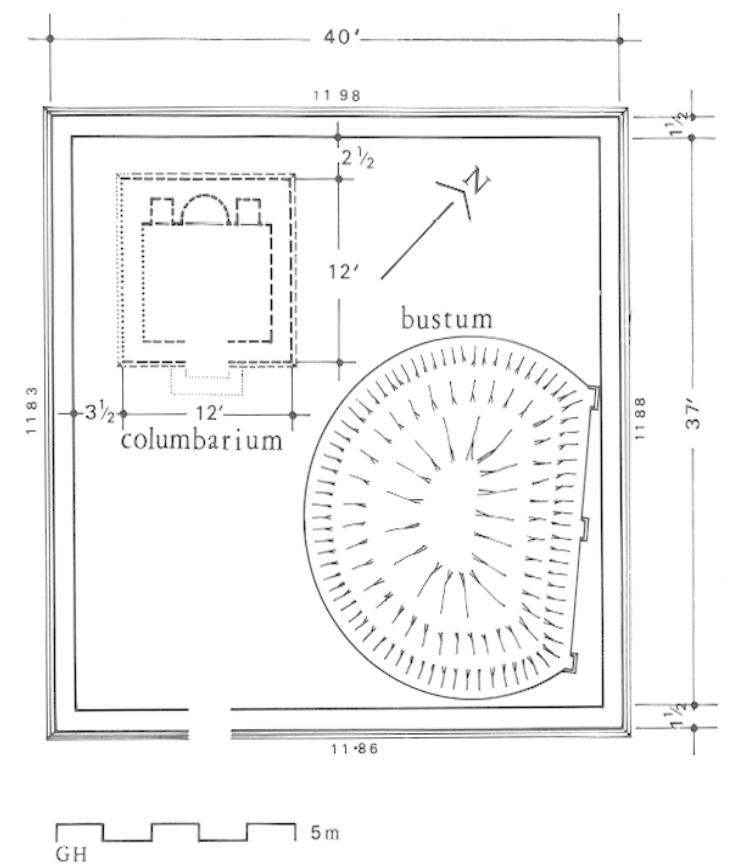

Fig. 31 - Plan du dernier état construit du site funéraire où le bustum est réduit à un tumulus.
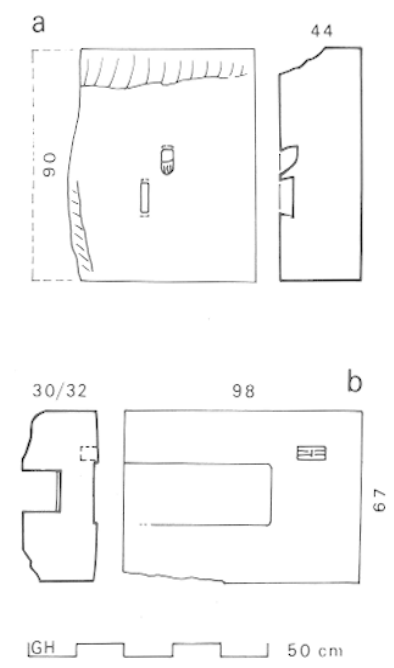

Fig. 32 - Détail de deux fragments de pierre de taille attribuables au columbarium.

$0,98 \mathrm{~m}$, épais de $0,30 \mathrm{~m} / 0,32 \mathrm{~m}$, plus délicat d'interprétation, pourrait être un morceau du seuil (fig. 32, b). Un des lits est creusé d'une dépression longitudinale large de $0,24 \mathrm{~m}$, profonde de $2 \mathrm{~cm}$ et mourant à une vingtaine de centimètres d'un about qui reçoit une cuvette en $\mathrm{V}$; on soupçonne un remords en suite de quoi cette face serait devenue le lit de pose. Le lit d'attente est creusé, à peu près en son milieu, d'une rainure large et profonde de $0,15 \mathrm{~m}$, qui fait penser à 
Fig. 33 - Joint de droite de la corniche présumée du columbarium.

Fig. 34 - Processus de taille

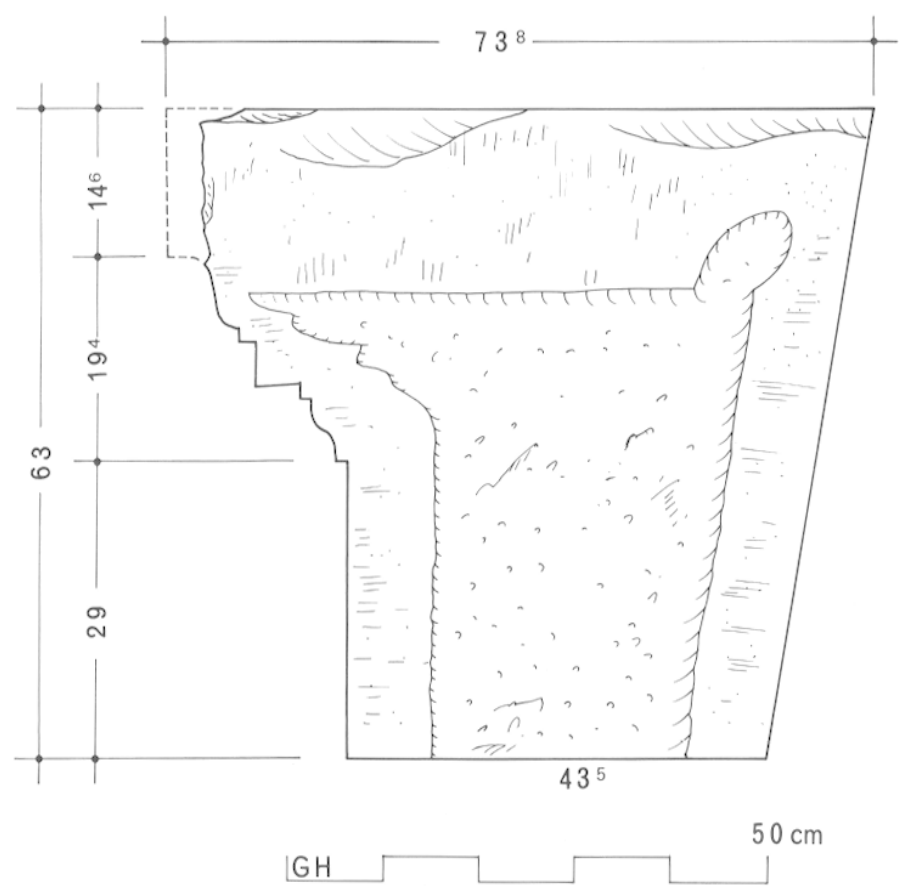
de la corniche du columbarium.
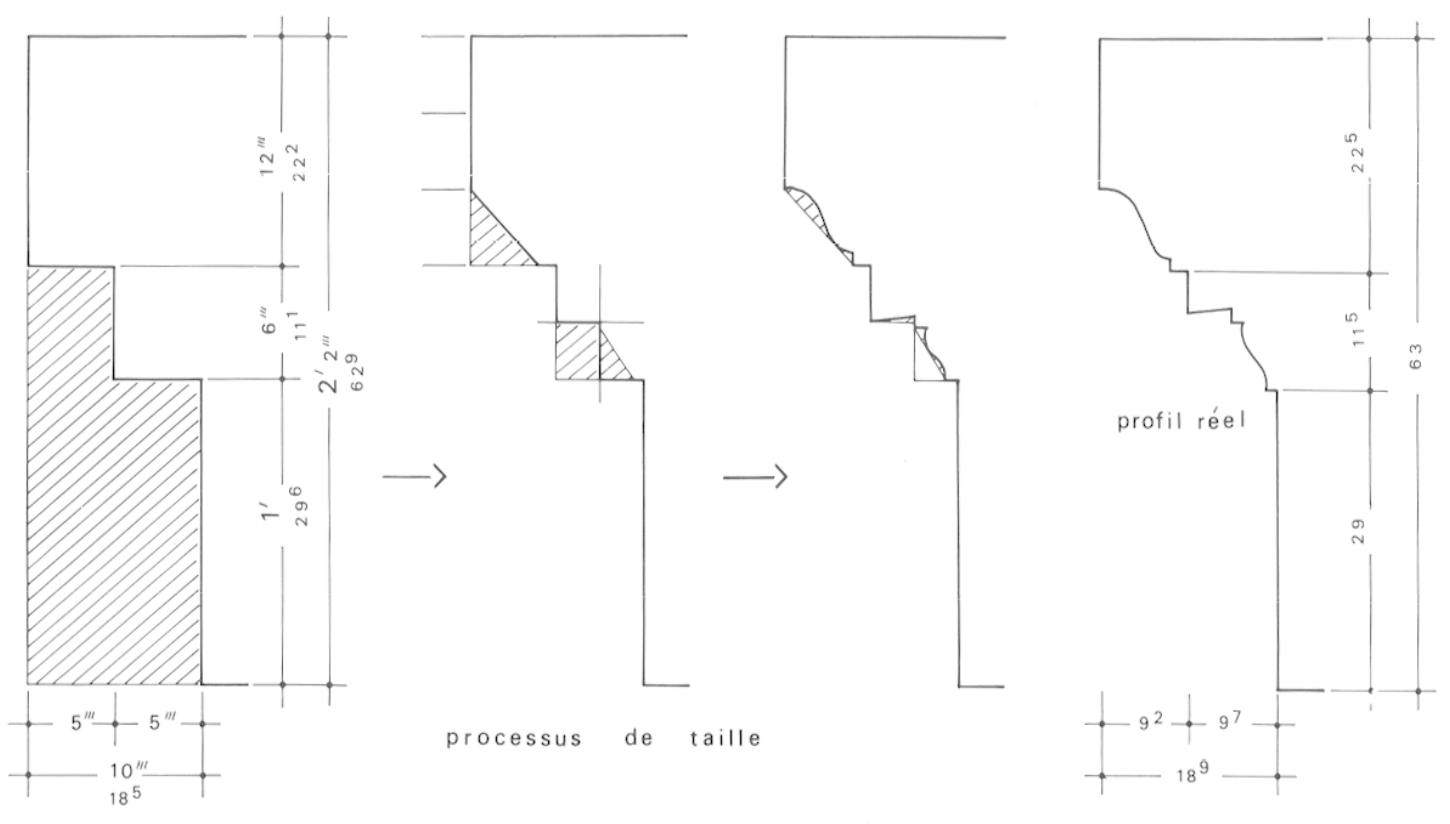

une fermeture à panneaux coulissants, justifiée pour un local ouvert seulement à l'occasion d'une crémation, quand il fallait ajouter une urne dans un loculus.

On serait tenté d'affecter aux acrotères des deux frontons de l'édicule, tel que nous avons cru pouvoir le restituer, les trois masques tragiques dispersés sur le terrain (en m1, m2 et m3 du plan, fig. 2), auxquels il convient d'ajouter l'exemplaire emmuré dans une propriété de Villelaure (cf. infra, p. 187). Ces figures représenteraient alors l'unique élément de datation absolue d'une construction entièrement arasée et qu'on serait ainsi conduit à placer dans la seconde moitié du $\mathbf{I}^{\text {er }}$ s., si l'existence du bustum ne la repoussait dans le dernier quart. 


\section{L'ENCLOS FUNÉRAIRE}

De l'enclos du second état ne restaient en place que la fondation réduite à une assise de grand appareil posée sur un réglage de moellons et en élévation, un petit quart de la première assise de transition. Le péribole a été implanté en calculant le périmètre au plus juste. Le bustum fut pratiquement arasé, l'assise d'appui du pan coupé porte les traces régulières en dents de scie imprimées par la pioche des terrassiers quand ils ont ouvert la tranchée (fig. 5 et 6); la même observation a été faite à l'est, au contact de la convexité du mur détruit avec la nouvelle clôture. Le tracé fut piqueté avec le souci de respecter les orientations du columbarium et le pied de l'enceinte s'appuie contre celui de l'édicule que vient chevaucher la première assise d'appareil. En revanche, on n'a tenu aucun compte de l'alignement droit du bustum réduit désormais à un simple tumulus, farci des tombées de sculptures et de moulures échappées au débitage de l'autel et de la paroi ordonnancée. Quant à l'entrée de l'area, il est douteux qu'elle ait été ménagée ailleurs que dans l'axe de la porte du columbarium (fig. 31).

Le moellonnage de mise à l'horizontale a été monté dans une tranchée ouverte un peu plus large que de besoin dans la couche végétale du sol vierge, une terre grise à petits nodules de calcaire blanc (cf. infra, couche 7). L'assiette de la fondation suit le relief, légèrement entaillé, du "bon sol" matérialisé par un horizon de "saffre" (cf. infra, couche 9), nom local de la marne d'érosion compactée issue de la "roque" sous-jacente (cf. infra, couche 10). Dans le sondage stratigraphique de la saignée sud-est (fig. 35), trois rangées de moellons se partagent une hauteur de $60 \mathrm{~cm}$; la rigole conserve une profondeur de quelque $58 \mathrm{~cm}$ au nord-est dans l'axe du bustum et au nord-ouest au dos du columbarium. A l'angle ouest, en revanche, l'appui se contente d'un unique lit de moellons. Cette maçonnerie ne déborde pas systématiquement la première ligne de quadratae, tout au plus a-t-on noté à l'alignement sud-est une saillie de 7 à $16 \mathrm{~cm}$; les caementa hourdés au mortier de chaux incorporent par endroits des libages en remploi.

\section{La STRATigraphie}

L'excavation ne couvrait, dans son développement maximal, qu'un carré de $16 \mathrm{~m}$ de côté. Une coupe de terrain a été pratiquée jusqu'aux strates géologiques ${ }^{53}$, à l'extrémité sud et à l'extérieur du

53 Carte géologique au $1 / 50000^{\circ}$, feuille XXXII-47 de Reillanne.

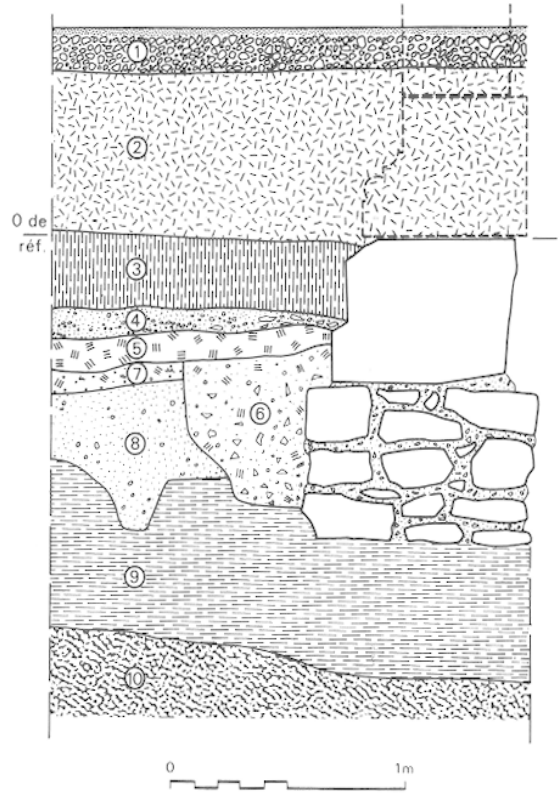

Fig. 35 - Coupe stratigraphique sur l'enclos funéraire en dd du plan.

mur oriental (en dd du plan fig. 2 et coupe fig. 35) et dix couches ont été identifiées.

1. De $+0,80$ à $+0,60:$ macadam asphalté du chemin vicinal dit route de Galon.

2. De $+0,60$ à 0 : humus et terre arable; couche de culture postérieure à la destruction des vestiges recouverts.

3. De 0 à $-0,30$ : argile d'origine ocre jaune, déplacée puis rapportée; elle occupait primitivement l'emplacement des strates remblayées 4 et 5 . La surface, actuellement perturbée, correspondrait approximativement au sol de circulation extérieur contemporain de la construction.

4. De $-0,30$ à $-0,40$ : gravillons, graviers, déchets de taille et sable jaune; couche de remblai.

5 . De $-0,40$ à $-0,50$ : terre végétale grise; couche de remblai postérieure à la clôture, en direction de laquelle elle remonte légèrement.

6. De $-0,45 \grave{a}-1,00$ : tranchée de fondation comblée avec ses propres déblais (matériaux mêlés des couches 7 et 8 ).

7. De $-0,50$ à $-0,60$ : terre gris sombre avec débris végétaux décomposés et petits nodules de calcaire correspondant à un sol nettement antérieur à la construction, la couche étant interrompue par la tranchée 6 et présentant un pendage vers l'est.

8. De $-0,60$ à $-0,95$ : marne sableuse grise du Miocène supérieur continental à petits galets, le "saffre»; la couche, recoupée par la tranchée 6 , est peu épaisse mais elle atteint plus de $100 \mathrm{~m}$ de puissance à quelques kilomètres au nord de l'agglo- 
mération, où elle contient testudo et des mammifères avec hipparion dominant ${ }^{54}$.

9. De $-0,95$ à $-1,50$ : marne bleue du Tortonien marin inférieur, dite "de Cabrière"; les fondations pénètrent cette strate d'une quinzaine de centimètres.

10. Vers $-1,50$ apparaît le plafond, en pente vers l'ouest, d'un étage géologique de même époque, une molasse calcaire blanche à pecten, dite "de Cucuron" et appelée localement la "roque», dont un éperon affleure à une centaine de mètres vers l'est ${ }^{55}$.

La fouille conduite dans l'enclos par décapages successifs de $0,10 \mathrm{~m}$ d'épaisseur, montre que l'argile de la couche 3 coïncide avec la première assise d'appareil; moins homogène, parsemée de matériel erratique inégalement conservé et de pierres en surface, elle est vierge et plus compacte en dessous de $-0,25$. L'absence des couches 4 et 5 ne doit pas surprendre car elles ont été manifestement rejetées à l'extérieur après édification de la clôture dont elles recouvrent le ressaut de fondation. De même, l'absence de la couche 7 , qui ne dépasse guère $0,10 \mathrm{~m}$, s'explique par l'obliquité de son pendage qui, prolongé vers l'area, aboutirait dans la partie remaniée de la couche 3 . Il importe aussi de souligner que, dans le secteur oriental de l'enclos, la couche 3 a été entamée par la tranchée de branchement d'eau ouverte en direction du pavillon en construction, telle que l'indique le pointillé-tireté orienté grossièrement nord-sud (fig. 2); les recherches localisées conduites autour des découvertes fortuites de mobilier faites à cette occasion ont perturbé ici l'ordonnance de cette strate, partout ailleurs homogène.

\section{LE GRAND APPAREIL}

La première assise de pierre taillée est une sorte d'eulhynteria, encore en fondation mais néanmoins apparente au-dessus du sol d'utilisation contemporain (fig. 36, I). Conservée sur tout son développement, elle comporte trente-six parpaings d'une roche calcaire très coquillière; une prospection récente, menée pour la mise à jour de la carte géologique, n'a repéré aucune trace de carrière antique sur les pentes méridionales du Lubéron en arrière du Cucuron, là où tout porte à croire que devaient se trouver les bancs exploités pour ce chantier. Les assises mesurent 0,56 m sur l'alignement nord-est, 0,555/0,575 m

54 A. Gaudry, Animaux fossiles du mont Lébéron. Etudes des vertébrés, Paris, 1873.

55 F. Fischfr, R. Tournotrër, Animaux fossiles du mont Lébéron. Étude des invertébrés, Paris, 1873. vers l'angle ouest. Il s'agissait donc de blocs uniformément abattus en carrière selon un module de deux pieds, avant dressage sur le tas et arasement général du lit d'attente pour mise à l'horizontale de la rangée complète. Vers le dedans, les faces arrières sont laissées brutes de débitage ou de dégrossissage à la broche sans recherche de mise à l'alignement. Sans doute faut-il voir dans les irrégularités des blocs 20 à 24 les traces résiduelles d'extraction attestées, notamment à l'arrière du parpaing 36 , où l'ouverture à l'escoude (sorte de pic) de traces ou tranches verticales de carrière, se traduit par des sillons courbes parallèles (fig. 37). En revanche, on aura certainement tenté d'obtenir en façades, tout au moins au lit d'attente, quatre arêtes rectilignes périmétrales retournées d'équerre destinées à annoncer, voire à guider l'implantation de la seconde assise qui était en réalité le pied de l'élévation. Les parements ont été dressés sous cette arête sur un quart de la hauteur des faces de front; ce nu était plus rarement retourné le long des joints verticaux et le travail a été carrément abandonné pour les blocs 6,7 et 9 . La saillie des bosses résiduelles, destinées de toute façon à être enterrées, varie de 2 à $21 \mathrm{~cm}$.

L'ordre de pose, avec un assemblage des angles en besace, serait le suivant : il semble qu'on soit parti de l'angle est, une fois scellés les éléments 1 et 36 . On aura atteint l'angle nord en laissant en bout de file la pierre 9 déborder sur l'alignement nordouest et cette avancée ne sera pas abattue. On pose ensuite le côté nord-ouest, toujours en laissant l'extrémité en attente, saillant retaillé en surface mais conservé au lit de pose. Suivait la rangée sudouest dont le bloc terminal $\left(\mathrm{n}^{0} 27\right)$ a disparu, sans doute à l'occasion de travaux de voirie modernes. Le périmètre était refermé sur le dernier côté du carré, en attaquant aux deux bouts par les quadratae 35 et 28 pour clore l'anneau avec le bouchon 31 , le plus court de la série. L'inventaire des mensurations maximales des pierres (tabl. V), dans les deux dimensions horizontales converties en pieds romains, trahit quelques valeurs répétitives : les largeurs de parpaings se répartissent en douze échantillons de 3 pieds $(38 \%)$ et vingt de 2 pieds et demi $(62 \%)$; le choix est plus ouvert dans les longueurs où les variantes sont identifiables en première analyse (tabl. VI).

Compte tenu des tolérances de la taille en carrière, on retiendra, après arrondissement au pied voisin, dix unités de 4 pieds, vingt de 5 et deux coupes aberrantes de $2 \frac{1 / 2}{2}$ et 6 .

L'assise de socle (fig. 36 , II), la première de l'élévation, n'avait conservé que onze panneresses, 


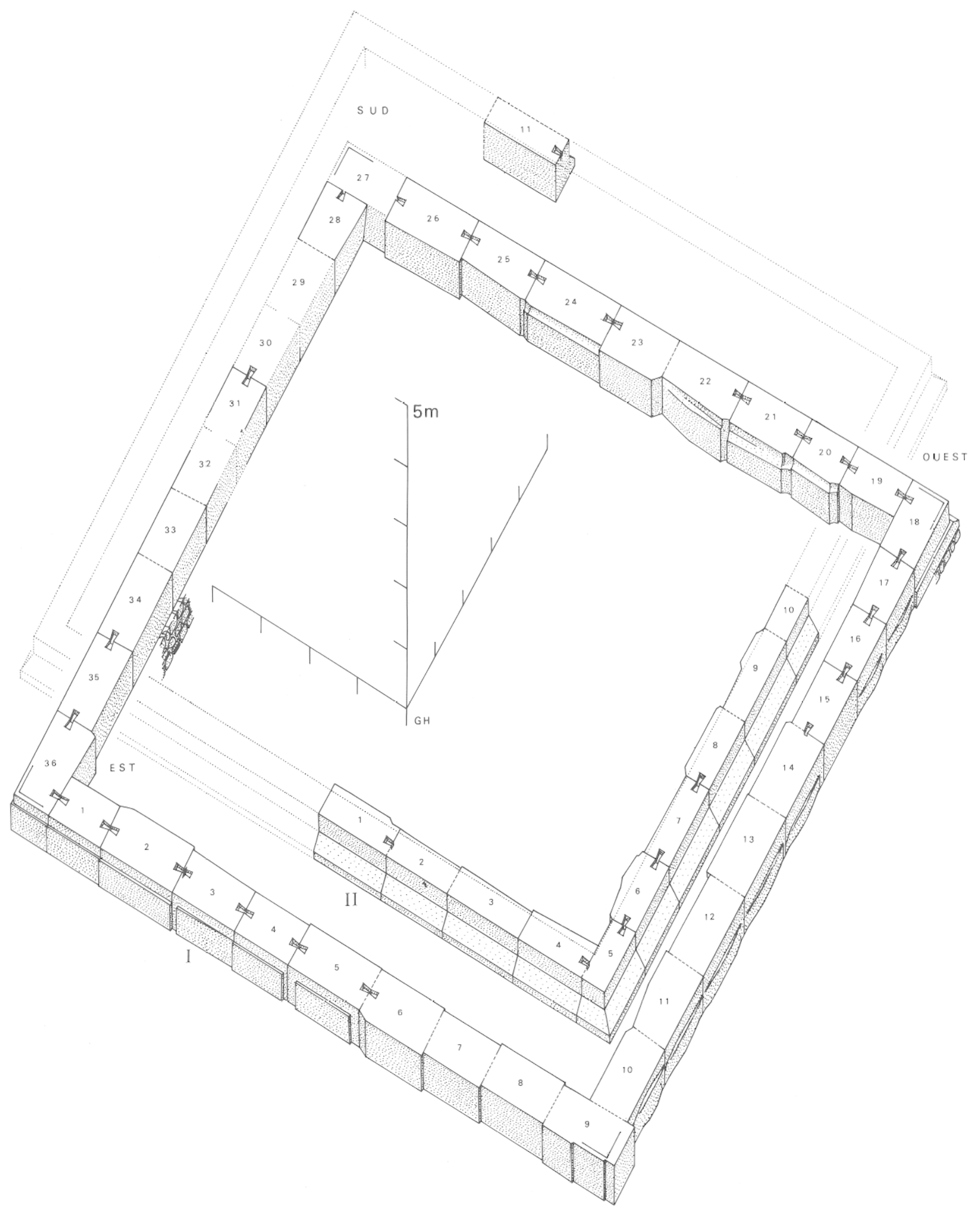

Fig. $36-$

Axonométrie en écorché des vestiges des deux premières assises en grand appareil de l'enclos. 
Tableau V. Assise I : dimensions des blocs (en m et pieds); les numéros des blocs renvoient à la figure 36 .

\begin{tabular}{|c|c|c|c|c|c|}
\hline \multicolumn{2}{|c|}{$\begin{array}{l}\text { Numéros } \\
\text { Des blocs }\end{array}$} & \multicolumn{2}{|c|}{$\begin{array}{l}\text { LARGEURS MAXIMALES } \\
\text { (bossages compris) }\end{array}$} & \multicolumn{2}{|c|}{$\begin{array}{l}\text { LONGUEURS } \\
\text { MAXIMALES }\end{array}$} \\
\hline Face NE & $\begin{array}{l}1 \ldots \\
2 \ldots \\
3 \ldots \\
4 \ldots \\
5 \ldots \\
6 \ldots \\
7 \ldots \\
8 \ldots \\
9 \ldots\end{array}$ & $\begin{array}{l}0,78 \\
0,95 \\
0,80 \\
0,795 \\
0,875 \\
0,90 \\
0,78 \\
0,79 \\
0,75\end{array}$ & $\begin{array}{l}21 / 2 \\
3 \\
21 / 2 \\
21 / 2 \\
3 \\
3 \\
21 / 2 \\
21 / 2 \\
21 / 2\end{array}$ & $\begin{array}{l}1,015 \\
1,505 \\
1,32 \\
1,16 \\
1,485 \\
1,32 \\
1,155 \\
1,31 \\
1,255\end{array}$ & $\begin{array}{l}31 / 2 \\
5 \\
41 / 2 \\
4 \\
5 \\
41 / 2 \\
4 \\
41 / 2 \\
41 / 2\end{array}$ \\
\hline Face NO & $\begin{array}{l}10 \ldots \\
11 \ldots \\
12 \ldots \\
13 \ldots \\
14 \ldots \\
15 \ldots \\
16 \ldots \\
17 \ldots \\
18 \ldots \\
\end{array}$ & $\begin{array}{l}0,795 \\
0,80 \\
0,77 \\
0,79 \\
0,86 \\
0,715 \\
0,705 \\
0,72 \\
0,80\end{array}$ & $\begin{array}{l}21 / 2 \\
21 / 2 \\
21 / 2 \\
21 / 2 \\
3 \\
21 / 2 \\
21 / 2 \\
21 / 2 \\
21 / 2\end{array}$ & $\begin{array}{l}1,345 \\
1,39 \\
1,52 \\
1,485 \\
1,43 \\
1,18 \\
1,085 \\
1,035 \\
1,495\end{array}$ & $\begin{array}{l}41 / 2 \\
5 \\
5 \\
5 \\
5 \\
4 \\
31 / 2 \\
31 / 2 \\
5\end{array}$ \\
\hline Face SO & $\begin{array}{l}19 \ldots \\
20 \ldots \\
21 \ldots \\
22 \ldots \\
23 \ldots \\
24 \ldots \\
25 \ldots \\
26 \ldots \\
27 \ldots \\
\end{array}$ & $\begin{array}{l}0,74 \\
0,82 \\
0,82 \\
0,87 \\
0,83 \\
0,79 \\
0,755 \\
0,81 \\
\quad ?\end{array}$ & $\begin{array}{l}21 / 2 \\
3 \\
3 \\
3 \\
3 \\
21 / 2 \\
21 / 2 \\
3\end{array}$ & $\begin{array}{c}1,095 \\
0,935 \\
1,305 \\
1,405 \\
1,215 \\
1,57 \\
1,35 \\
1,50 \\
?\end{array}$ & $\begin{array}{l}4 \\
33^{1 / 2} \\
41 / 2 \\
5 \\
4 \\
51 / 2 \\
41 / 2 \\
5\end{array}$ \\
\hline Face SE & $\begin{array}{l}28 \ldots \\
29 \ldots \\
30 \ldots \\
31 \ldots \\
32 \ldots \\
33 \ldots \\
34 \ldots \\
35 \ldots \\
36 \ldots \\
\ldots\end{array}$ & $\begin{array}{c}0,81 \\
? \\
0,73 \\
0,775 \\
? \\
? \\
0,77 \\
0,83 \\
0,82\end{array}$ & $\begin{array}{l}3 \\
21 / 2 \\
21 / 2\end{array}$ & $\begin{array}{c}1,075 \\
? \\
? \\
0,79 \\
? \\
1,27 \\
1,51 \\
1,37 \\
1,765\end{array}$ & $\begin{array}{l}2^{1 / 2} \\
4^{1 / 2} \\
5 \\
4^{1 / 2} \\
6\end{array}$ \\
\hline
\end{tabular}

Tableau VI. Assise I : tableau récapitulatif des longueurs des blocs (en pieds).

\begin{tabular}{|c|c|c|}
\hline LONGUEUR & Quantité & Pourcentage \\
\hline . & 1 & $3 \%$ \\
\hline $51 / 2$. & 1) & $3 \% *$ \\
\hline $\begin{array}{l}5^{\prime} \ldots \ldots \\
41 / 2 \ldots \ldots\end{array}$ & $\left.\begin{array}{r}10 \\
9\end{array}\right\}=20$ & $\left.\begin{array}{ll}31 & \% * \\
28 & \% *\end{array}\right\}=62 \%$ \\
\hline $\begin{array}{l}4^{\prime} \ldots \ldots \\
31 / 2 \ldots \ldots\end{array}$ & $\left.\begin{array}{l}5 \\
5\end{array}\right\}=10$ & $\left.\begin{array}{l}16 \%{ }^{* * *} \\
16 \% * *\end{array}\right\}=32 \%$ \\
\hline $21 / 2 \ldots \ldots$ & 1 & $3 \%$ \\
\hline
\end{tabular}

très érodées par les intempéries, groupées en équerre sur les deux retours de l'angle nord, si l'on néglige le peu qui subsiste du bloc 11 à cheval sur les quadratae 24 et 25 de l'euthynteria et le chicot accolé à la pierre 10. Ces éléments restent bruts de carrière sur leur face interne où ils étaient par conséquent enterrés. En revanche, ils étaient parementés en façade où la modénature (fig. 38) comporte, en partant du bas, un piédestal continu avec bandeau, boudin, listel et cavet renversé, puis le départ de la tapisserie du mur aveugle; la hauteur d'assise mesure toujours 2 pieds théoriques $(0,555 / 0,56 \mathrm{~m}$ 
contrôlés). Les cotes de détail de l'embasement se répartissent verticalement de la façon suivante (tabl. VII).

Tableau VII. Assise I : cotes des différents éléments de la modénature (en $\mathrm{m}$ et pieds).

\begin{tabular}{|l|l|r|l|}
\hline & $\begin{array}{c}\text { Fourchette } \\
\text { MesuréE }\end{array}$ & $\begin{array}{c}\text { Conversion En Pieds } \\
\text { Et DIGITI }\end{array}$ & $\begin{array}{c}\text { Valeur } \\
\text { Nominale }\end{array}$ \\
\hline Bandeau ... & $0,13 / 0,15$ & $1 / 2$ pieds $=8^{\prime \prime \prime}$ & 0,148 \\
Boudin ... & $0,105 / 0,084$ & $5^{\prime \prime \prime}$ & 0,0925 \\
Filet ..... & $0,025 / 0,038$ & $1^{\prime \prime \prime}$ & 0,0185 \\
Cavet..... & $0,07 / 0,064$ & $4^{\prime \prime \prime}$ & 0,074 \\
\hline
\end{tabular}

Quant à la saillie du bandeau sur le nu du mur, $0,16 \mathrm{~m} / 0,172 \mathrm{~m}$, elle prétendait sans doute égaler la moitié de la hauteur, autrement dit un demi-pied et un digitus (ou 9 digiti de valeur nominale $=0,1665 \mathrm{~m}$ ). Pour des raisons strictement opératoires, la mouluration a dû être mise en façon une fois seulement les parpaings épannelés assemblés à leur place définitive et selon un processus qui peut être ainsi rétabli (fig. 39) :

a-le bloc est dèlardé à 14 digiti sous le lit d'attente et à la verticale du parement fini, c'est-àdire sur une profondeur de 9 digiti;

$\mathrm{b}$ - à partir de l'arête saillante ainsi obtenue, on trace deux droites à un demi-pied de l'arête, horizontalement et verticalement, puis on abat le chanfrein;

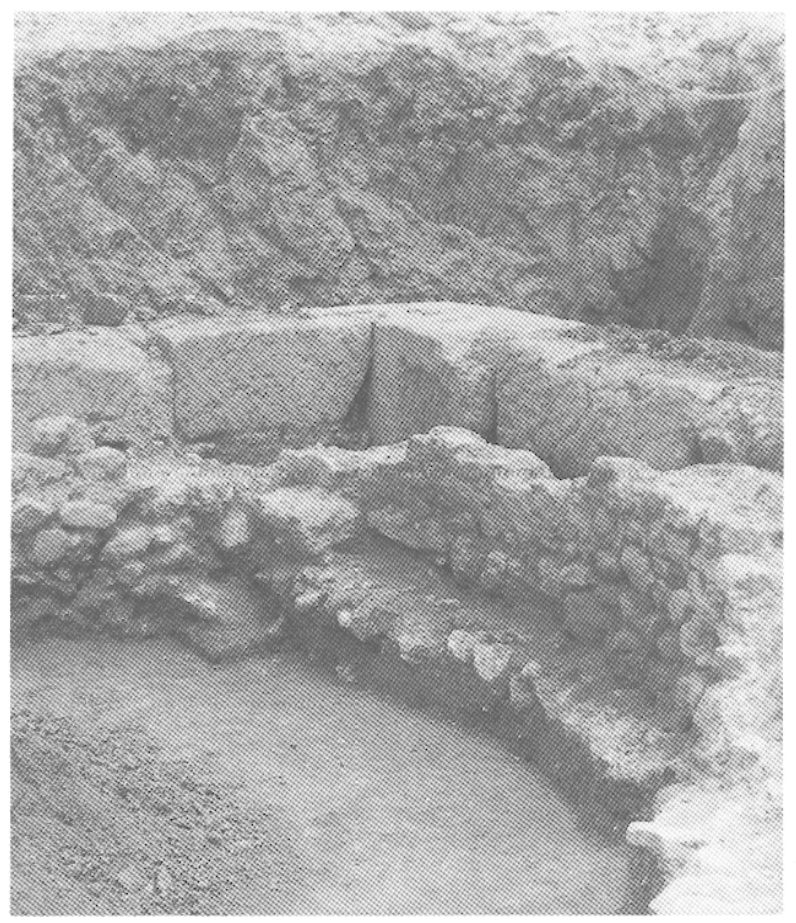

Fig. 37 - Angles est du buslum et de l'enclos carré vus de l'interrieur.

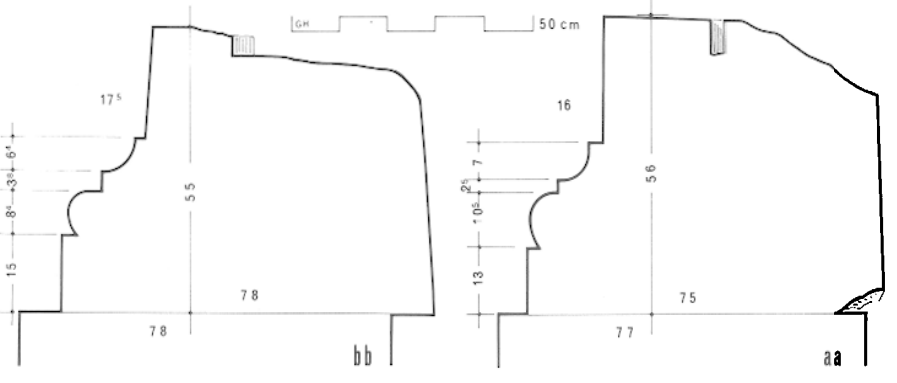

Fig. 38 - Profils en aa et bb de la pierre de socle de l'enclos.

$c$-une première horizontale est menée à la pointe sur le milieu du plat chanfreiné, une seconde à un demi-pied au-dessus du lit de pose (ou à 2 digiti de l'arête basse du chanfrein);

d-il ne restc plus qu'à enlever au ciscau et au grattoir un minimum de matière en dégageant le cavet, en abattant verticalement le filet $\mathrm{V}$ et horizontalement le retour du bandeau $\mathrm{H}$ et en façonnant la convexité du tore.

Le jeu de la règle et de la pointe dans les tracés successifs explique les écarts qui altèrent les mesures élémentaires tout autant que les flottements constatés entre les deux profils de référence et le calibre théorique. Quant aux cotes horizontales caractéristiques des pierres de cette seconde assise, elles sont répertoriées dans le tableau VIII.

Les joints sont généralement bien ajustés après taille du cadre d'anathyrose et mise en contact à la serra dentata; il n'est guère qu'à la rencontre en besace de 1-36 que le joint reste ouvert de $1 \mathrm{~cm}$ vers l'intérieur.

Tableau VIII. Assise II : dimensions des blocs (en m et pieds); les numéros des blocs renvoient à la figure 36 .

\begin{tabular}{|c|c|c|c|c|}
\hline $\begin{array}{l}\text { Numéros } \\
\text { DES bLocs }\end{array}$ & \multicolumn{2}{|c|}{$\begin{array}{c}\text { LARGEURS MAXIMALES } \\
\text { AU LIT DE POSE }\end{array}$} & \multicolumn{2}{|c|}{$\begin{array}{l}\text { LONGUEURS } \\
\text { MAXIMALES }\end{array}$} \\
\hline $\begin{aligned} \text { Face NE } & 1 \ldots \\
& 2 \ldots \ldots \\
& 3 \ldots \ldots \\
& 4 \ldots \ldots\end{aligned}$ & $\begin{array}{c}? \\
? \\
0,69 \\
0,79\end{array}$ & $\begin{array}{l}21 / 2 \\
21 / 2\end{array}$ & $\begin{array}{l}1,40 \\
1,235 \\
1,48 \\
1,315\end{array}$ & $\begin{array}{l}5^{\prime} \\
4 \\
5 \\
41 / 2\end{array}$ \\
\hline $\begin{aligned} \text { Face No } & 5 \ldots . \\
& 6 \ldots \\
& 7 \ldots \\
& 8 \ldots \\
& 9 \ldots \\
& 10 \ldots \\
& \ldots \ldots\end{aligned}$ & $\begin{array}{l}0,665 \\
0,80 \\
0,665 \\
0,73 \\
0,72 \\
0,61\end{array}$ & $\begin{array}{l}21 / 2 \\
21 / 2 \\
21 / 2 \\
21 / 2 \\
21 / 2 \\
2\end{array}$ & $\begin{array}{l}1,36 \\
1,235 \\
1,45 \\
1,30 \\
1,51 \\
0,87\end{array}$ & $\begin{array}{l}4^{1 / 2} \\
4 \\
5 \\
41 / 2 \\
5 \\
3\end{array}$ \\
\hline Face SO $11 \ldots$. & 0,65 & 2 & $?$ & \\
\hline
\end{tabular}




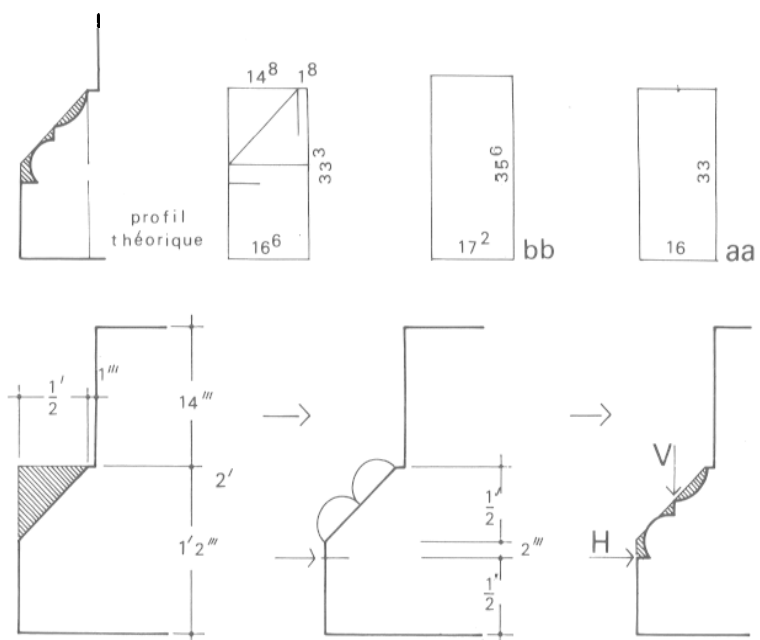

Fig. 39 - Processus de taille de la moulure de socle du mur d'enclos.

Les quartiers d'appareil étaient brêlés à la louve (fig. 30); les vingt-deux cavités visibles, placées comme il convient au milieu du lit d'attente, orientées selon la grande dimension des blocs et taillées verticalement en queue d'aronde, présentent des dimensions à peu près standardisées : ouverture de $2,5 \mathrm{~cm}$ sur $8,5 \mathrm{~cm} / 13 \mathrm{~cm}^{56}$, profondeur de $8,5 / 13,5 \mathrm{~cm}^{57}$. Les cuvettes de ripage sont ouvertes à la demande en fonction de la position du joint dans l'assise de recouvrement; il arrive qu'elles mordent sur un trou de louve quand le hasard amène le joint d'en dessus à tomber au milieu du bloc (par exemple, fig. $36, \mathrm{I}, \mathrm{n}^{\text {os }} 3,4,16$ et 30 ) ou qu'elles s'y ajoutent en prolongement (fig. $36, \mathrm{II}, \mathrm{n}^{\circ} 6$ ). La cupule se ramène parfois à un élargissement partiel du trou de louve (fig. $36, \mathrm{n}^{\text {os }} 18$ et 19 ); sur le bloc 36 (fig. $36, \mathrm{I}, \mathrm{n}^{\circ} 36$ ), la mortaise a été aménagée une première fois, il a fallu ensuite la retailler de quelques centimètres dans les deux sens. Ces encoches servaient, on le sait, à buter le plat de la pince pour faire riper le bloc parallèlement à la façade jusqu'à ce que son joint vienne au conlact de la pierre en place.

L'assemblage longitudinal de l'assise est obtenu par l'encastrement sur chaque joint d'une double queue d'aronde en chêne, dont il restait des traces, rentrée en force dans deux mortaises contrariées de plan trapézoïdal (fig. 30). Plusieurs occurrences où

56 Deux largeurs de 3 et $3,5 \mathrm{~cm}$; pour les longueurs, moyenne de $9 \mathrm{~cm}$, mode de $11 \mathrm{~cm}$ et médiane de $10 \mathrm{~cm}$.

57 Pour les profondeurs, moyenne de $11,4 \mathrm{~cm}$, mode de $11 \mathrm{~cm}$ et médiane de $11,5 \mathrm{~cm}$; les dimensions des trous de louve étaient évidemment imposées par celles de la louve utilisée sur le chantier.
Fig. 40 - Reconstitution du calibre en tôle utilisć pour le tracé des demi-queues d'aronde destinées à l'assemblage longitudinal des parpaings d'assises de l'enclos.

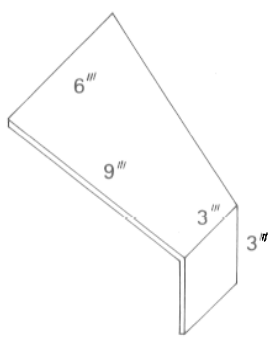

les pinces aux joints ne sont pas en correspondance et où les profondeurs diffèrent (notamment fig. 36, I, $\mathrm{n}^{\text {os }} 19,20$ et $\left.\mathrm{II}, \mathrm{n}^{\mathrm{os}} 5,6\right)$ montrent que les demiqueues d'aronde ont été préparées sur le chantier mais avant le brêlage des blocs et en utilisant un calibre censé garantir l'uniformité des tenons et des mortaises; les longueurs jouent entre 11,5 et $19,5 \mathrm{~cm}$, les largeurs aux ailes entre 8 et $16 \mathrm{~cm}$, les pinces entre 4,5 et $7,5 \mathrm{~cm}$, les profondeurs entre 4,5 et $8 \mathrm{~cm}^{58}$, le calibre devait être une lame de fer pliée (fig. 40) étalonnée à 3-6-9 digiti ${ }^{59}$. Ce dispositif est présent sur la courtine de Marseille, au milieu du II $^{e} \mathrm{~s}$. avant notre ère ${ }^{60}$. Le parement interne de cette seconde assise n'était pas aligné non plus, le sol intérieur de l'enclos devait régner, à peu de chose près, avec son lit d'attente (fig. 10).

Si la construction du péribole est postérieure à celle du columbarium, le décalage chronologique n'est guère que la conséquence d'un avancement normal du chantier. L'étroitesse du tour d'échelle large de 2 pieds et demi à 3 pieds et demi qui sépare, au niveau de l'élévation, la bâtisse du mur de l'area ${ }^{\mathbf{6 1}}$, aurait fortement gêné le constructeur si l'édicule avait dû être monté en second : clôture et columbarium appartiennent à une même commande.

\section{TOMBE 5: L'INHUMATION TARDIVE}

La fréquentation de la nécropole familiale paraît se poursuivre jusque dans la seconde moitié

$58 \mathrm{Si}$ les fourchettes minimum-maximum sont assez ouvertes, les mensurations relevées sur les vingt et une queues d'aronde de l'assise I et les cinq de l'assise II conduisent à une égalité de la moyenne, de la médiane et du mode, $16 / 16,1 \mathrm{~cm}$ pour les longueurs, $11,8 / 12 \mathrm{~cm}$ pour les ailes, $6,3 / 6,5 \mathrm{~cm}$ pour les pinces et $6 / 6,2 \mathrm{~cm}$ pour les profondeurs.

59 Equivalences nominales : $3^{\prime \prime \prime}=5,55 \mathrm{~cm} ; 6^{\prime \prime \prime}=$ $11,1 \mathrm{~cm}$ et $9^{\prime \prime \prime}=16,65 \mathrm{~cm}$.

60 G. Hallier, Pierre de taille et mesures normalisées : les enceintes hellénistiques d'Apollonia de Cyrénaïque et de Massalia, in : La fortification dans l'histoire du monde grec, Actes du colloque, CNRS 614, Valbonne, 1982, Paris, 1986, p. 269.

61 Autrement dit, environ 0,74 et 1,04 m. 


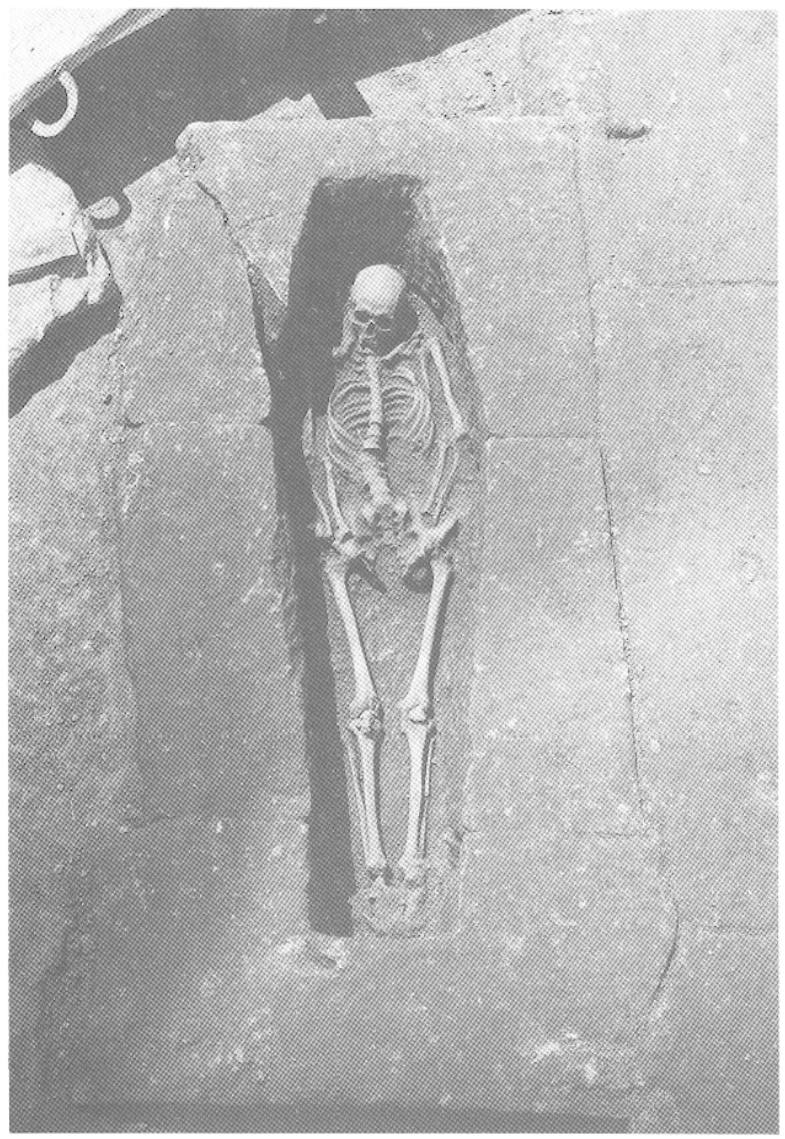

Fig. 41 - Massif de fondation résiduel du columbarium avec la tombe tardive ouverte et le squelette en place.

du II" s. Beaucoup plus tard et bien après l'abandon du site, à une date difficile à préciser, peut-être la seconde moitié du $\mathrm{IV}^{\mathrm{r}} \mathrm{s}$. (cf. infra), les constructions, édicule et enclos, subissent un démontage organisé : toutes les pierres taillées susceptibles de remploi sont récupérées, à l'exclusion des blocs moulurés ou sculptés qui sont débités pour le four à chaux. Une sorte de plate-forme affleurait encore à l'arrière de la chapelle disparue; on en tira parti pour aménager un sarcophage rupestre en excavant une fosse au pic, sur 0,35/0,37 m de profondeur (fig. 41). La cuve, longue de $1,86 \mathrm{~m}$, revêt en plan une allure anthropomorphique vaguement rhomboïdale aux pointes abattues; sa largeur va se rétrécissant, de $0,51 \mathrm{~m}$ au milieu à $0,27 / 0,29 \mathrm{~m}$ vers ses extrémités. Sous le couvercle peu étanche formé de deux dalles de récupération épaufrées, elle renfermait le squelette d'un homme âgé d'au moins 28 ans et d'une taille comprise entre $1,66 \mathrm{~m}$ et $1,69 \mathrm{~m}^{62}$, en

62 II. Camps-Fabrer, C. Maître, Étude anthropologique d'un squelette recueilli à Cucuron, Les Travaux $d u$ Laboratoire d'Anthropologie, de Préhistoire et d'Ethnologie des Pays de la Méditerranée Occidentale, 1, 1970, p. 2-7. décubitus dorsal tendu, les mains sur les hanches, le crâne au sud-ouest reposant sur un moellon. La fosse était comblée de terre d'infiltration et ne contenait aucun mobilier. Les mensurations de la cavité tolèrent des conversions voisines de 1,2 et 6 pieds romains : force est bien de se contenter de ce pauvre critère de datation, ajouté à une unique monnaie constantinienne dispersée, pour reporter au BasEmpire cette inhumation isolée.

\section{Le matériel eRratique}

Il a semblé hors de propos de pousser la précision jusqu'à faire état de la totalité du matériel erratique (dans lequel sont comprises les offrandes du catalogue A. Dumoulin dont la relation avec une structure funéraire déterminée reste imprécise) qui n'apporte rien à la précision chronologique des ensembles décrits. Du moins semble-t-il souhaitable de mentionner les objets qui présentent un intérêt par euxmêmes ou qui précisent l'occupation du site ou la nature de certaines séries.

\section{Céramiques à parois fines}

La typologie à laquelle on se référera est celle que F. Mayet a établie sur la céramique à parois fines de Bétique en raison de l'attribution qu'elle a donné à certains tessons provenant de nos fouilles ${ }^{63}$ et, pour s'en tenir au secteur du Lubéron, aux découvertes antérieures de Cucuron même ${ }^{64}$, de Cavaillon ${ }^{65}$, et $\mathrm{d}^{\prime} \mathrm{Apt}^{68}$. Mais la texture de la plupart des argiles et la nature des engobes laissent subsister quelques doutes sur leur affectation à des ateliers ibériques ou italiques ${ }^{67}$.

\section{Lampes (fig. 42)}

1 Dessus de lampe à simples volutes formant canal ouvert sur la coupelle. Dérivée du type Deneauve V-IJ. Deux sillons obliques tracés à main levée dans la pâte fraîche marquent la naissance du bec. Pâte dure, fine, gris clair (C. 81), dépourvue d'engobe.

D. M. BAII.Fy, A Catalogue of the Lamps of the British Museum. II. Roman Lamps Made in Italy, Londres, 1980; - J. Denfauve, Lampes de Carthage, Paris, 1969.

63 F. MAYET, Les céramiques à parois fines dans la péninsule ibérique, Paris, 1975, p. 158.

64 H. Ror.tand, Informations archéologiques, Gallia, 18, 1960, p. 267, fig. 5; - F. MAYET, op. cit., p. 151.

65 A. Dumoulin, Les puits et fosses de la colline SaintJacques à Cavaillon (Vaucluse), Gallia, 23, 1965, p. 1-85; F. MAYET, op. cit., p. 151-158.

66 A. Dumoulin, Découverte d'une nécropole galloromaine à Apt (Vaucluse), Gallia, 22, 1964, p. 107; F. MAYET, op. cit., p. 158.

67 A. Ricci, Ceramica a pareti sottili, Enciclopedia dell'arte antica, II. Ceramica fine romana nel bacino meditteraneo (lardo ellenismo e primo impero), Rome, 1985, p. 231-357. 


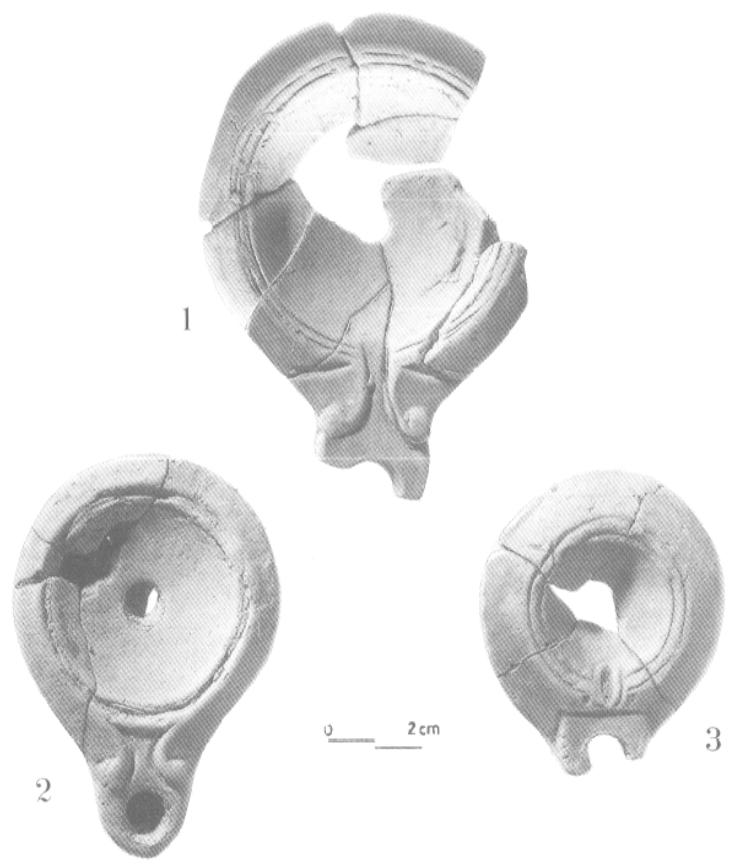

Fig. 42 - Matériel erratique : lampes.

2 Petite lampe sans anse. Dérivée du type Deneauve V-D à volutes simples non saillantes. Pàte savonneuse, jaune rosé, sans couverte; facture lourde et grossière.

3 Petite lampe dépourvue de queue. Le bec est limité par un sillon droit. Imitation des types Deneauve VII-A, Bailey type F. Les deux points placés aux extrémités du sillon sur la forme classique sont ici déportés de part et d'autre d'un ovale interrompant, dans l'axe du bec, la bordure de la coupelle. Pâte friable, savonneuse, gris clair (C. 81) dépourvue de couverte. Facture grossière. Bailey date son type $F$ de la fin des Flaviens à Hadrien.

Le mauvais état de conservation de ces exemplaires n'est peut-être pas entièrement attribuable a la nature du sol. Les pièces répertoriées ici présentent la mème argile gris clair, peu dure, dépourvue de couverte, qui n'est pas sans analogie avec le matériau de la majorité des vases à parois fines. Il faut sans doute y reconnaitre la production d'officines annexes des grands ateliers italiques. Cette impression est renforcée par des formes qui, bien qu'inédites, sont inspirées de la typologie classique. La chronologie semble cohérente avec celle du mobilier des dépôts à incinération. Elle s'échelonnerait du milieu du I $^{\mathrm{er}} \mathrm{s}$. aux environs de celui du $\mathrm{II}^{\mathrm{e}} \mathrm{s}$.

\section{Amphore}

Une amphore gréco-italique de tradition rhodienne, du type Dressel 2/4, a été découverte très précisément au-dessus de la tombe 1. Il est impossible de certifier qu'elle était en relation directe avec elle, mais elle pourrait éventuellement lui appartenir étant donné sa datation qui se place entre le $\mathrm{II}^{\mathrm{e}} \mathrm{s}$. avant J.-C. et la fin du rer $s$. de notre ère. Elle confirmerait ainsi l'ancienneté du dépôt le plus précoce.

\section{Numismalique}

Les monnaies erratiques, toutes illisibles, se limitent à deux dupondii, l'un d'Auguste, l'autre de Claude, auxquels s'ajoute un moyen bronze d'Antonin qui semble prouver, avec d'autres éléments dispersés moins précis, la poursuite de la fonction funéraire des structures jusqu'au milieu du ${ }{ }^{e} \mathrm{~s}$. au moins. Un petit bronze de la dynastie constantinienne atteste, avec l'inhumation de la tombe 5 , sinon la conservation des maçonneries, tout au moins la permanence d'une occupation funéraire dans le courant du Ive $s$.

\section{**}

L'étude de l'architecture des différentes phases du monument de Cucuron et l'analyse du matériel qui fut mis au jour au cours des fouilles font apparaître la complexité et la richesse de l'ensemble. C'est un monument qui vit, se développe et s'adapte au gré des changements que lui font subir ses utilisateurs, jusqu'à n'être plus au IV $\mathbf{s}$. qu'un lieu ressenti comme funéraire et où l'on pouvait encore aménager, vaille que vaille, une fosse creusée à coups de pic dans le soubassement du columbarium arasé. Il est frappant toutefois de le constater pendant la période que l'on pourrait appeler "active" du mausolée, la fonction sépulcrale ne cesse de se renforcer par une architecture et une décoration sculptée de plus en plus imposante. Après la fosse en pleine terre, puis le tumulus à enceinte pseudo-circulaire et son autel de style italique encore très traditionnel, on passe à un columbarium dont l'enceinte aux assises en grand appareil laisse imaginer, à défaut de pouvoir les restituer - des proportions fort imposantes. Si l'on ajoute que les quatre masques de type colossal présentés plus loin appartenaient selon toute probabilité à cette phase de la construction, on voit que dans le dernier quart du $\mathrm{I}^{\mathrm{er}} \mathrm{s}$., le mausolée de Cucuron, même s'il ne pouvait rivaliser avec le faste de son voisin, celui des Domitii de Rognes, ne devait pas manquer d'allure.

Roger GuÉry et Gilbert Hallier 